\title{
Propargylation of CoQ0 through the Redox Chain Reaction
}

Robert Pawlowski, Maciej Stodulski*, and Jacek Mlynarski*

Institute of Organic Chemistry, Polish Academy of Sciences, Kasprzaka 44/52, 01-224 Warsaw, Poland

\section{Supporting Information}

\section{Table of Contents}

1. Copies of ${ }^{1} \mathrm{H}$ and ${ }^{13} \mathrm{C}$ NMR spectra

2. Mechanistic studies - LCMS analysis of raw reaction mixture S40 
1. Copies of ${ }^{1} \mathrm{H}$ and ${ }^{13} \mathrm{C}$ NMR spectra

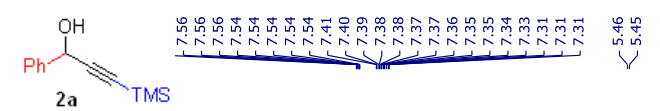

$\stackrel{M}{\text { M. }}$

${ }^{1} \mathrm{H} \mathrm{NMR}\left(400 \mathrm{MHz}, \mathrm{CDCl}_{3}\right)$

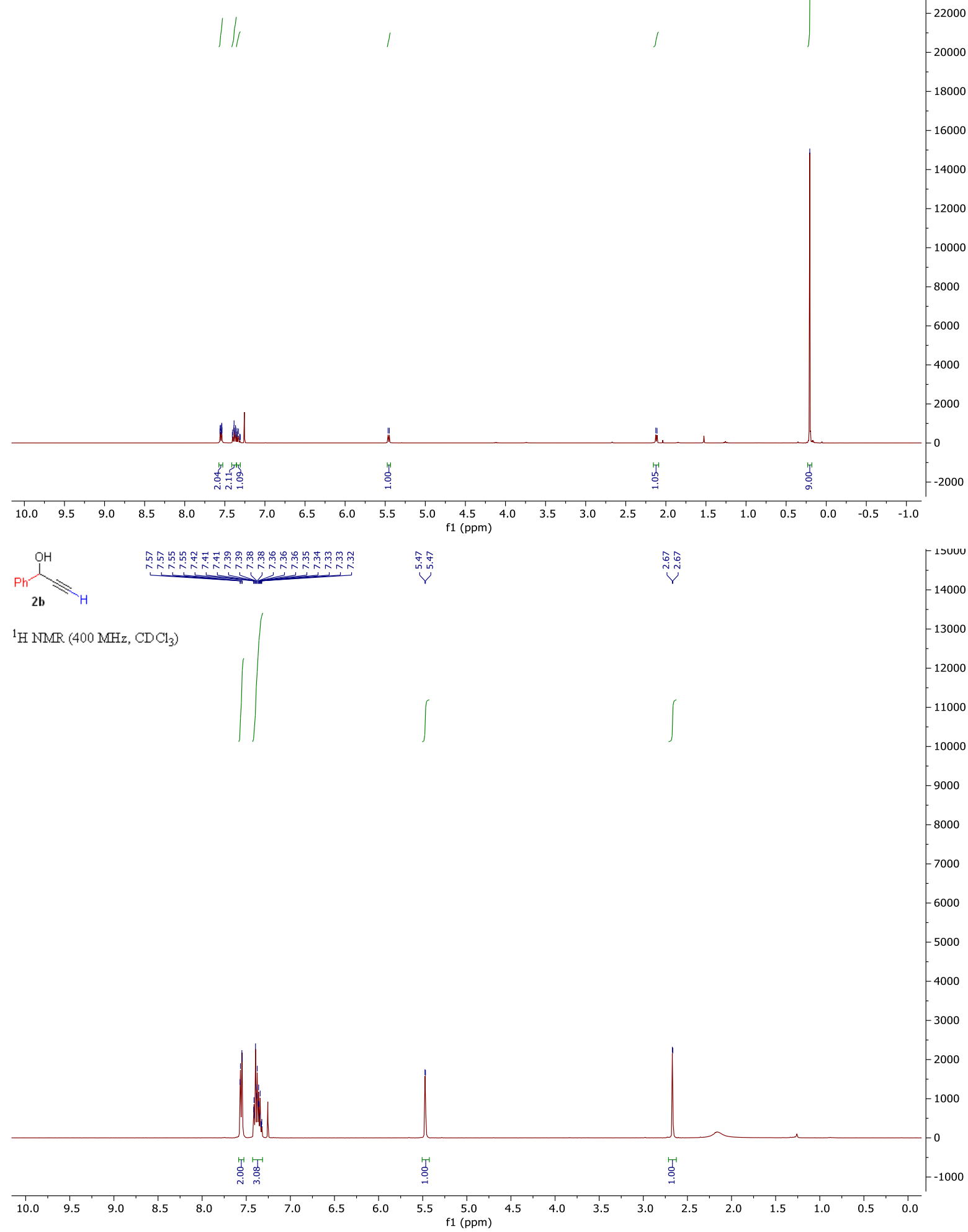


${ }_{2 c} \leqslant \sum_{H}$

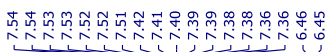

${ }^{1} \mathrm{H} \mathrm{NMR}\left(400 \mathrm{MHz}, \mathrm{CDCl}_{3}\right)$
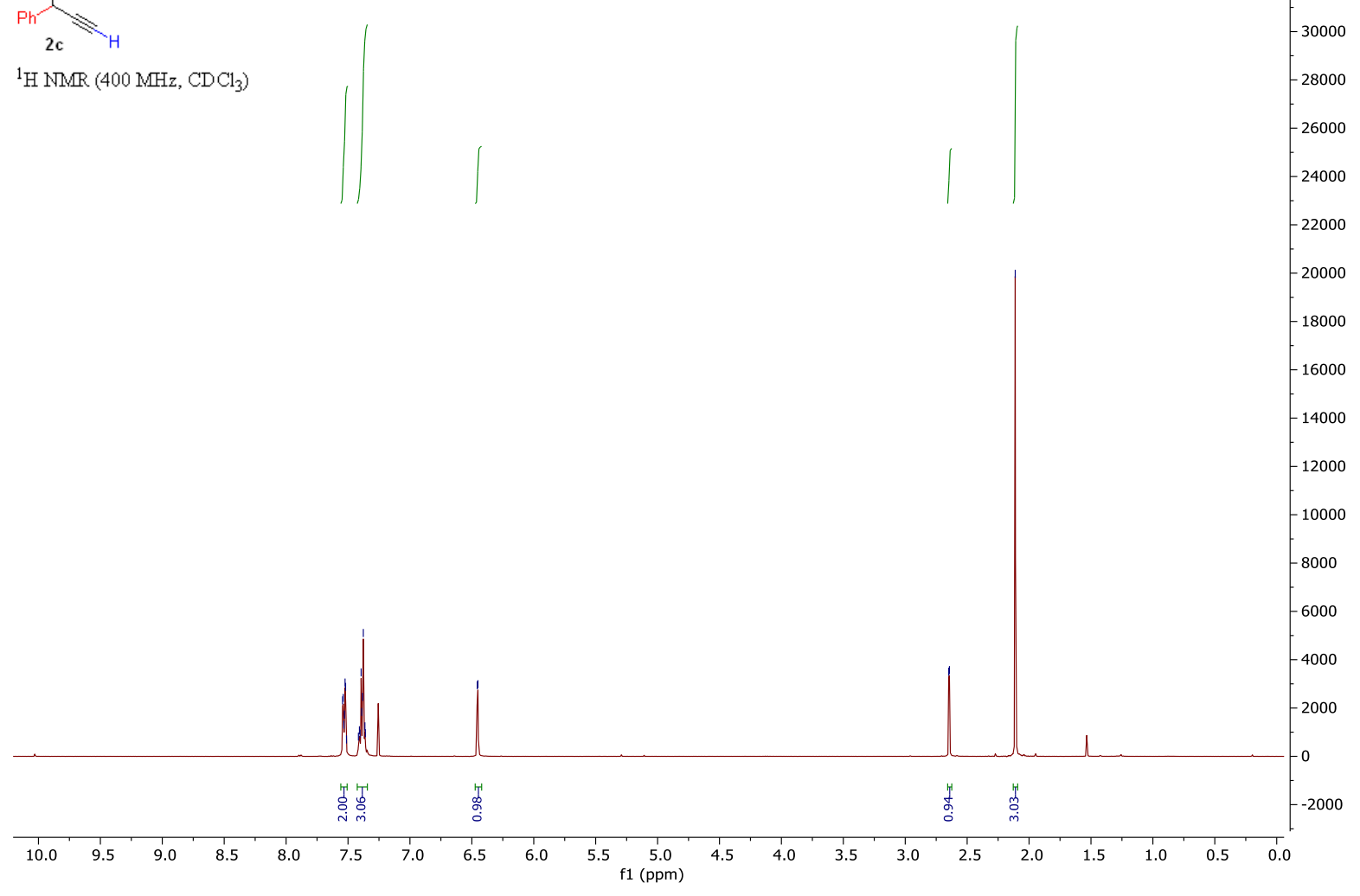
2d

${ }^{1} \mathrm{H} \mathrm{NMR}\left(400 \mathrm{MHz}, \mathrm{CDCl}_{3}\right)$

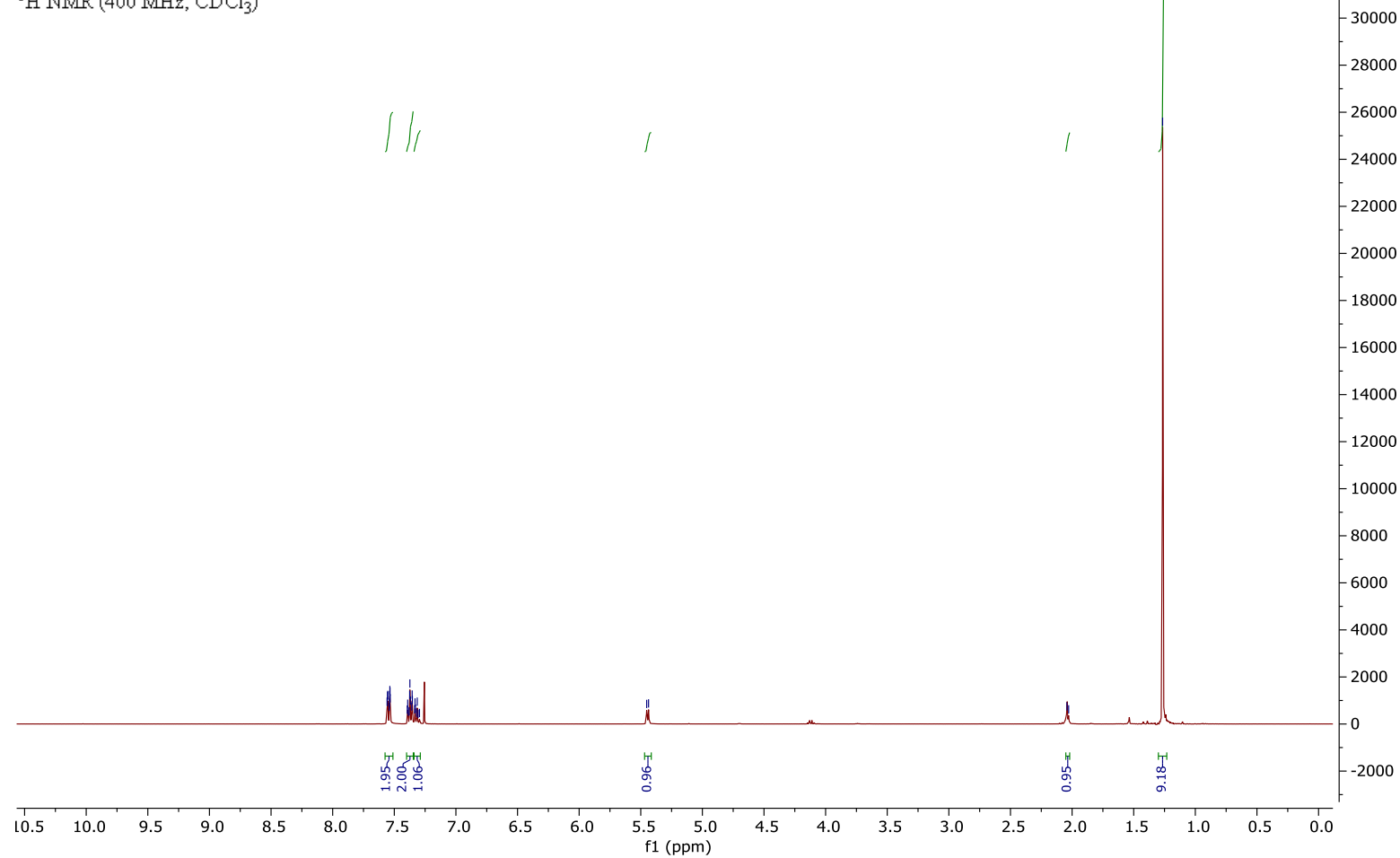


${ }_{2 \mathrm{e}}^{\mathrm{OH}} \approx \mathrm{OMs}_{\mathrm{Ms}}$

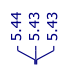

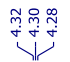

$\underbrace{20}$

${ }^{1} \mathrm{H} \mathrm{NMR}\left(400 \mathrm{MHz}, \mathrm{CDCl}_{3}\right)$

$-15000$

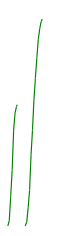

$-14000$

(

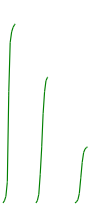

$-13000$

$-12000$
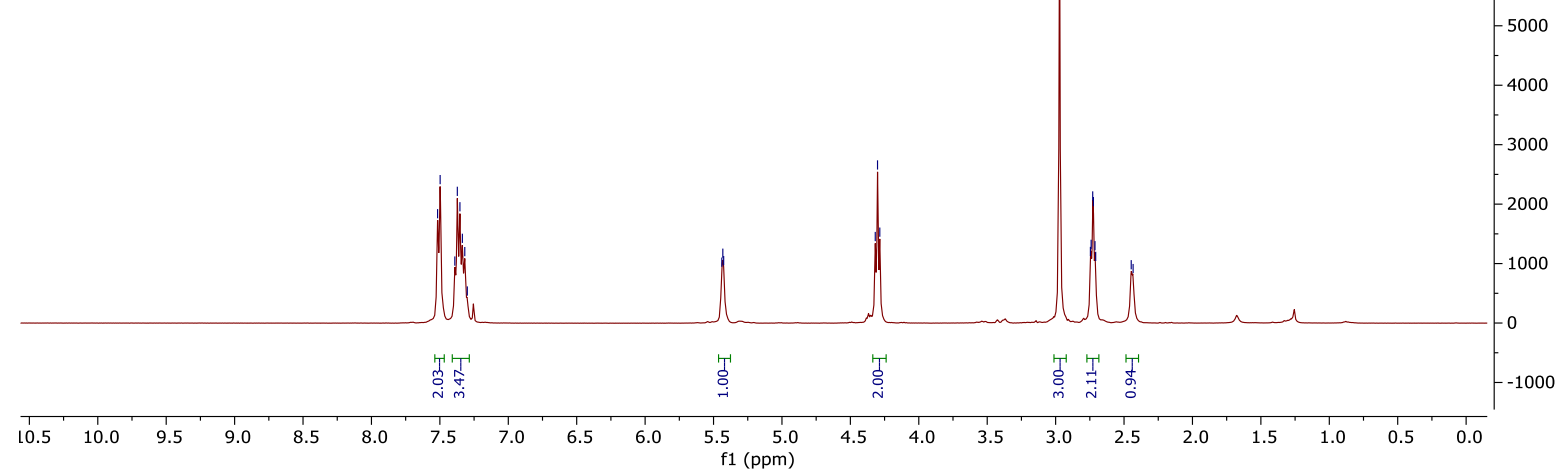

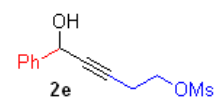
高

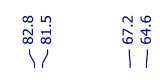

${ }^{13} \mathrm{C}\langle\mathrm{H}\} \mathrm{MMR}\left(100 \mathrm{MHz}, \mathrm{CDCl}_{3}\right)$

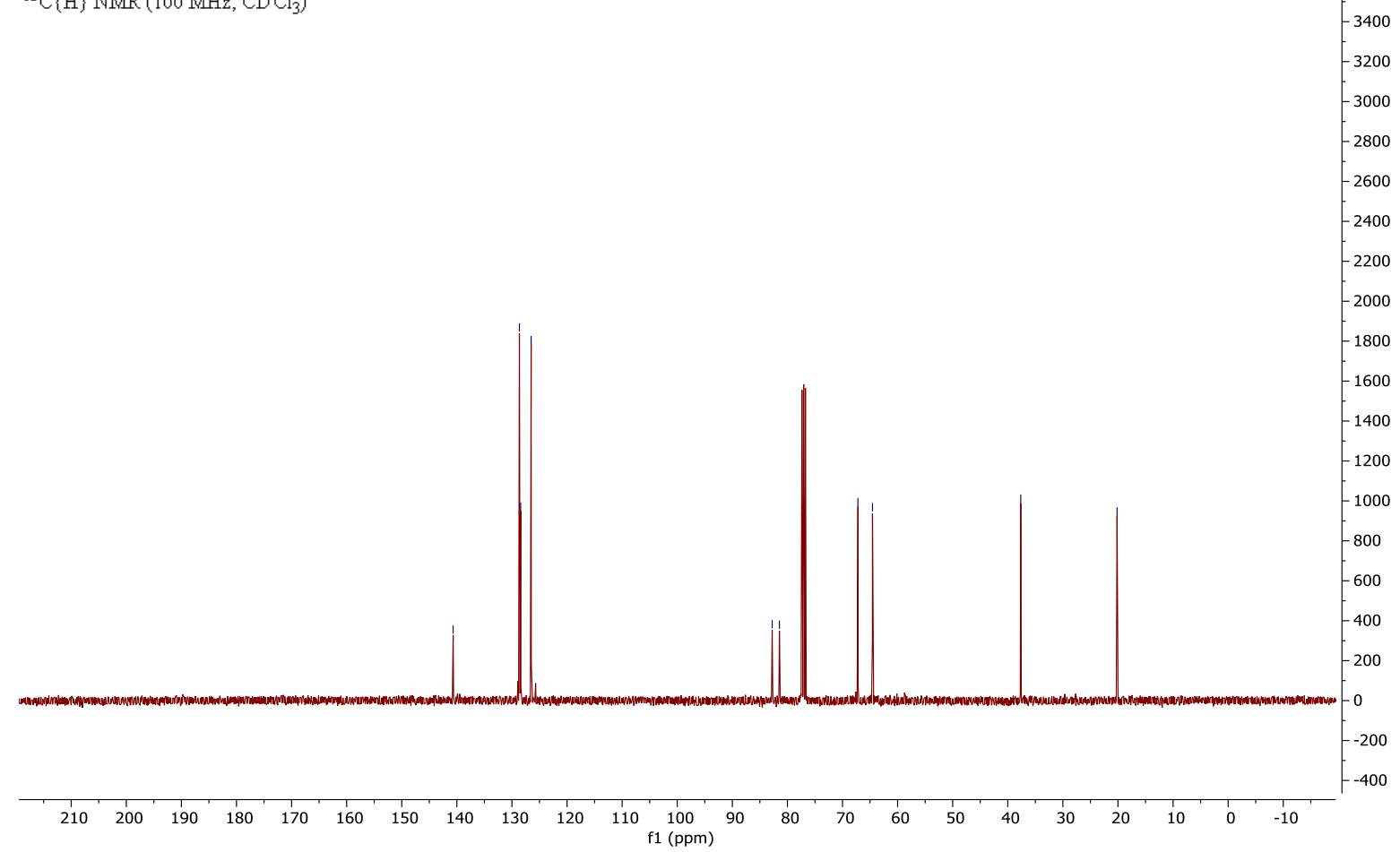



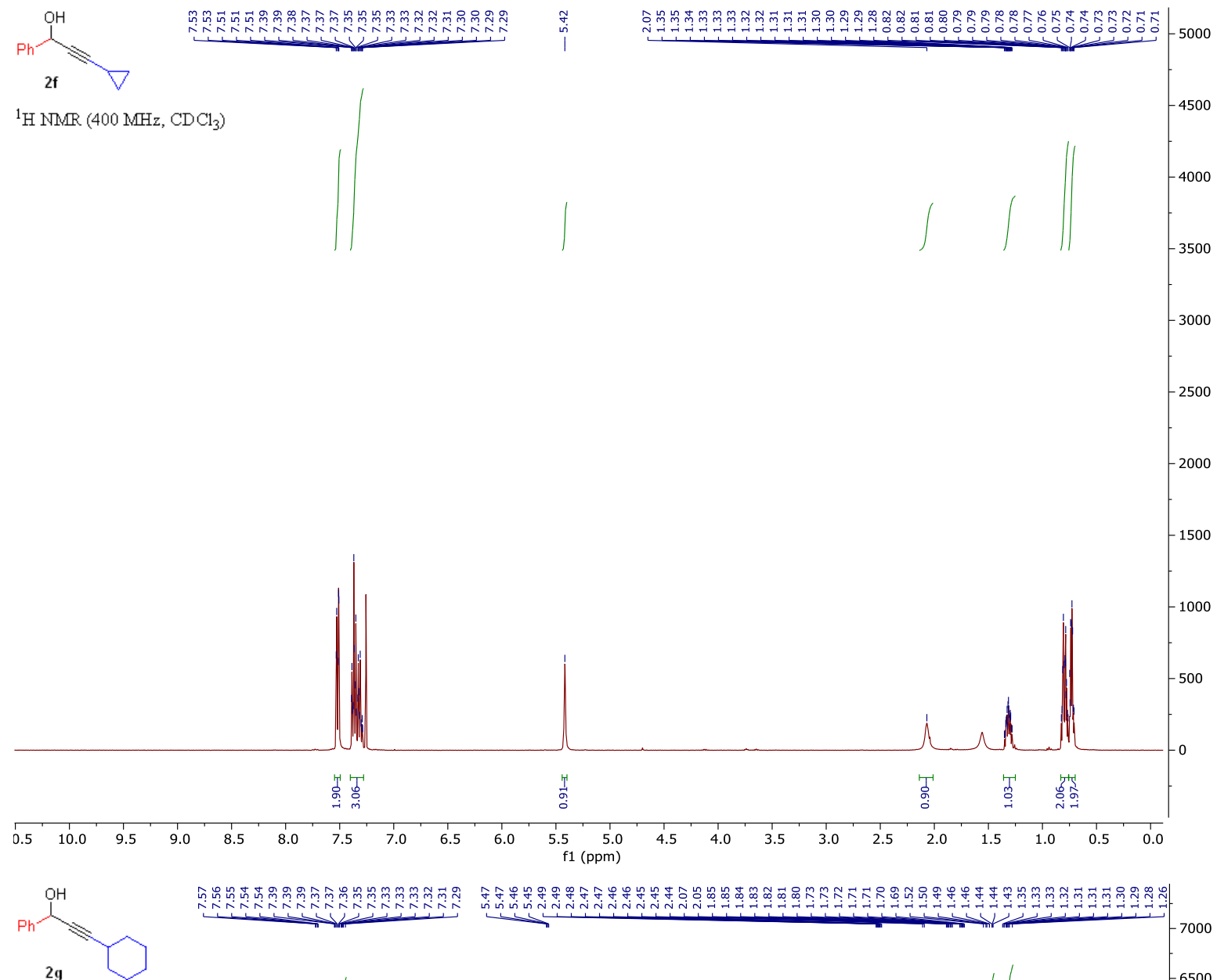

${ }^{1} \mathrm{H}$ NMR $\left(400 \mathrm{MHz}, \mathrm{CDCl}_{3}\right)$

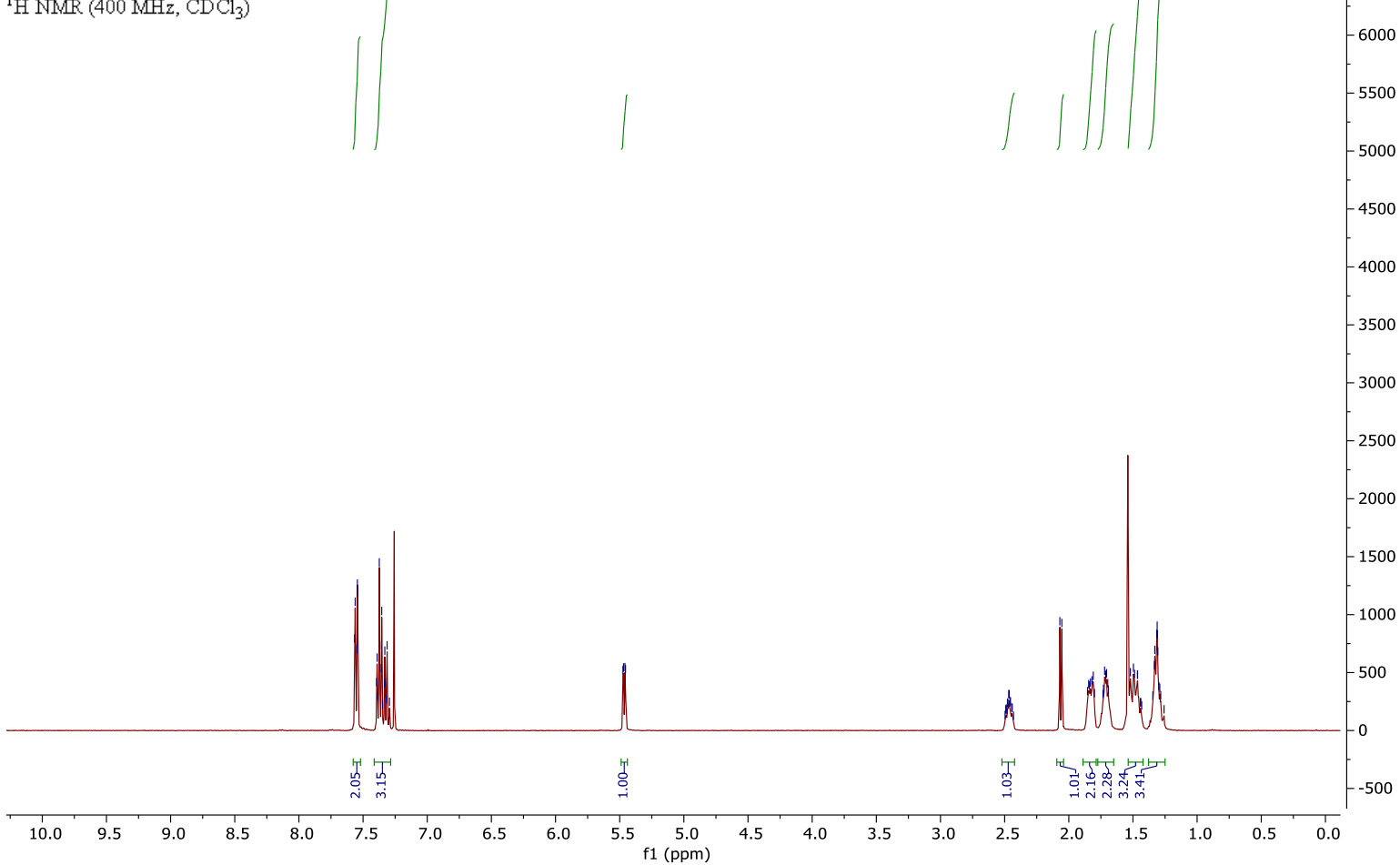




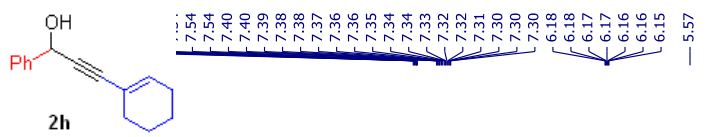

$\mathrm{H} \operatorname{NMR}\left(400 \mathrm{MHz}, \mathrm{CDCl}_{3}\right)$

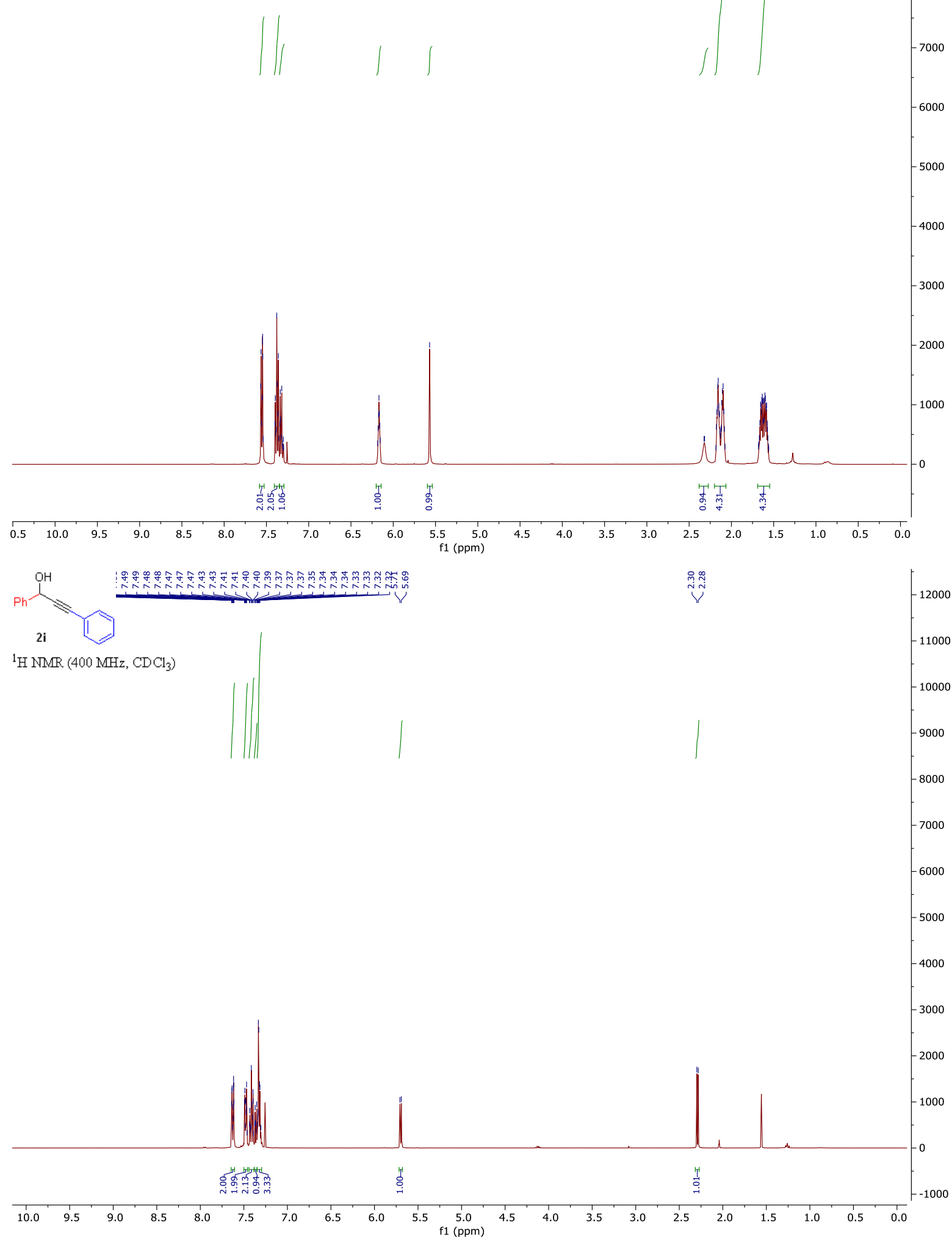




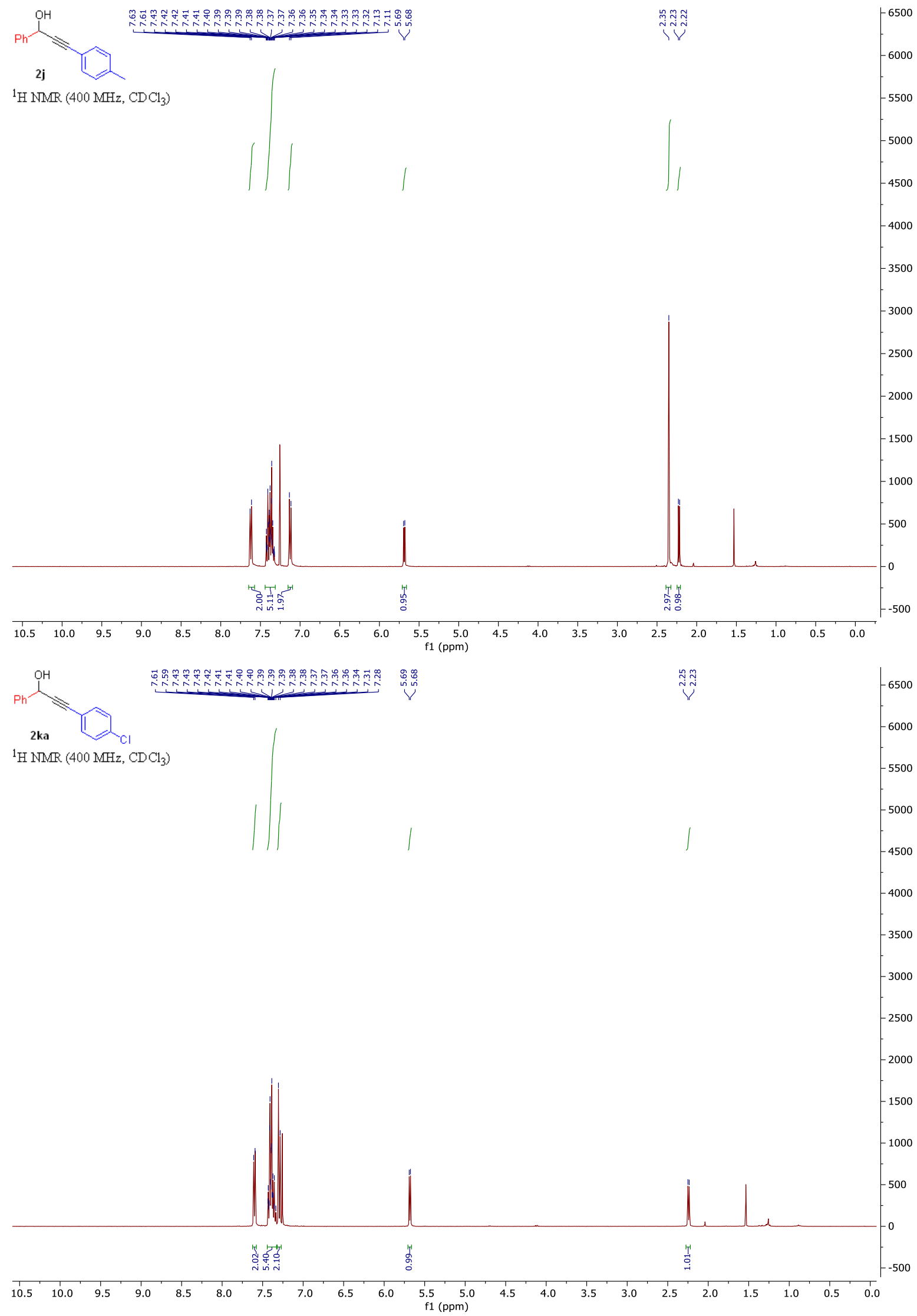




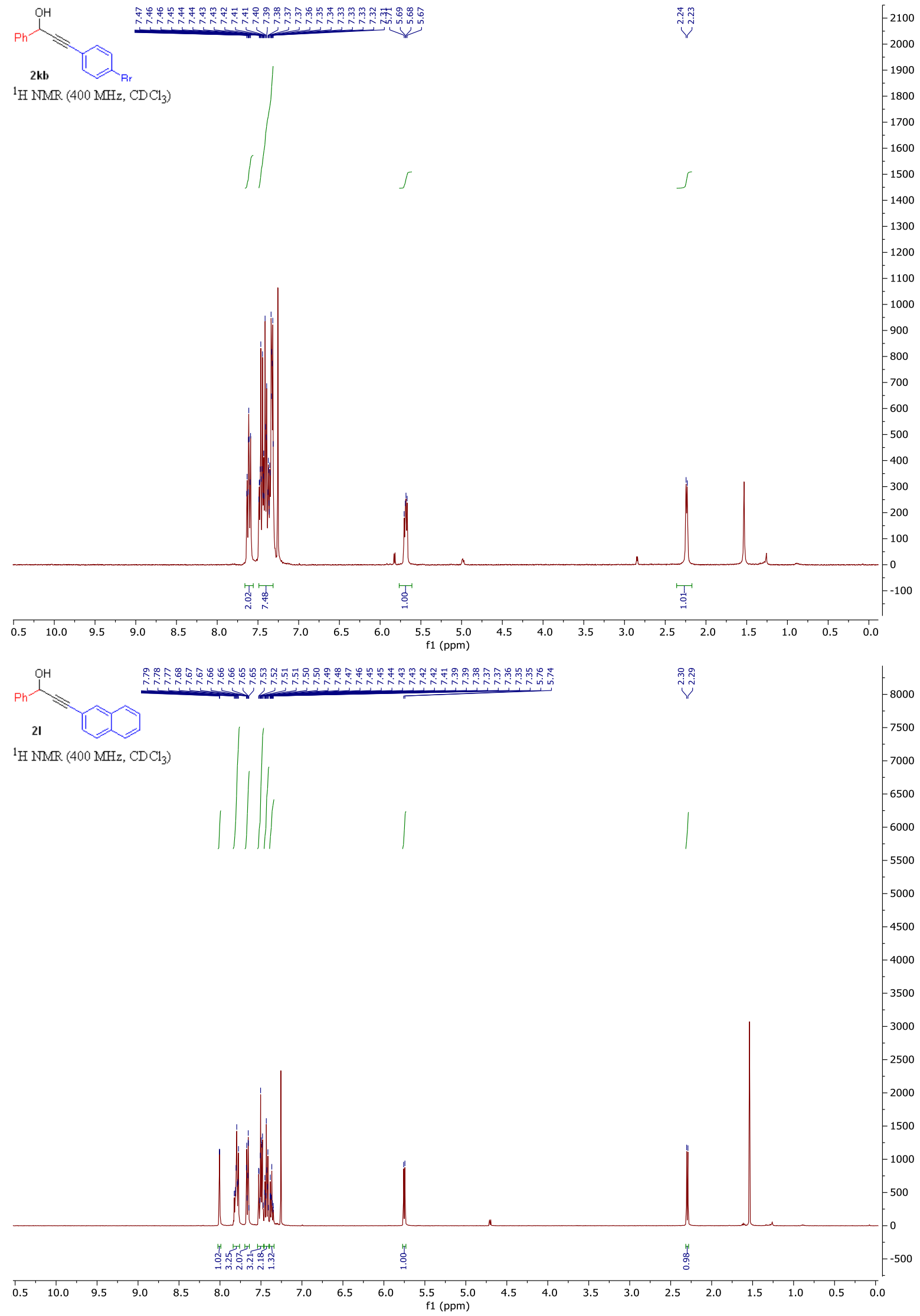




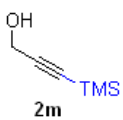

${ }^{1} \mathrm{H}$ MMR $\left(400 \mathrm{MHz}, \mathrm{CDCl}_{3}\right)$
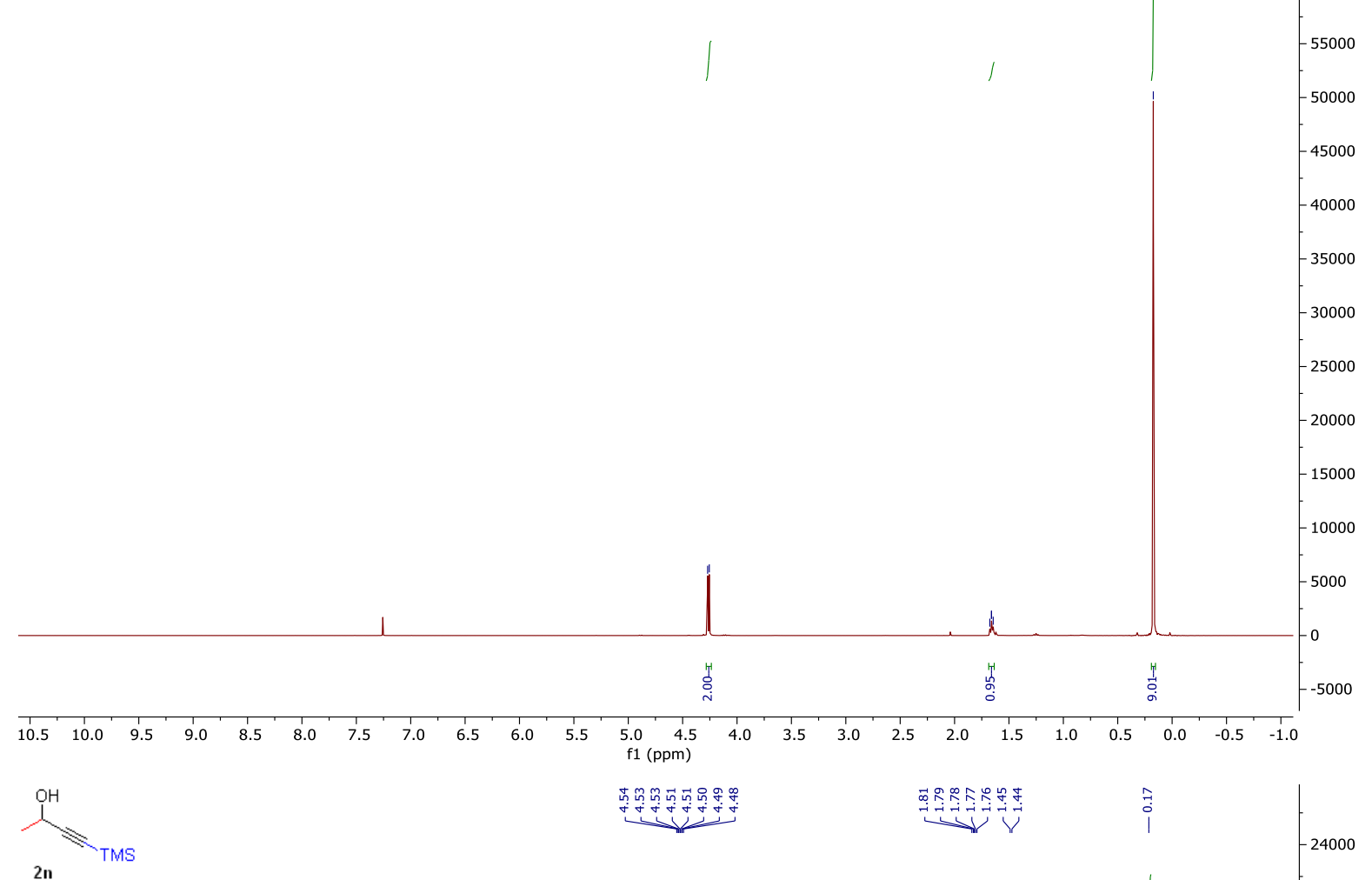

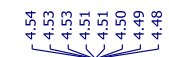

2n

$\left.{ }^{1} \mathrm{H} \mathrm{NMR} \mathrm{(400} \mathrm{MHz,} \mathrm{CDCl}_{3}\right)$

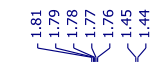

'

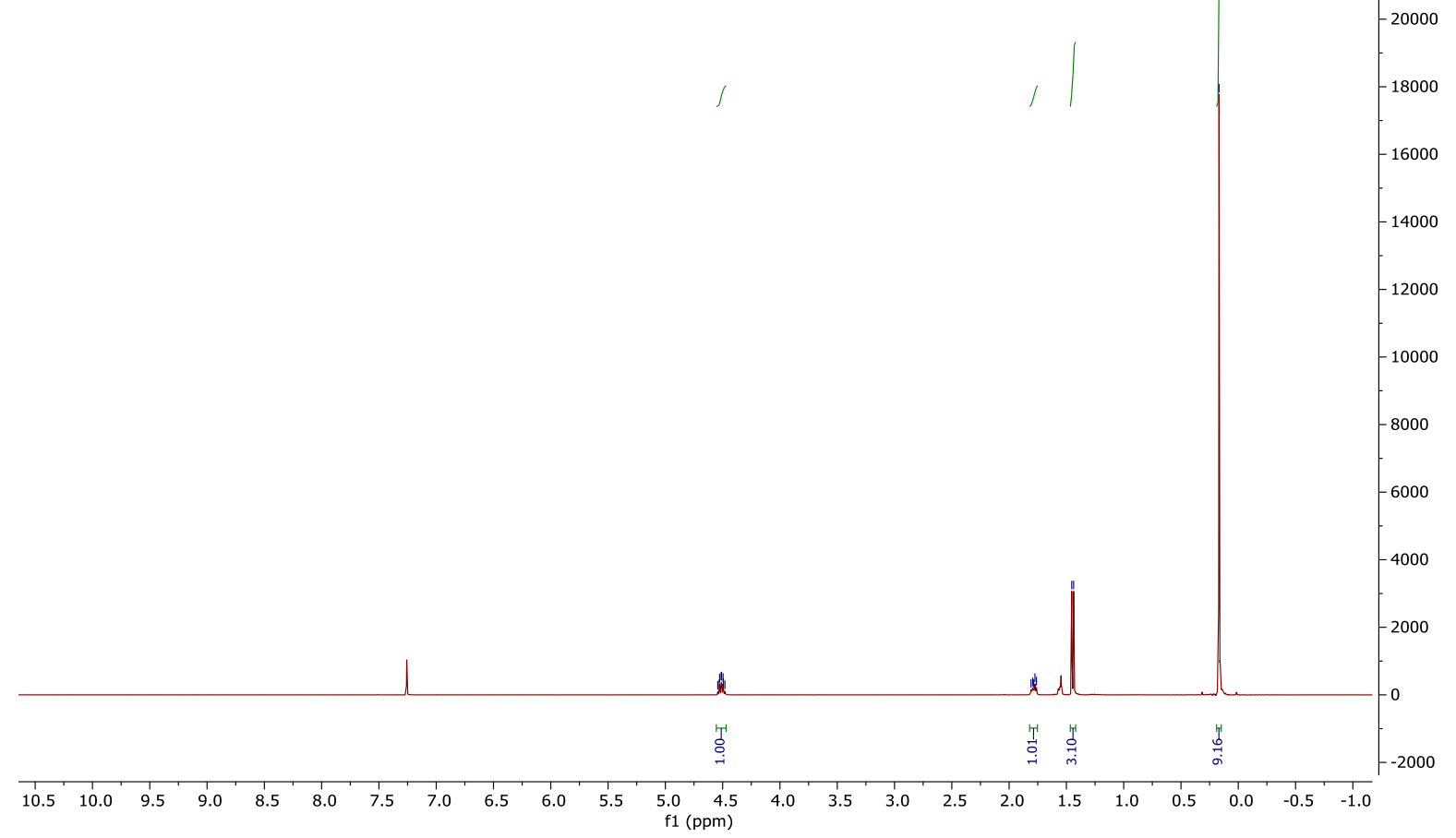




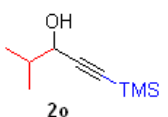

${ }^{1} \mathrm{H} \mathrm{NMR}\left(400 \mathrm{MHz}, \mathrm{CDCl}_{3}\right)$

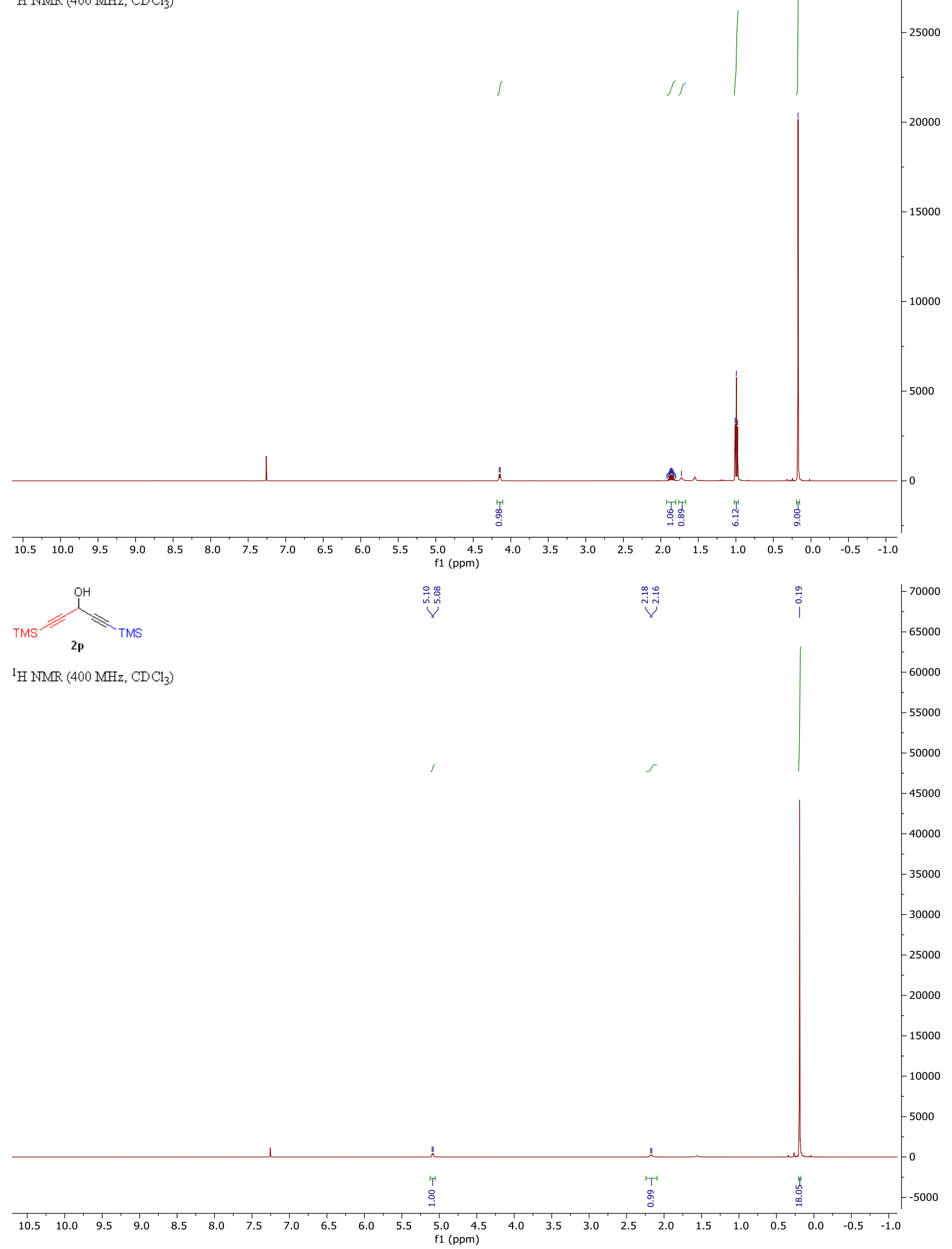




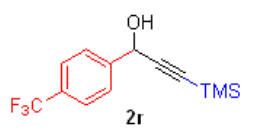

${ }^{1} \mathrm{H} \mathrm{NMR}\left(400 \mathrm{MHz}, \mathrm{CDCl}_{3}\right)$
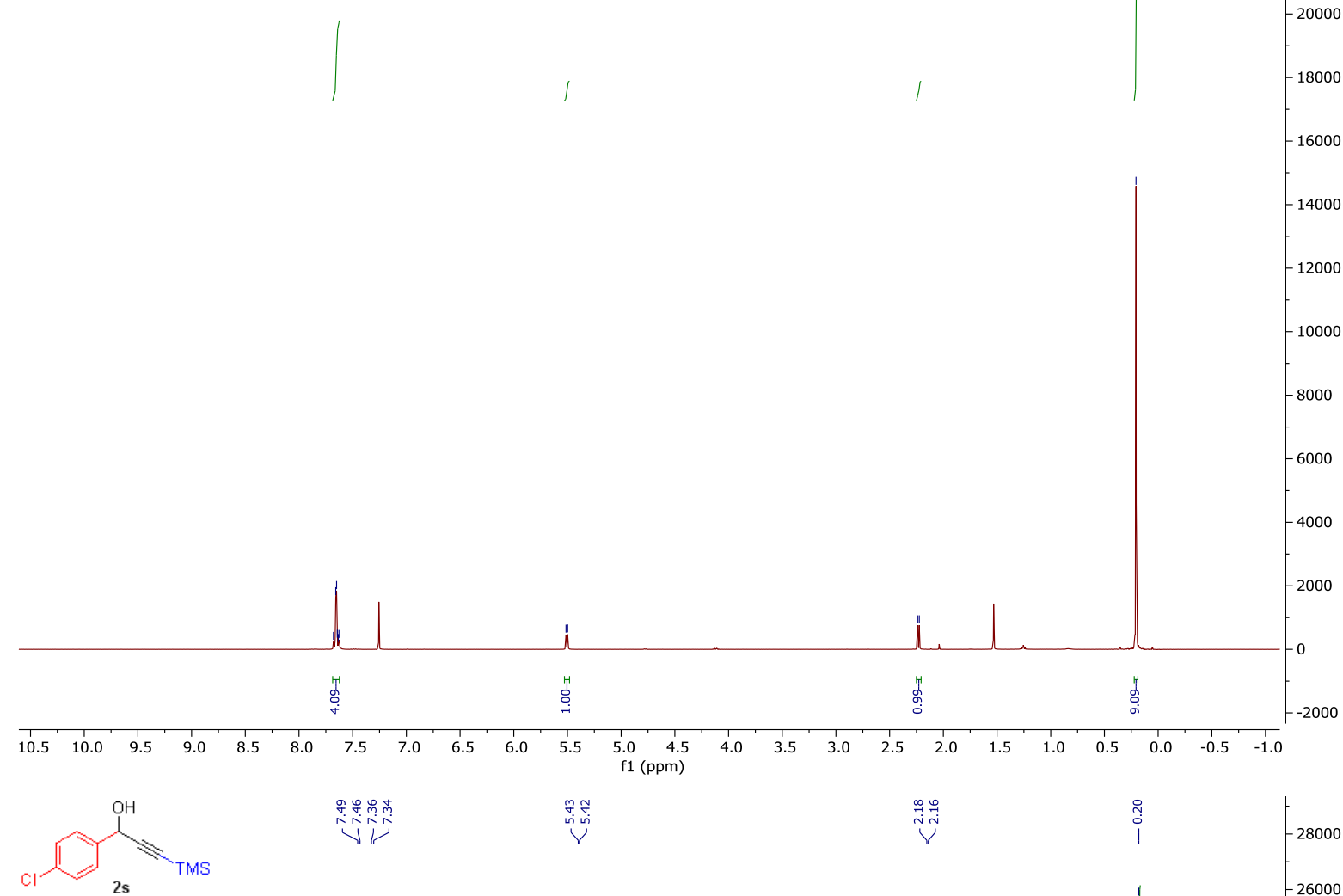

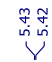

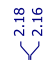

28000

${ }^{1} \mathrm{H} \mathrm{NMR}\left(400 \mathrm{MHz}, \mathrm{CDCl}_{3}\right)$

(

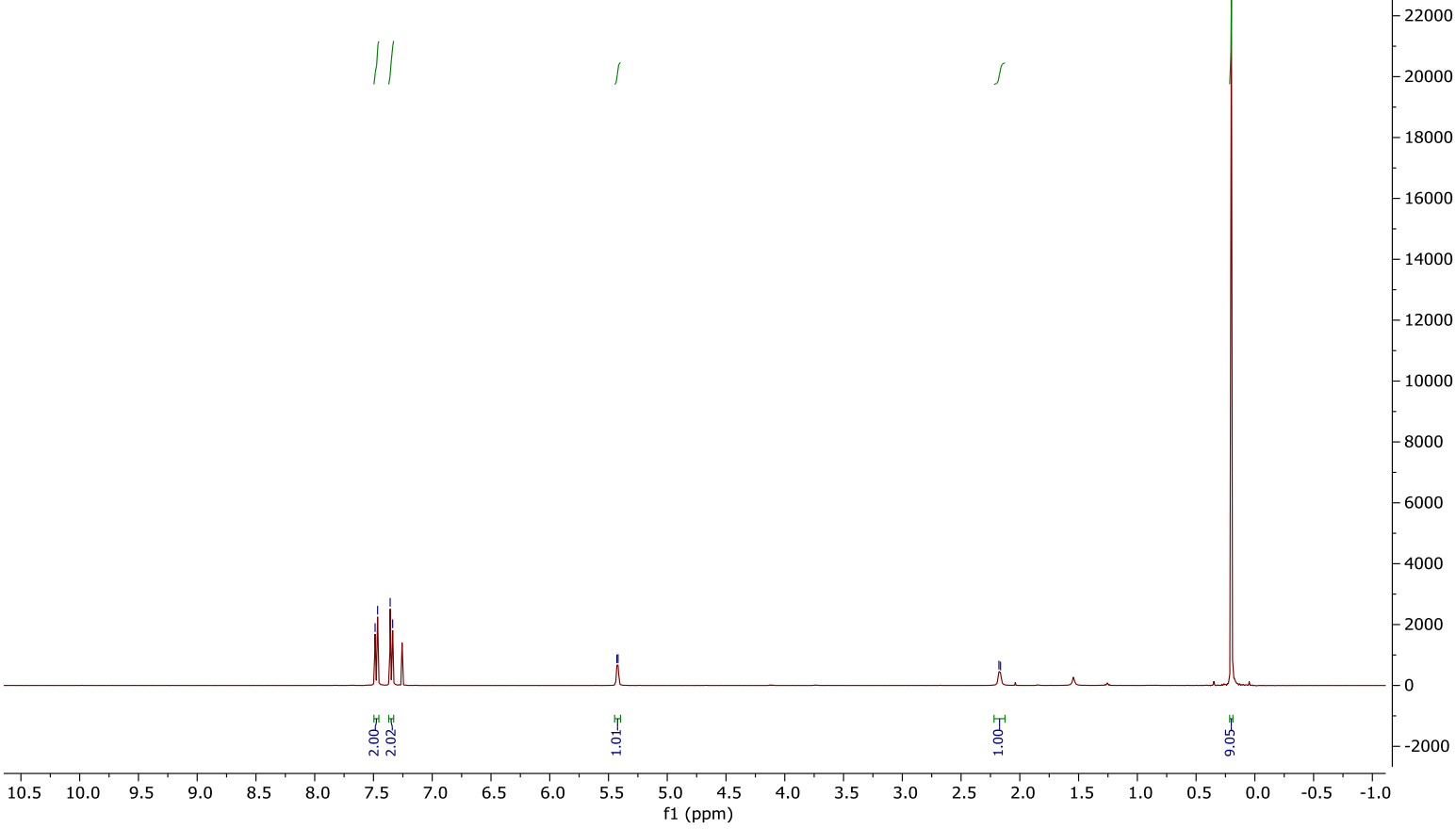




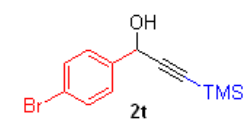

${ }^{1} \mathrm{H} \mathrm{NMR}\left(400 \mathrm{MHz}, \mathrm{CDCl}_{3}\right)$
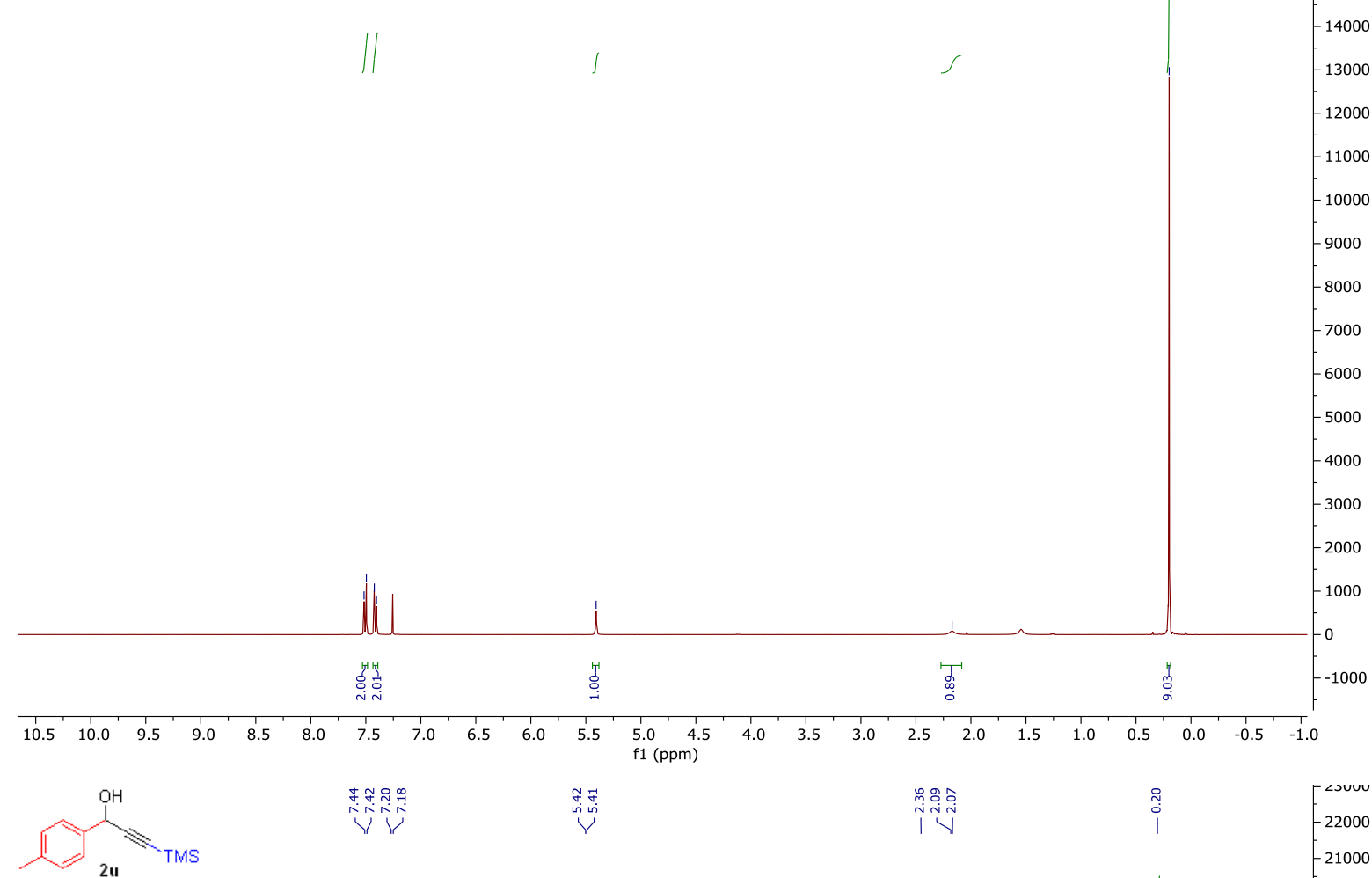

每尔

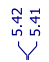

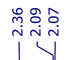

$-22000$

$-21000$

${ }^{1} \mathrm{H} \mathrm{NMR}\left(400 \mathrm{MHz}, \mathrm{CDCl}_{3}\right)$

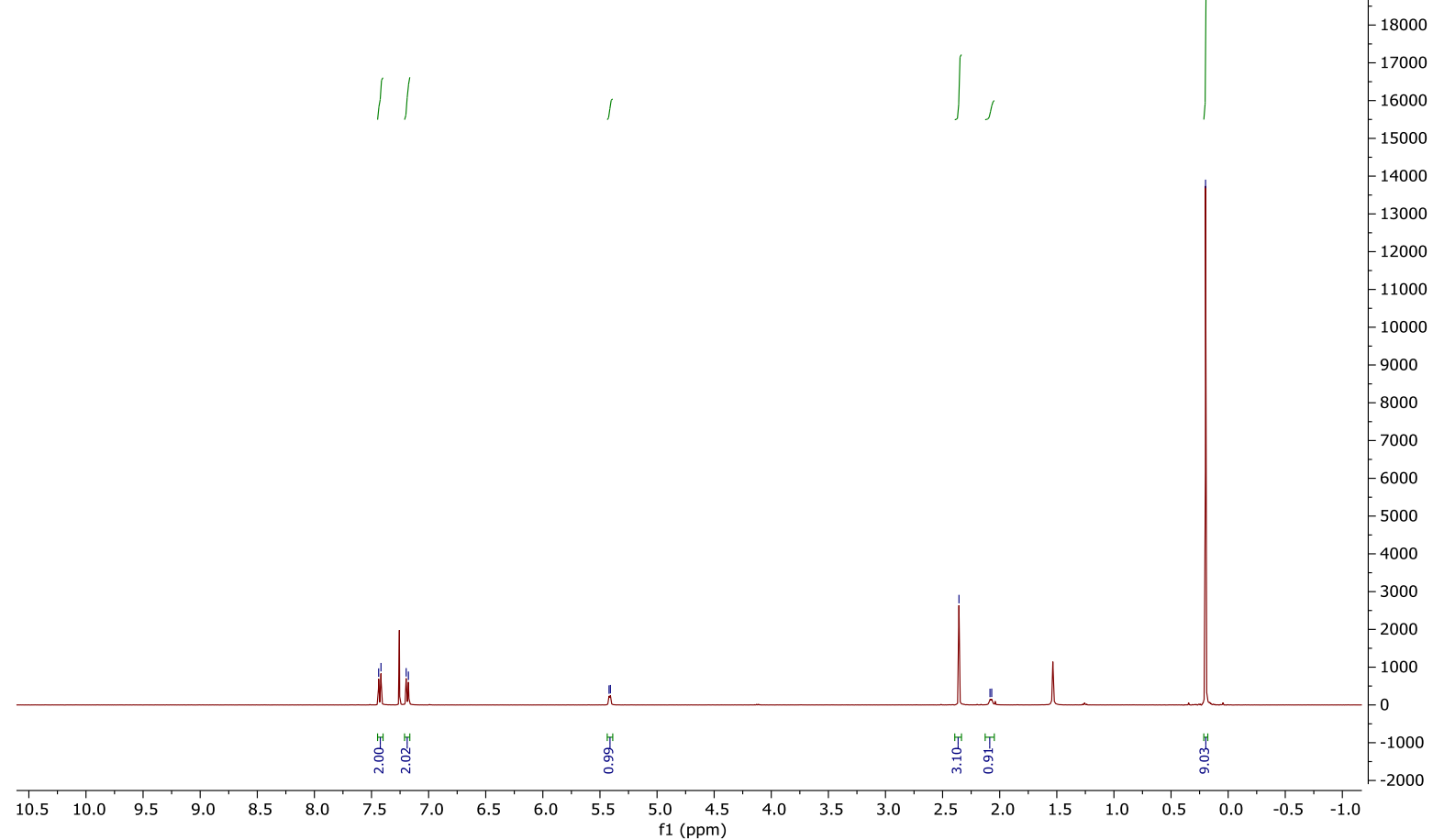




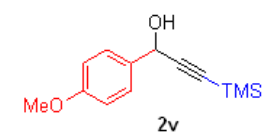

糸

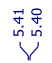

$\stackrel{\overrightarrow{0}}{i}$

$\stackrel{\grave{i}}{i}$

$\stackrel{8}{i}$

${ }^{1} \mathrm{H} \mathrm{NMR}\left(400 \mathrm{MHz}, \mathrm{CDCl}_{3}\right)$

${ }^{1} \mathrm{H} \operatorname{NMR}\left(400 \mathrm{MHz}, \mathrm{CDCl}_{3}\right)$

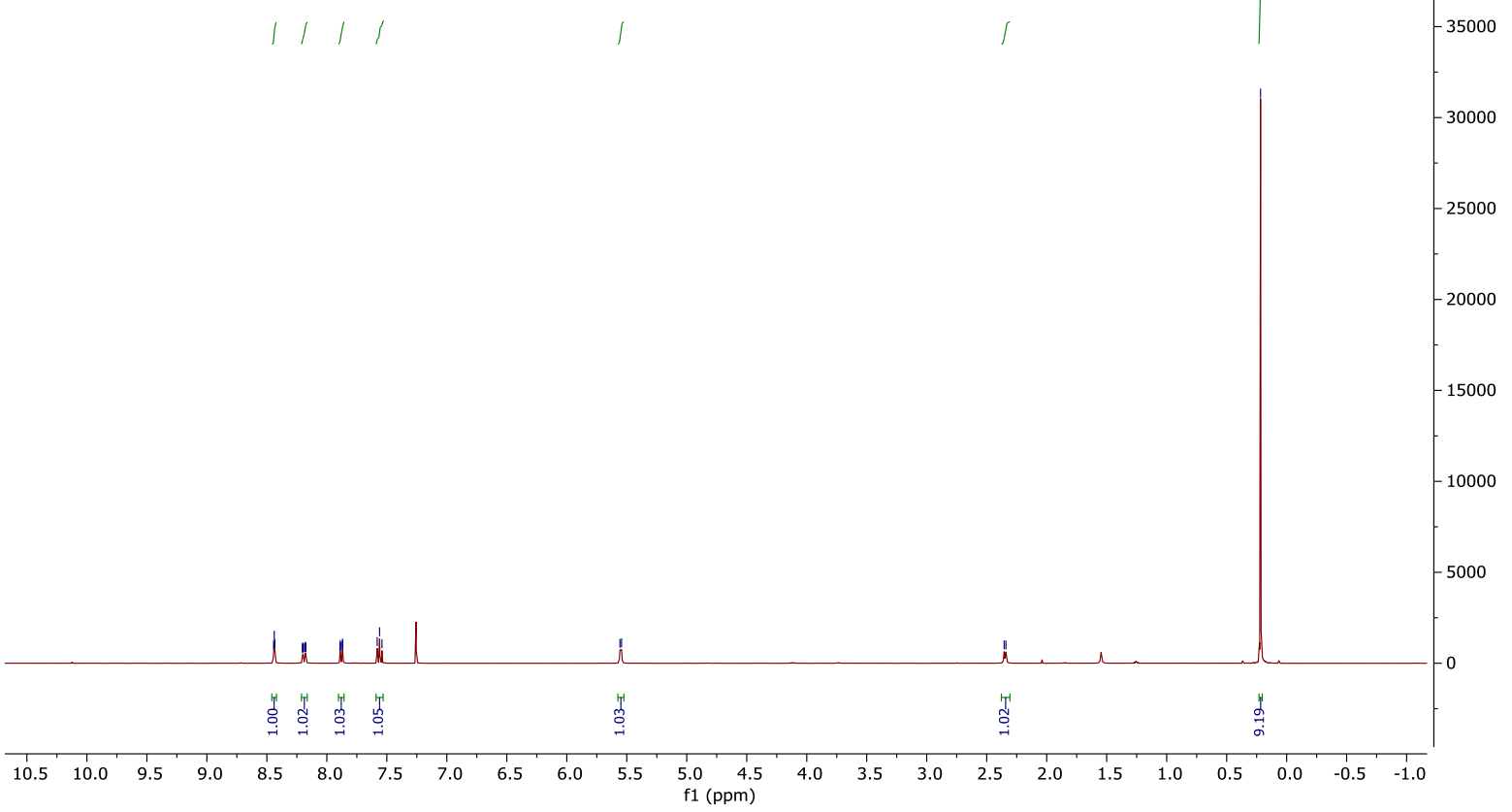




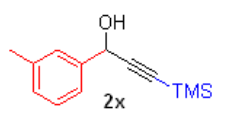

${ }^{1} \mathrm{H} \mathrm{NMR}\left(400 \mathrm{MHz}, \mathrm{CDCl}_{3}\right)$
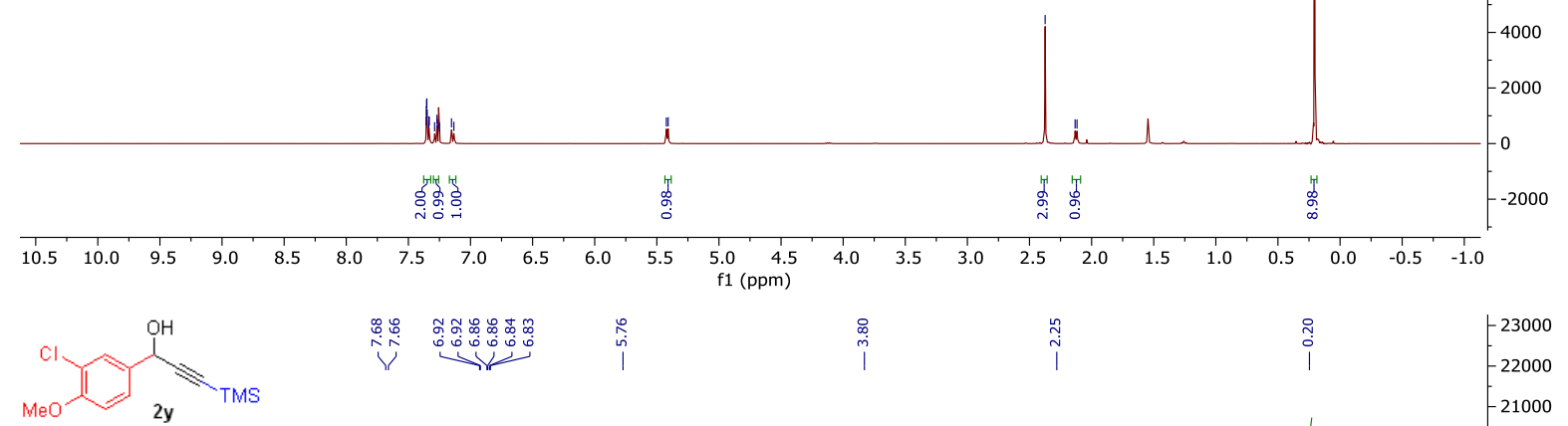

îj $\stackrel{\infty}{i}$

${ }^{1} \mathrm{H} \mathrm{NMR}\left(400 \mathrm{MHz}, \mathrm{CDCl}_{3}\right)$

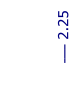

'Hing (40,

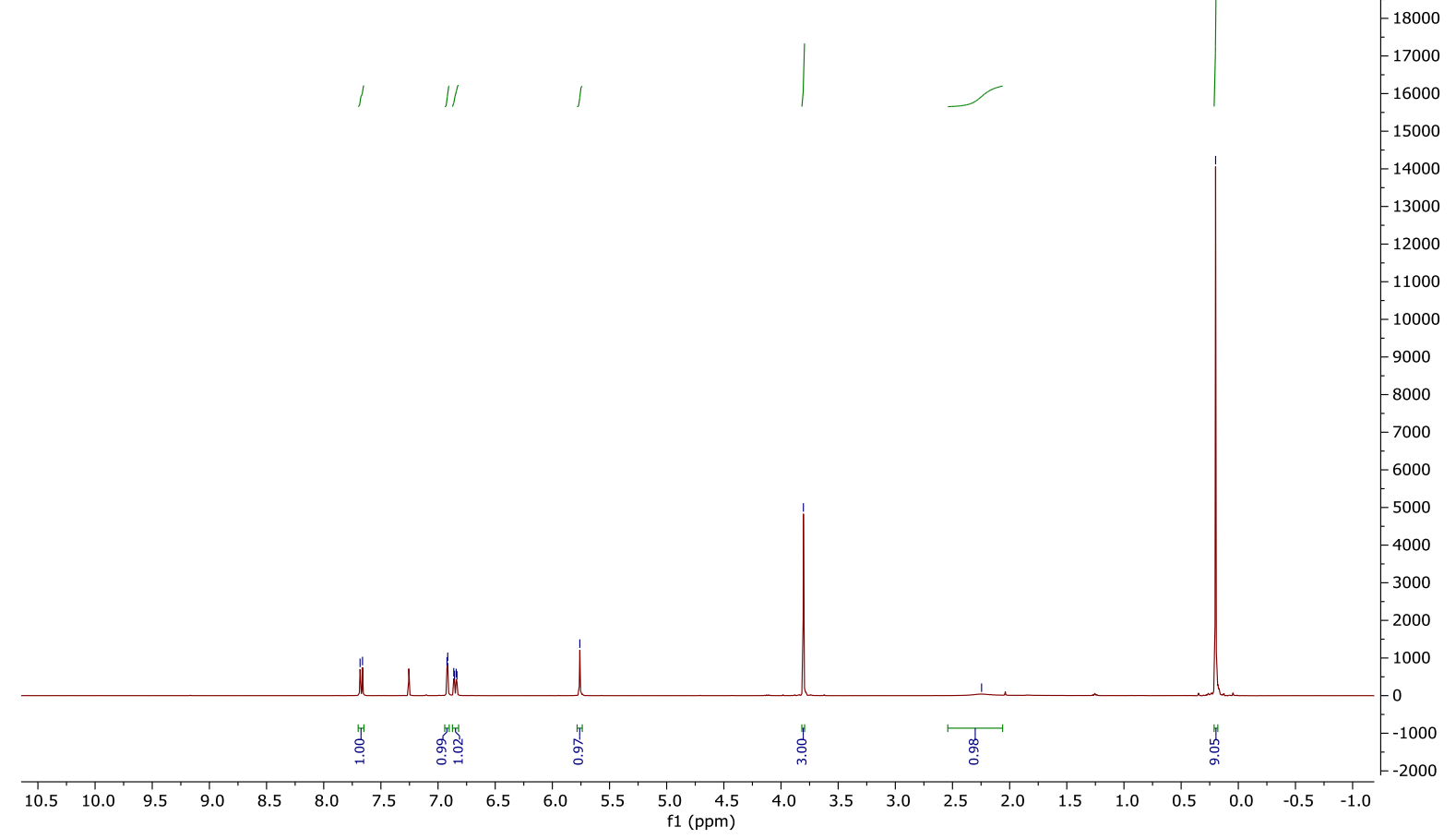


MeO

${ }^{13} \mathrm{C}\langle\mathrm{H}\} \mathrm{NMR}\left(100 \mathrm{MHz}, \mathrm{CDCl}_{3}\right)$
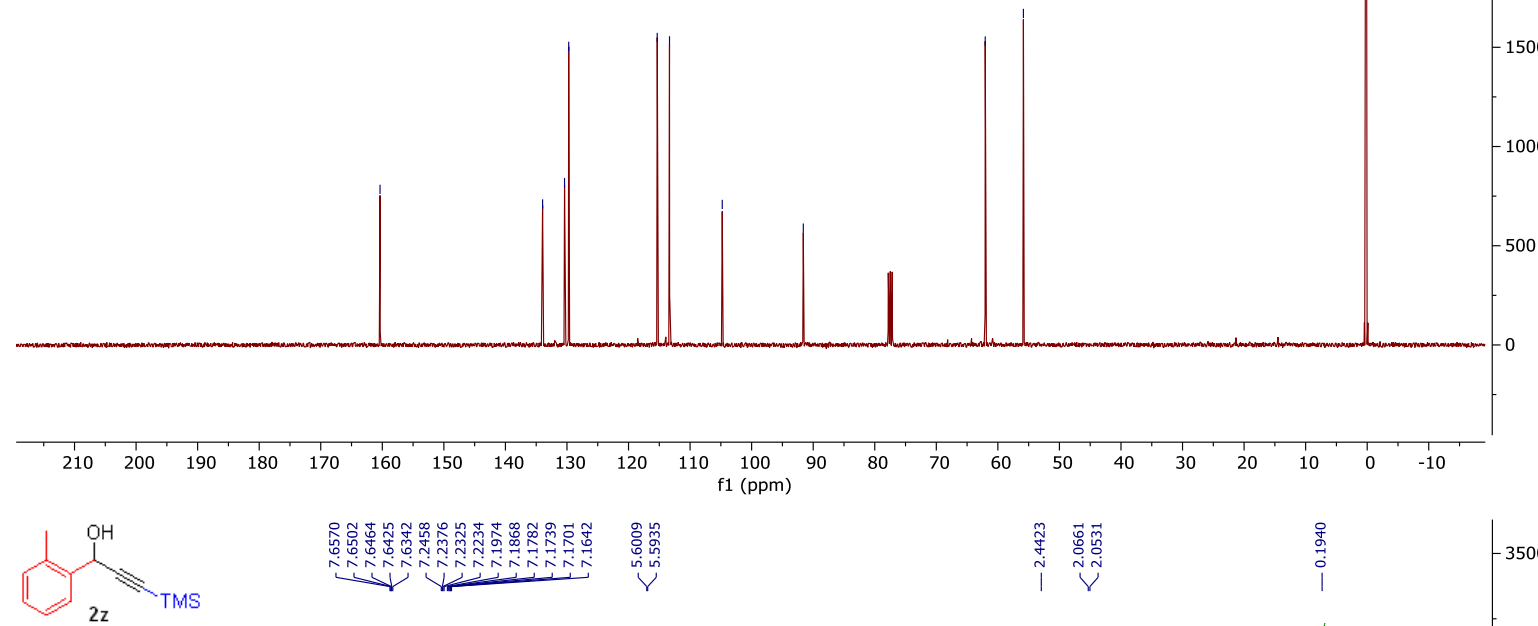

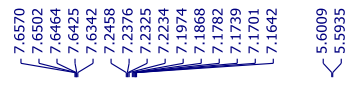

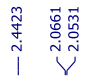

i⿱

${ }^{1} \mathrm{H} \mathrm{NMR}\left(400 \mathrm{MHz}, \mathrm{CDCl}_{3}\right)$

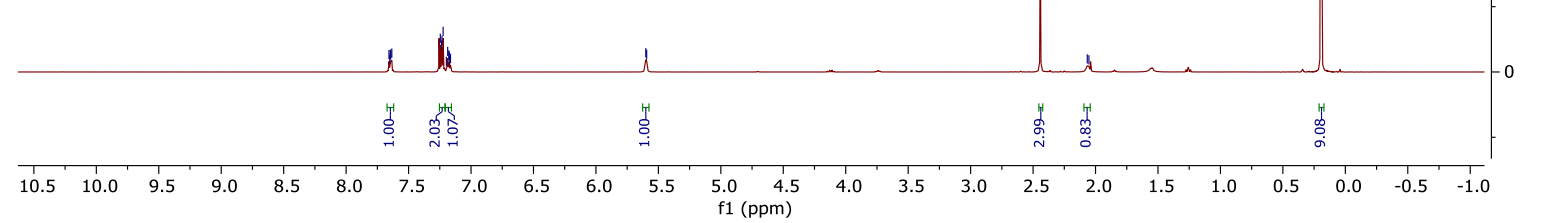


$\underbrace{O H M S}_{\text {2aa }}$

象

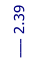

ঙฺุ

$-15000$

$-14000$

$\left.{ }^{1} \mathrm{H} \mathrm{NMR} \mathrm{(400} \mathrm{MHz}, \mathrm{CDCl}_{3}\right)$
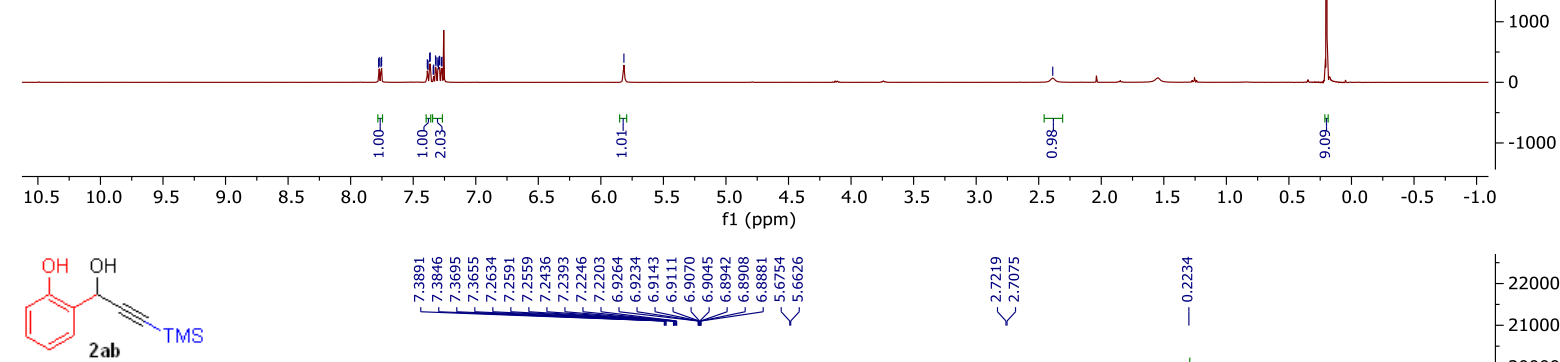

2ab TMS

ฟัi

${ }^{1} \mathrm{H} \mathrm{NMR}\left(400 \mathrm{MHz}, \mathrm{CDCl}_{3}\right)$

\section{(ppm)}

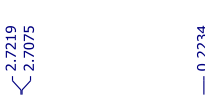

ָָ
0
$i$

$-22000$

$-20000$

$-19000$

$-18000$

$-17000$

$-16000$

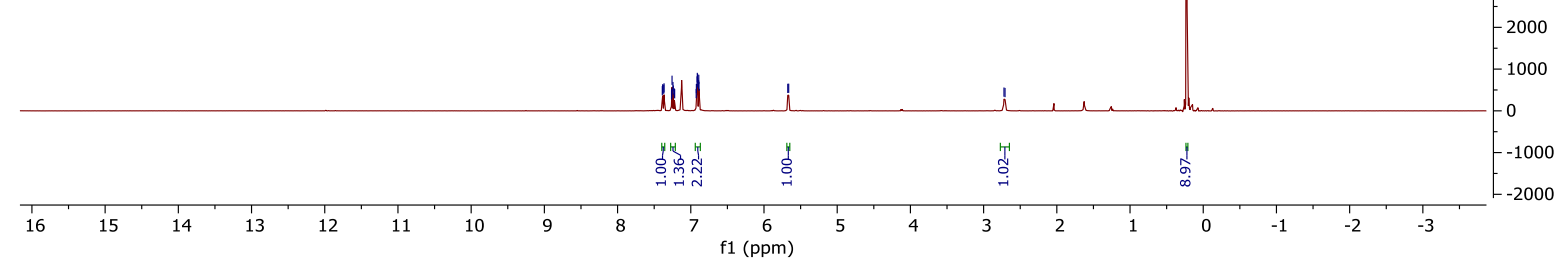




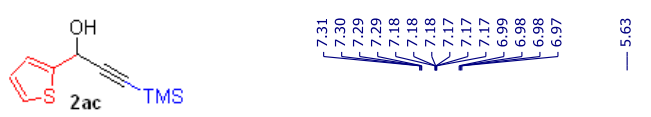

管

${ }^{1} \mathrm{H} \mathrm{NMR}\left(400 \mathrm{MHz}, \mathrm{CDCl}_{3}\right)$
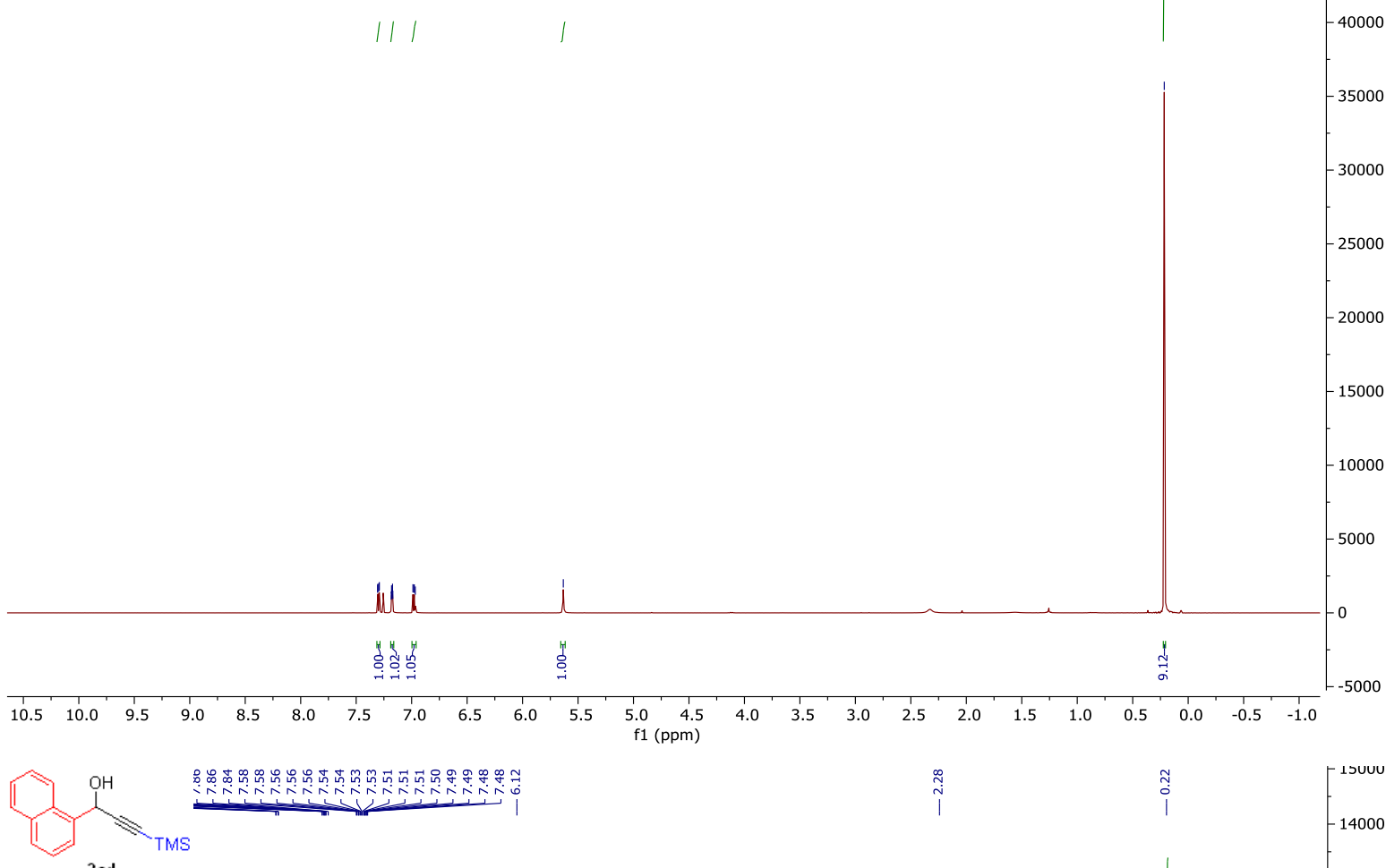

$\stackrel{\infty}{\sim}$

2ad

${ }^{1} \mathrm{H} \mathrm{NMR}\left(400 \mathrm{MHz}, \mathrm{CDCl}_{3}\right)$

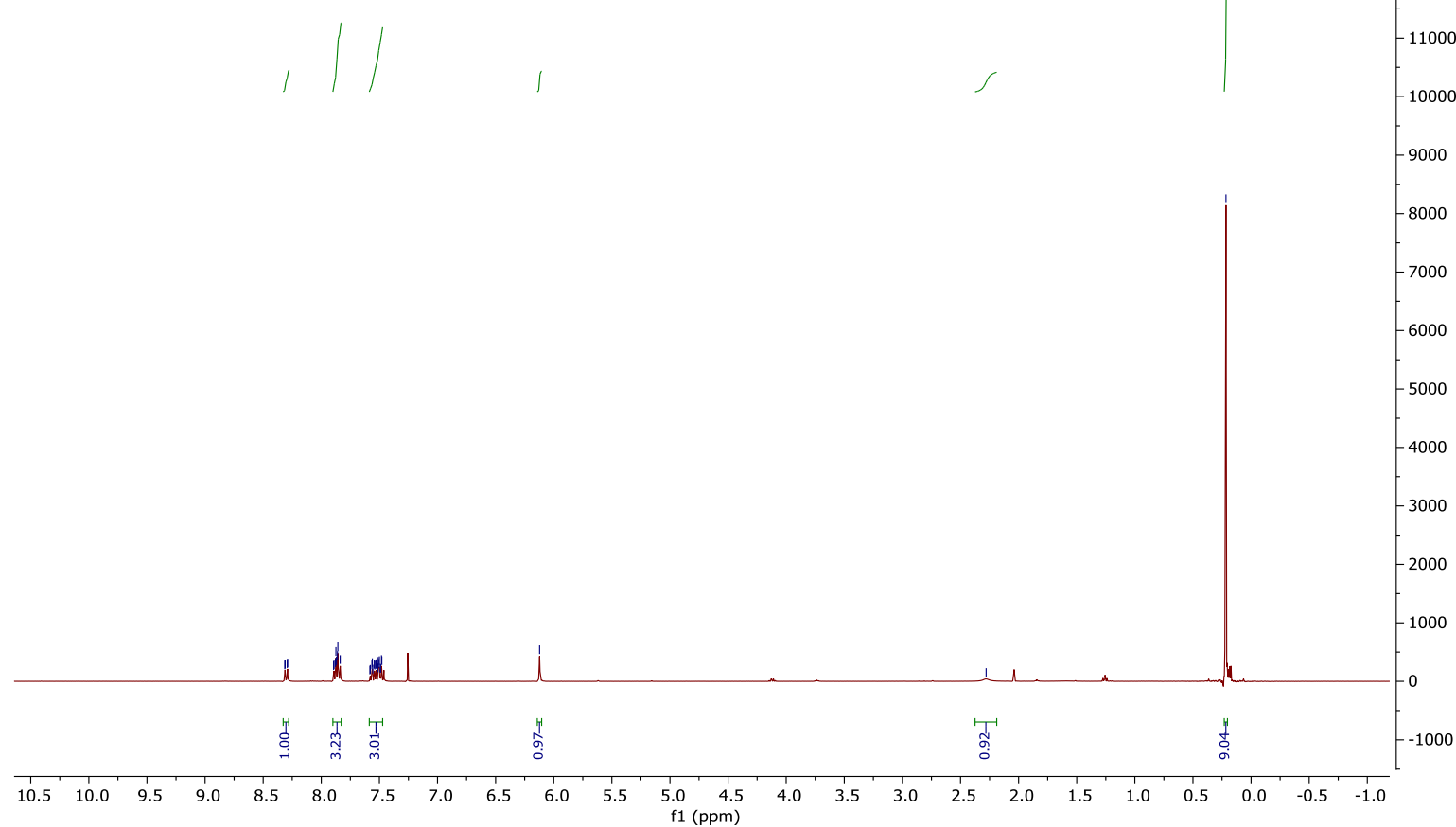




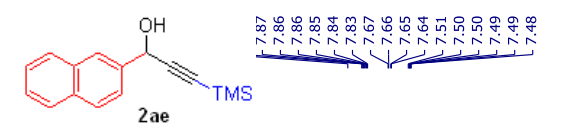

$\left.{ }^{1} \mathrm{H} \mathrm{NMR} \mathrm{(400} \mathrm{MHz,} \mathrm{CDCl}_{3}\right)$
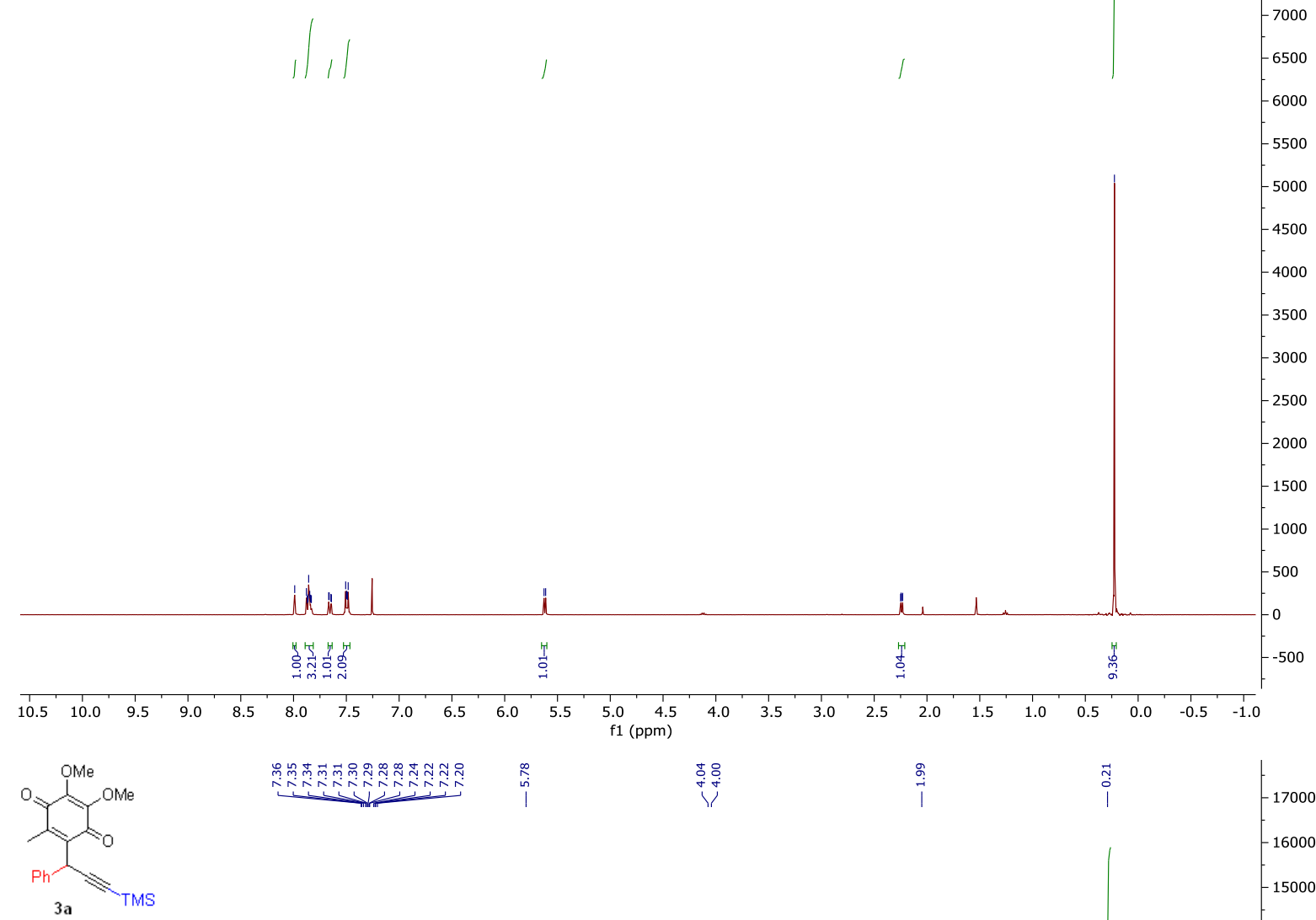

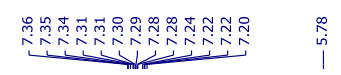

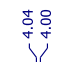

$\stackrel{8}{\rightarrow}$

${ }^{1} \mathrm{H} \mathrm{NMR}\left(400 \mathrm{MHz}, \mathrm{CD} \mathrm{Cl}_{3}\right)$

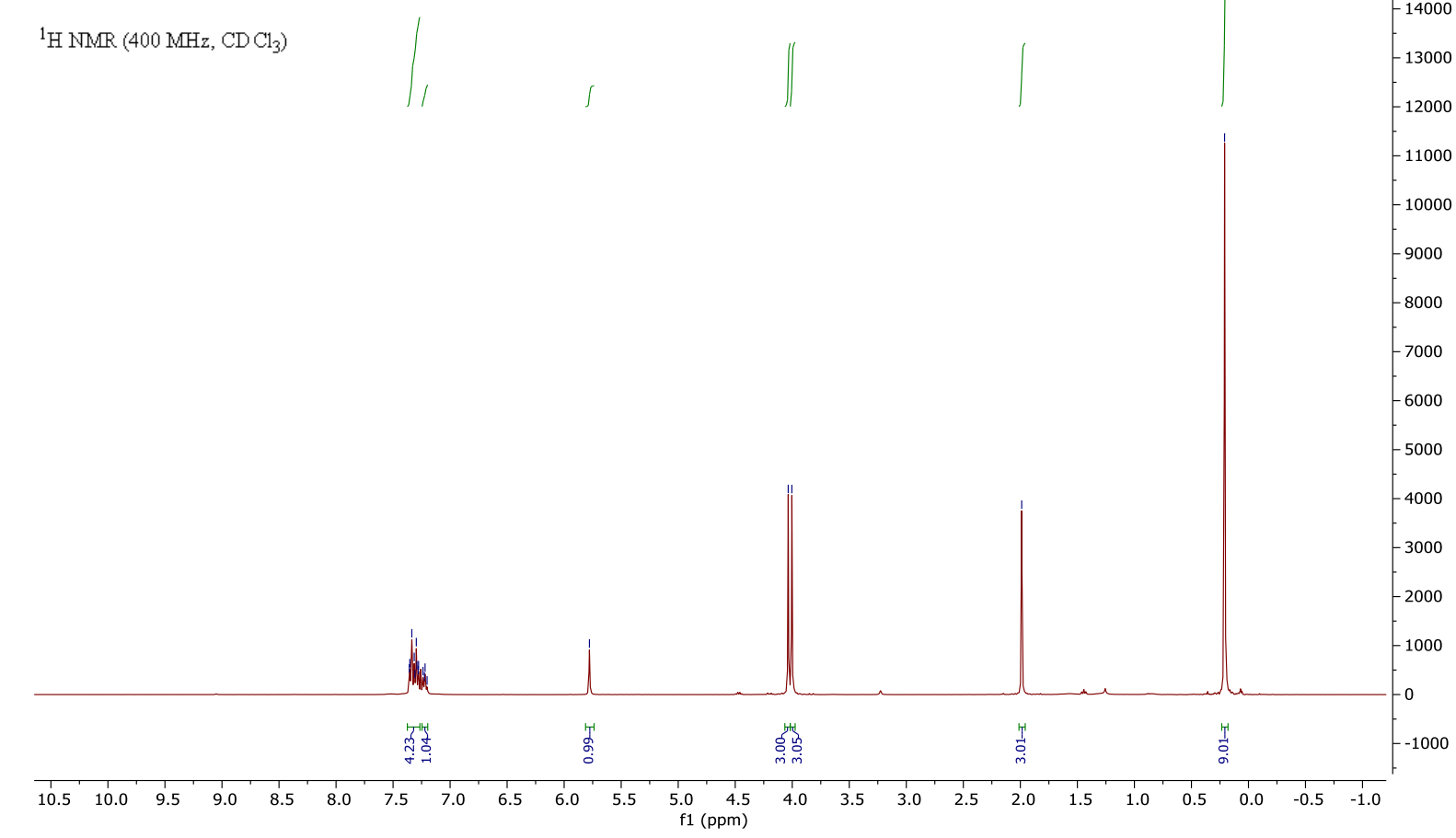




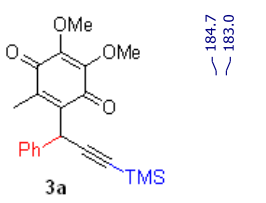

${ }^{13} \mathrm{C}(\mathrm{H}) \mathrm{NMR}\left(100 \mathrm{MHz}, \mathrm{CDCl}_{3}\right)$
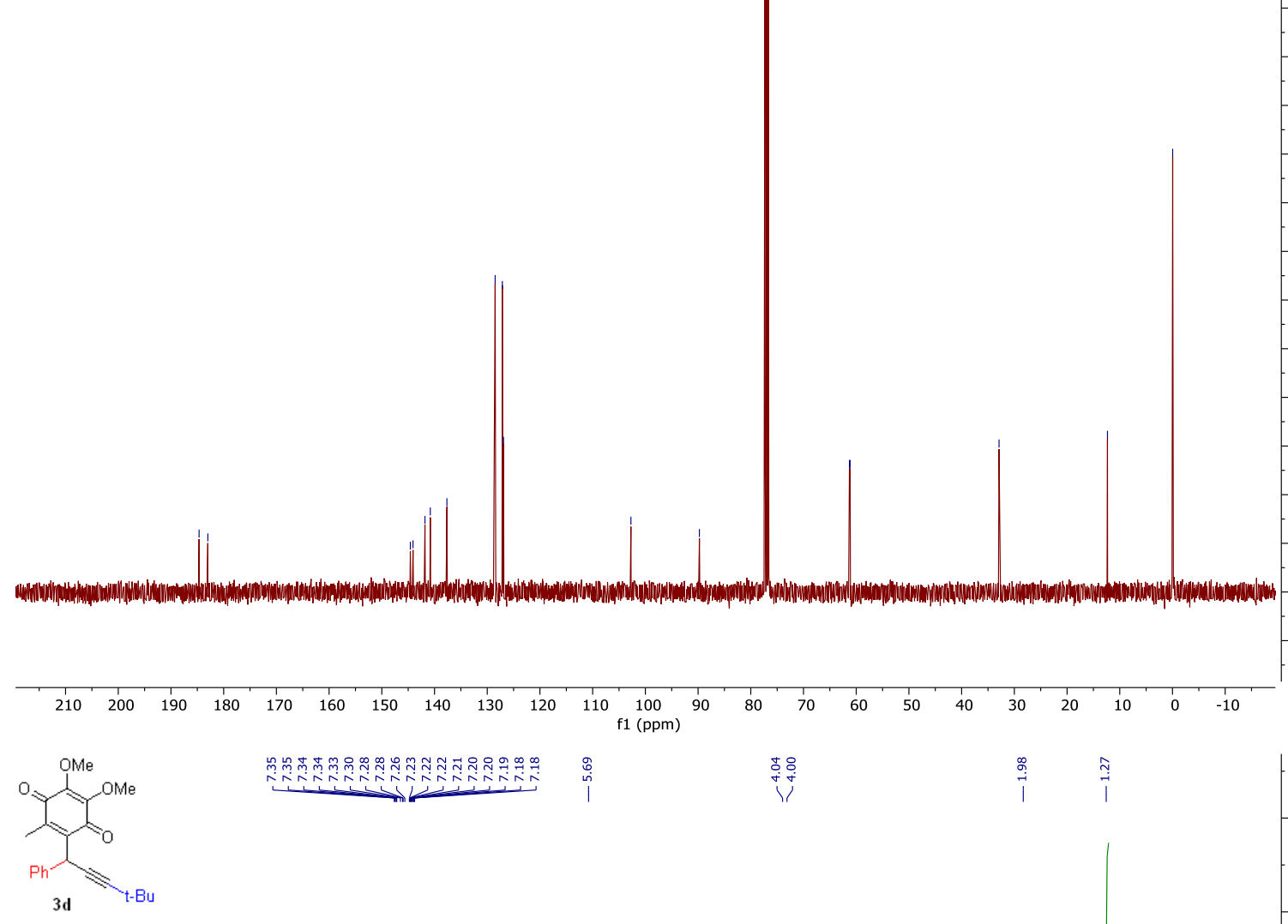

|

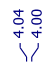

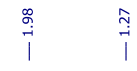

${ }^{1} \mathrm{H} \mathrm{NMR} \mathrm{(400} \mathrm{MHz,} \mathrm{CD} \mathrm{Cl}$ )

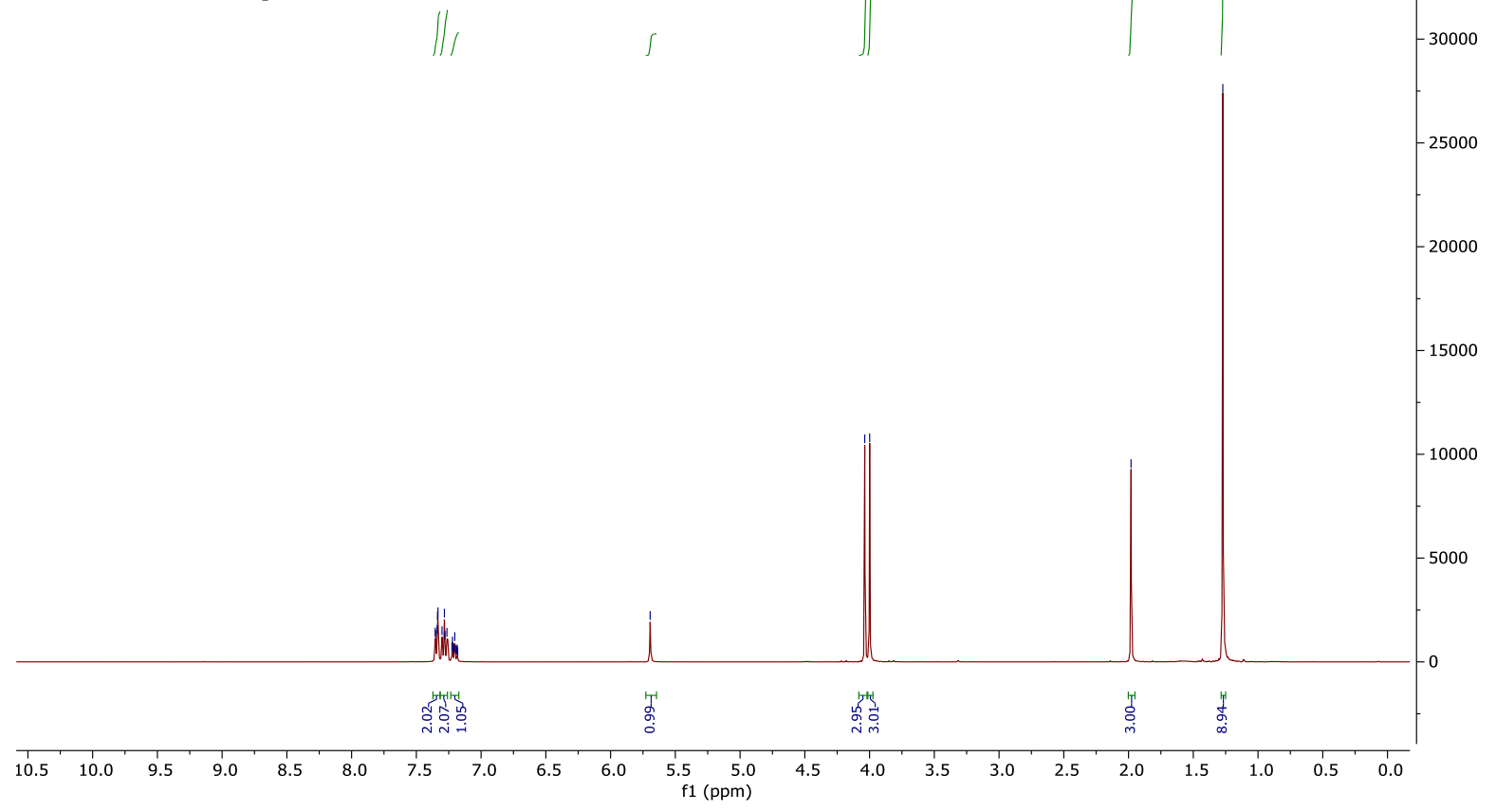




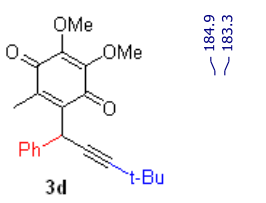

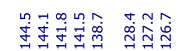

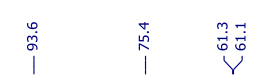

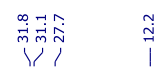

$-1700$

$-1600$

$-1500$

1400

${ }^{13} \mathrm{C}\{\mathrm{H}\} \mathrm{NMR}\left(100 \mathrm{MHz}, \mathrm{CD} \mathrm{Cl}_{3}\right)$
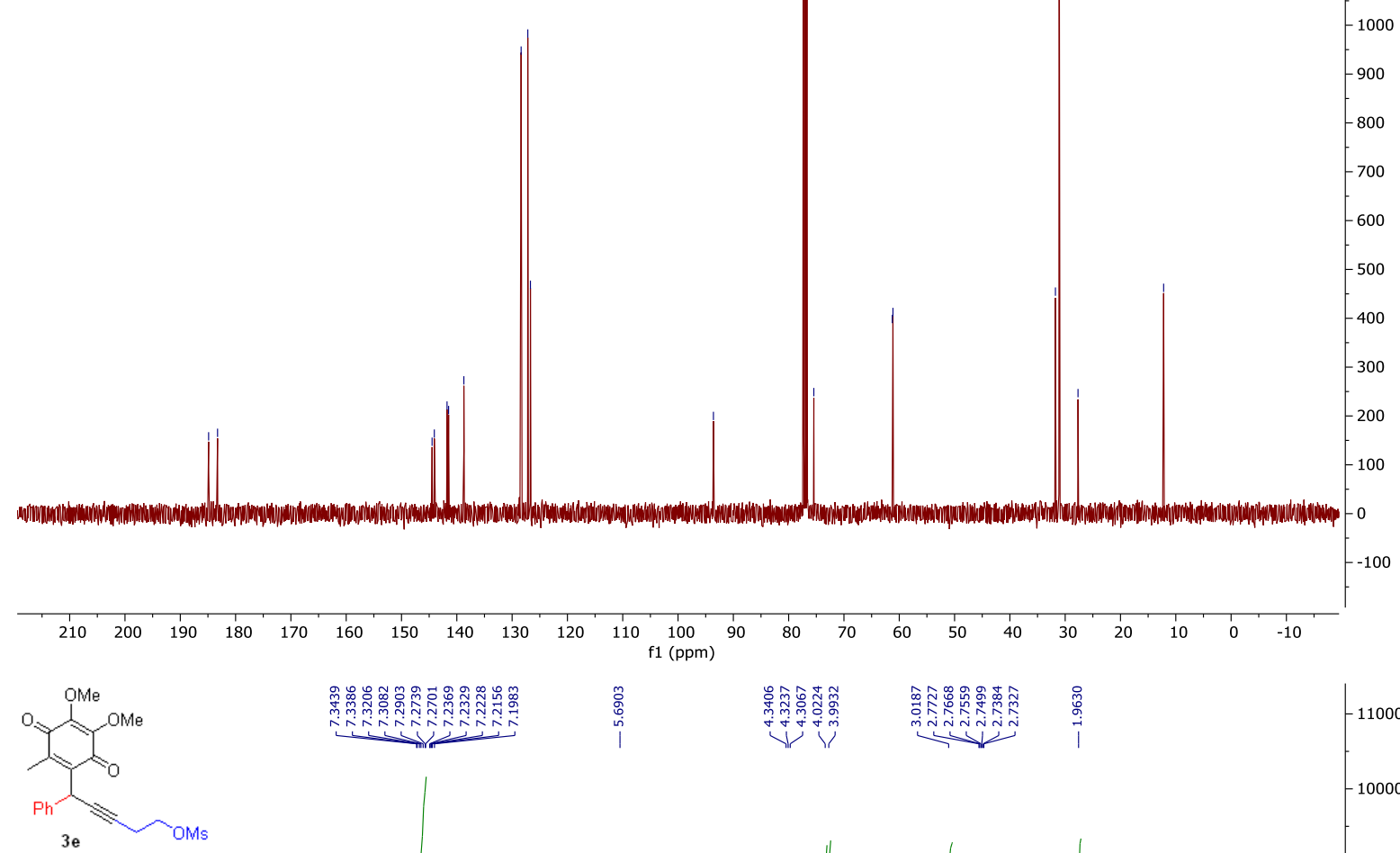

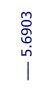

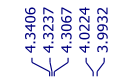

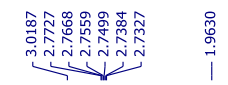

$-11000$

${ }^{1} \mathrm{H} \mathrm{NMR}\left(400 \mathrm{MHz}, \mathrm{CD} \mathrm{Cl}_{3}\right)$
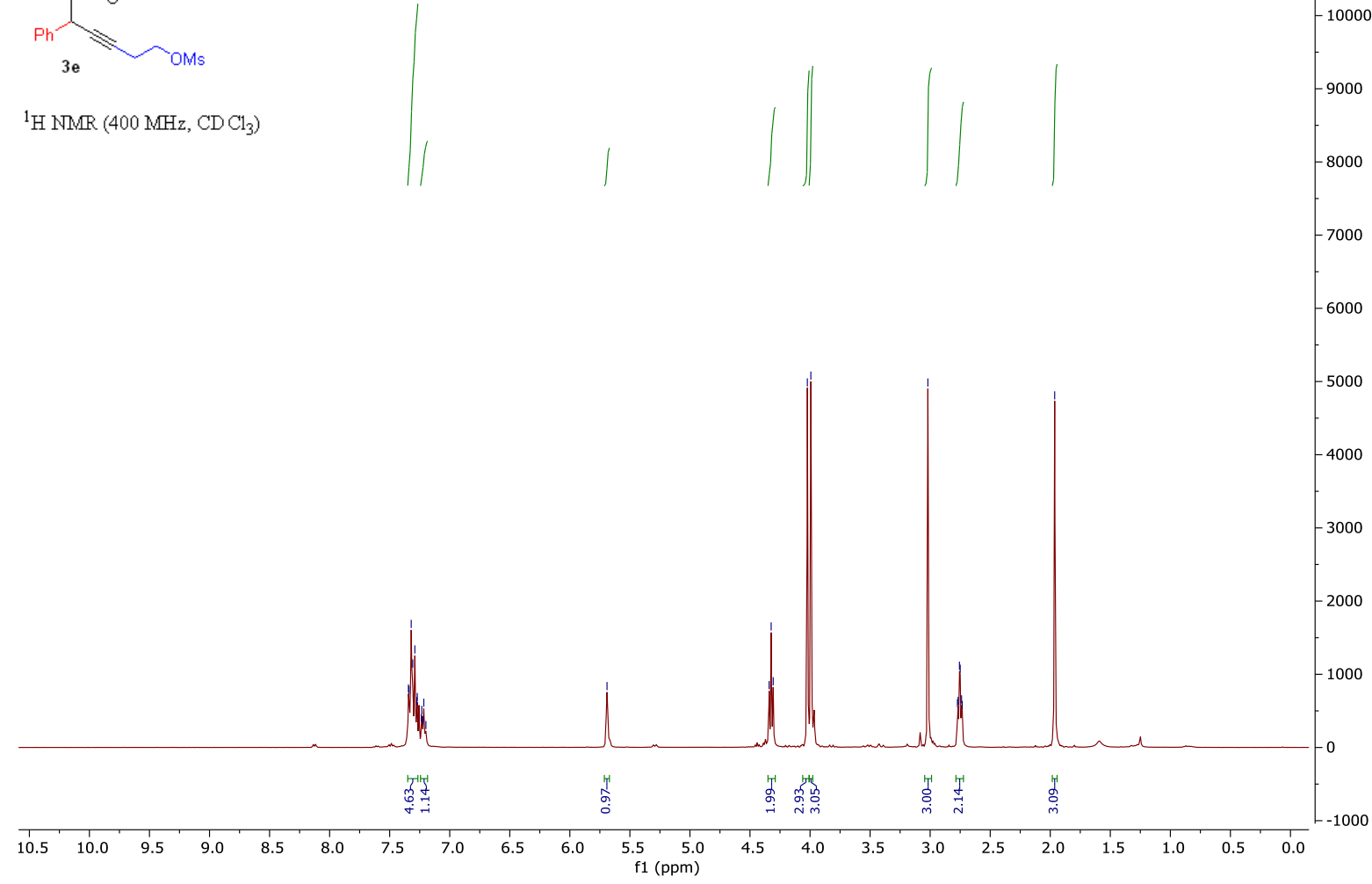


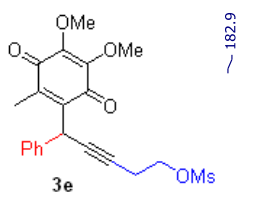

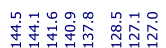

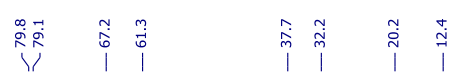

${ }^{13} \mathrm{C}\{\mathrm{H}\} \mathrm{NMR}\left(100 \mathrm{MHz}, \mathrm{CD} \mathrm{Cl}_{3}\right)$
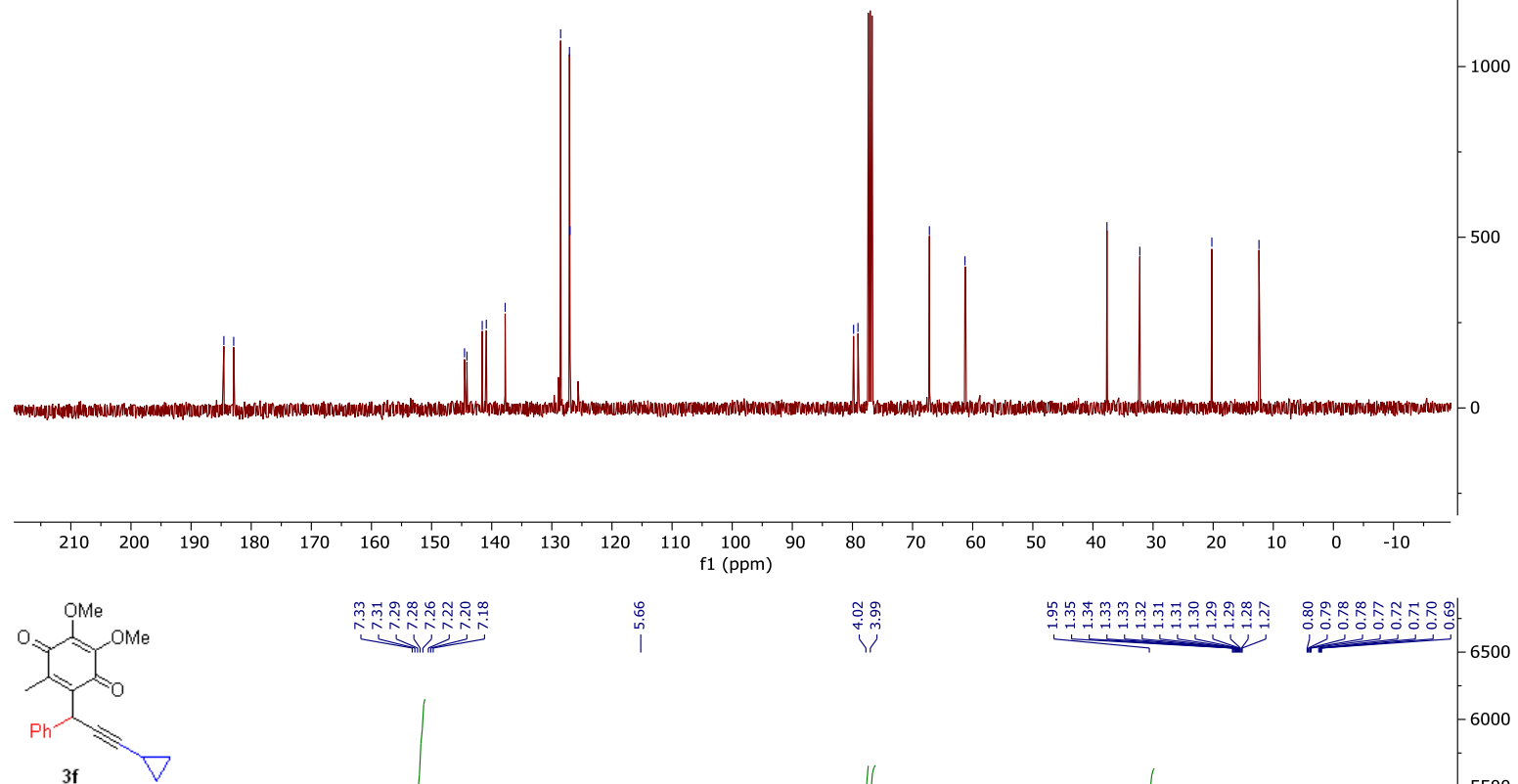

${ }^{1} \mathrm{H} \mathrm{NMR} \mathrm{(400} \mathrm{MHz,} \mathrm{CD} \mathrm{Cl}_{3}$ )

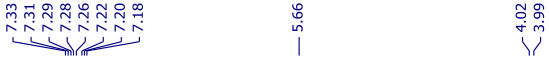

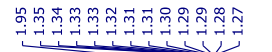

650

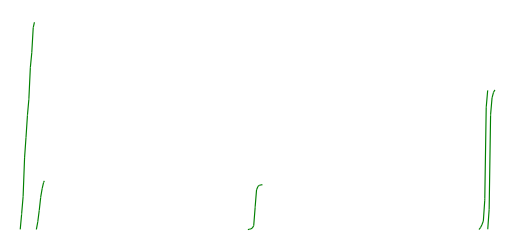

$-6000$

5500

5000

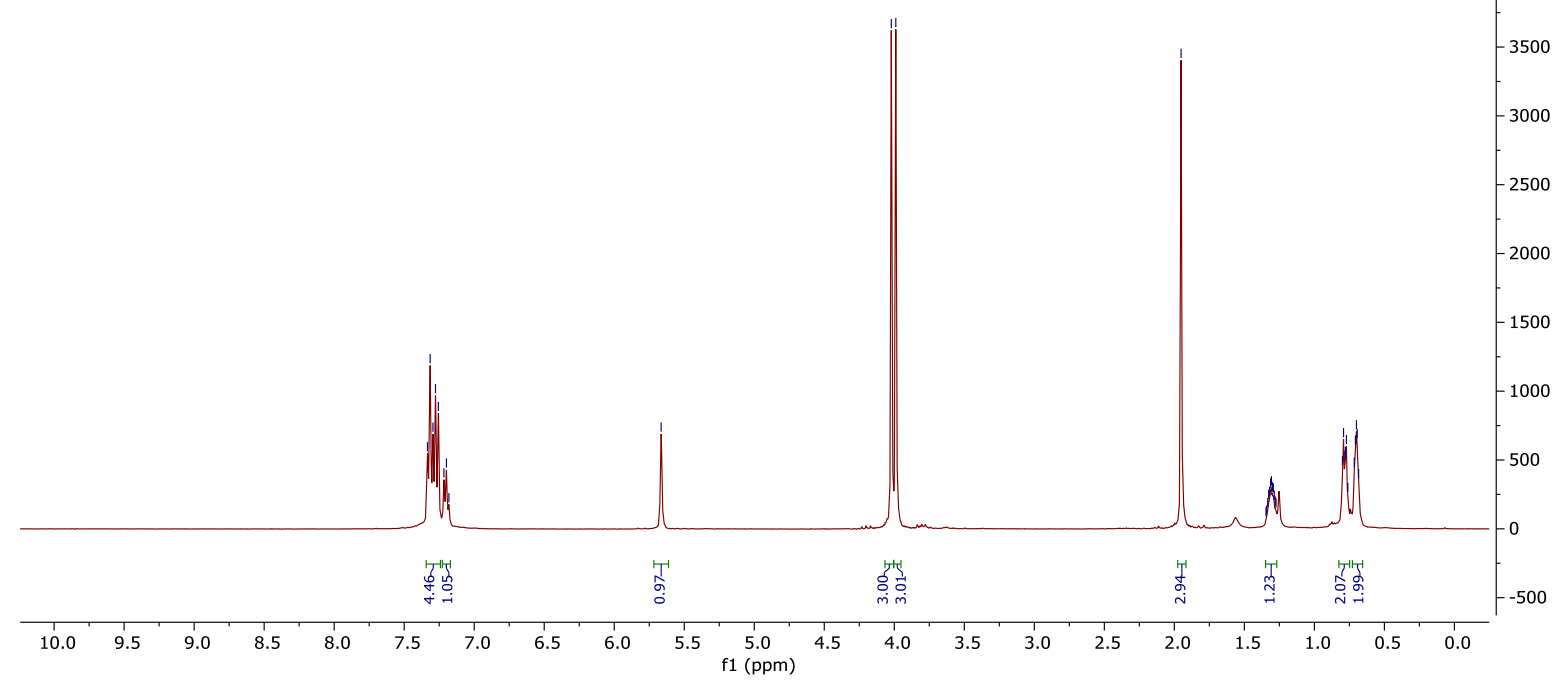




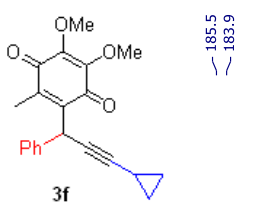

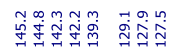

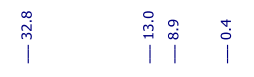

${ }^{3} \mathrm{C}\{\mathrm{H}\} \mathrm{NMR}(100 \mathrm{MHz}, \mathrm{CD} \mathrm{Cl} 3)$

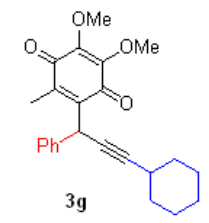

$\underbrace{20000}_{-24000}$

H MMR ( $\left.400 \mathrm{MHz}, \mathrm{CD} \mathrm{Cl}_{3}\right)$
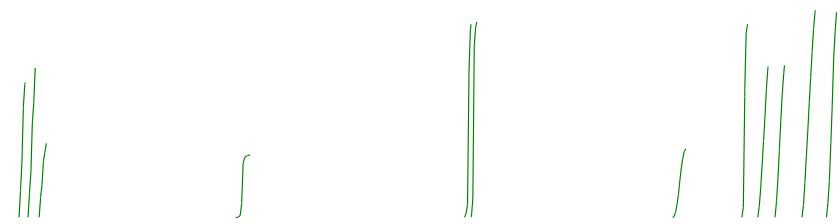

22000

20000

18000

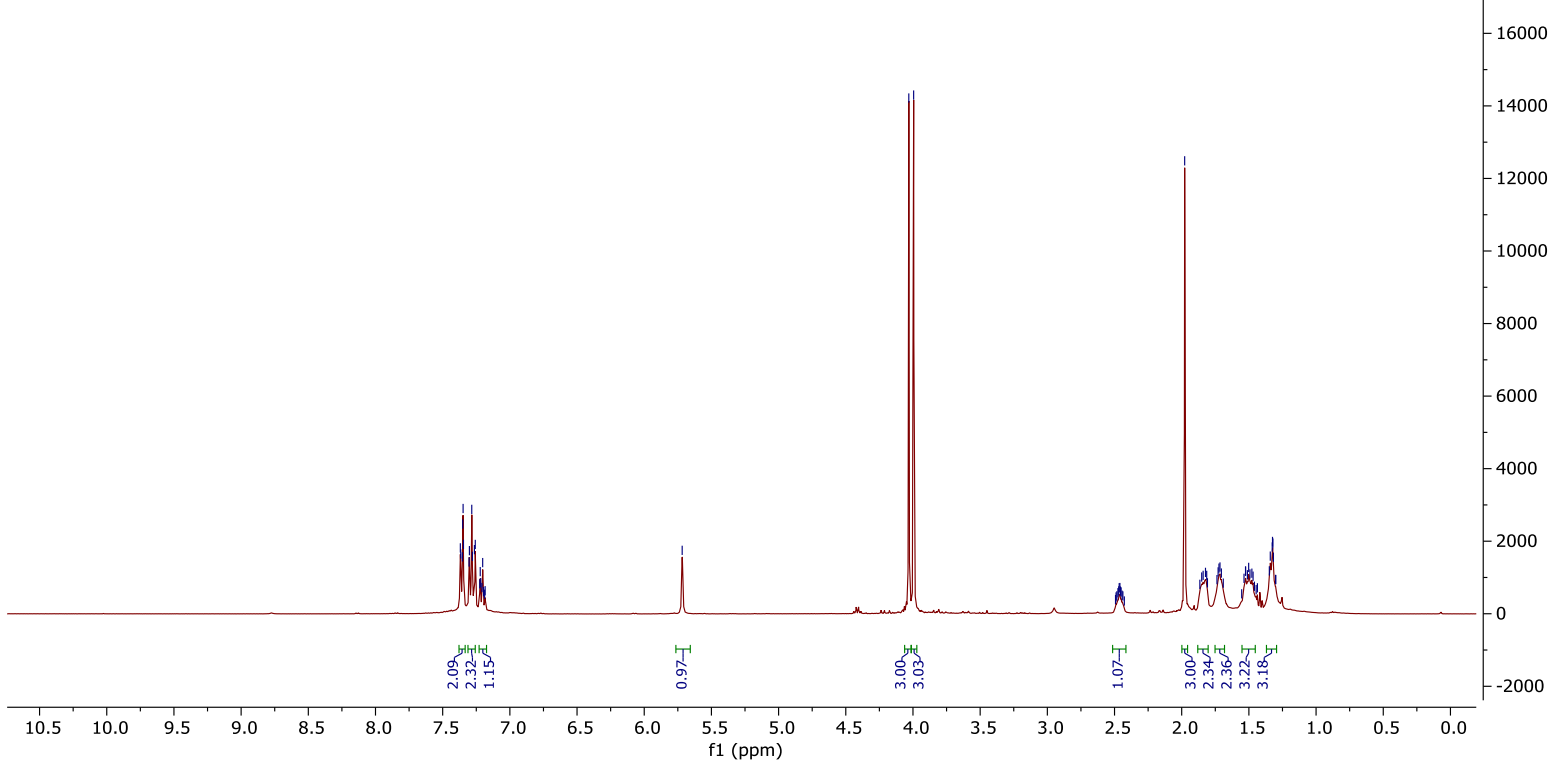



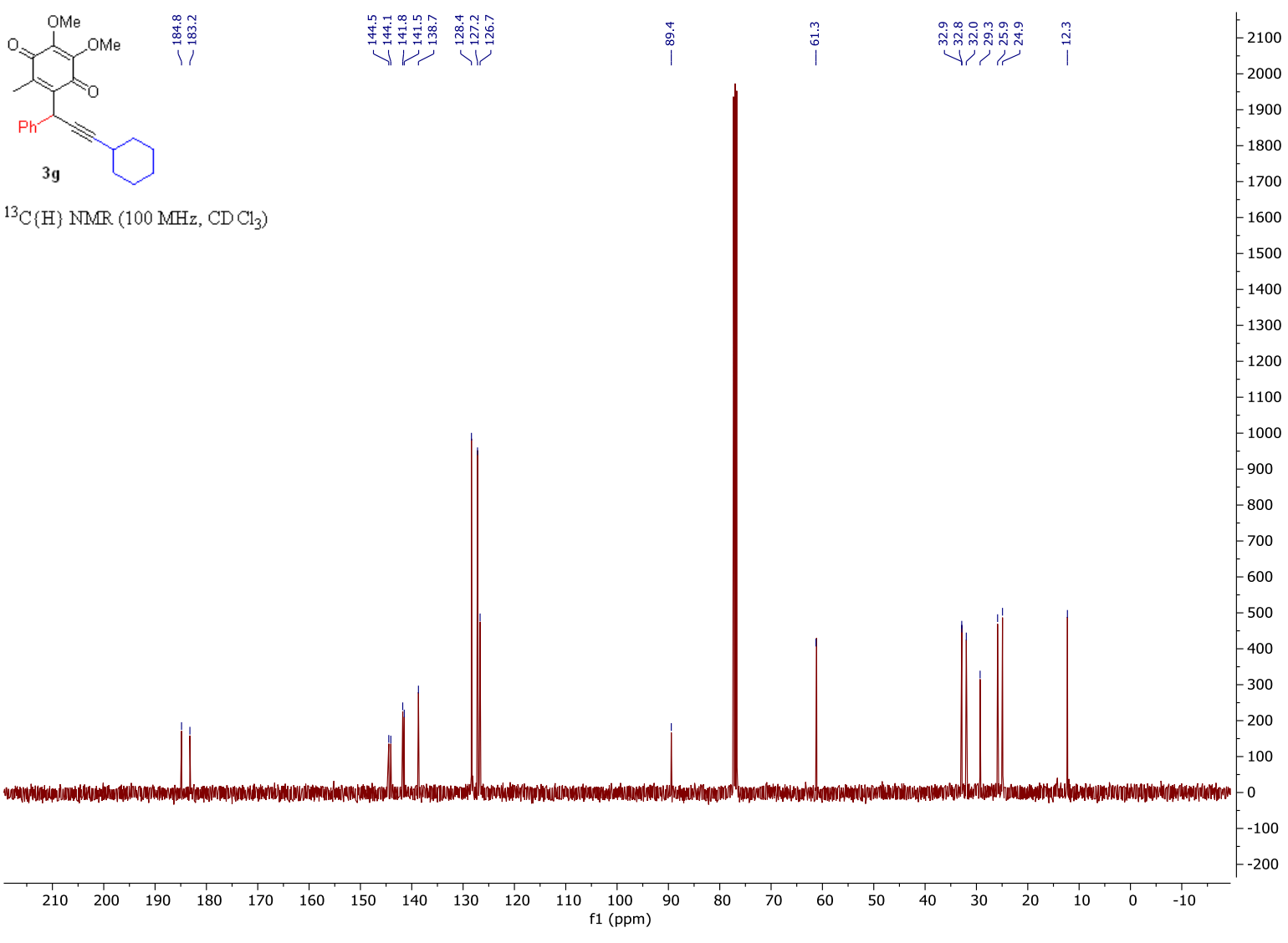

${ }^{1} \mathrm{H} \mathrm{NMR}\left(400 \mathrm{MHz}, \mathrm{CD} \mathrm{Cl}_{3}\right)$

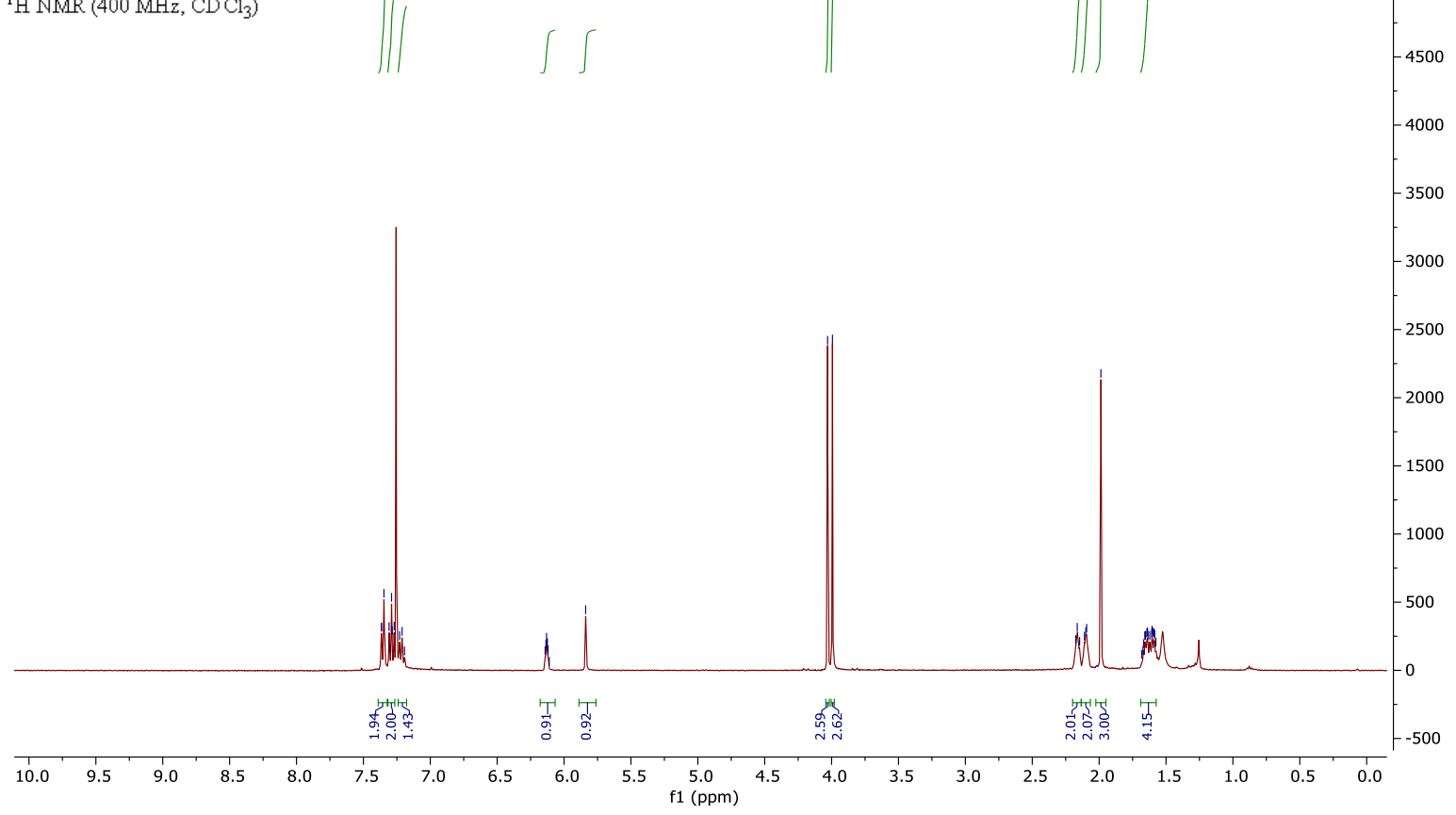

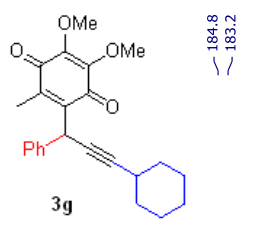

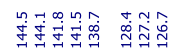

${ }^{13} \mathrm{C}(\mathrm{H}) \mathrm{NMR}\left(100 \mathrm{MHz}, \mathrm{CD} \mathrm{Cl}_{3}\right)$

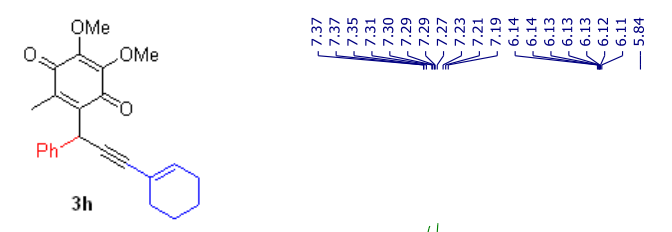

. 


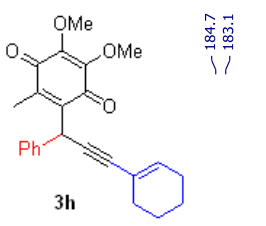

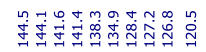

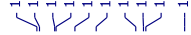

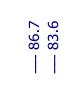

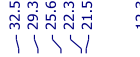

$-1900$

${ }^{13} \mathrm{C}(\mathrm{H}) \mathrm{NMR}(100 \mathrm{MHz}, \mathrm{CD} \mathrm{Cl}$ )
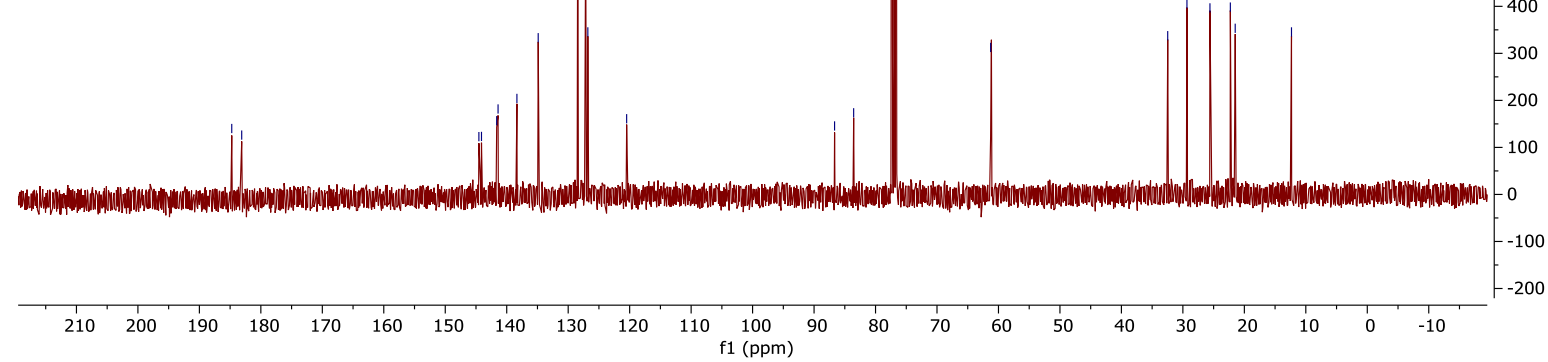
$-200$

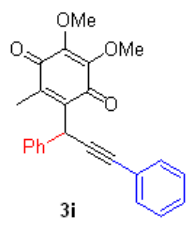

${ }^{1} \mathrm{H} \mathrm{NMR}\left(400 \mathrm{MHz}, \mathrm{CD} \mathrm{Cl}_{3}\right)$

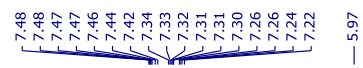

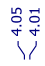

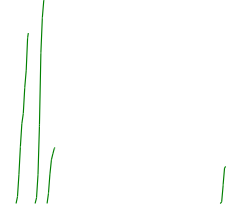

$-6000$ 5500 5000

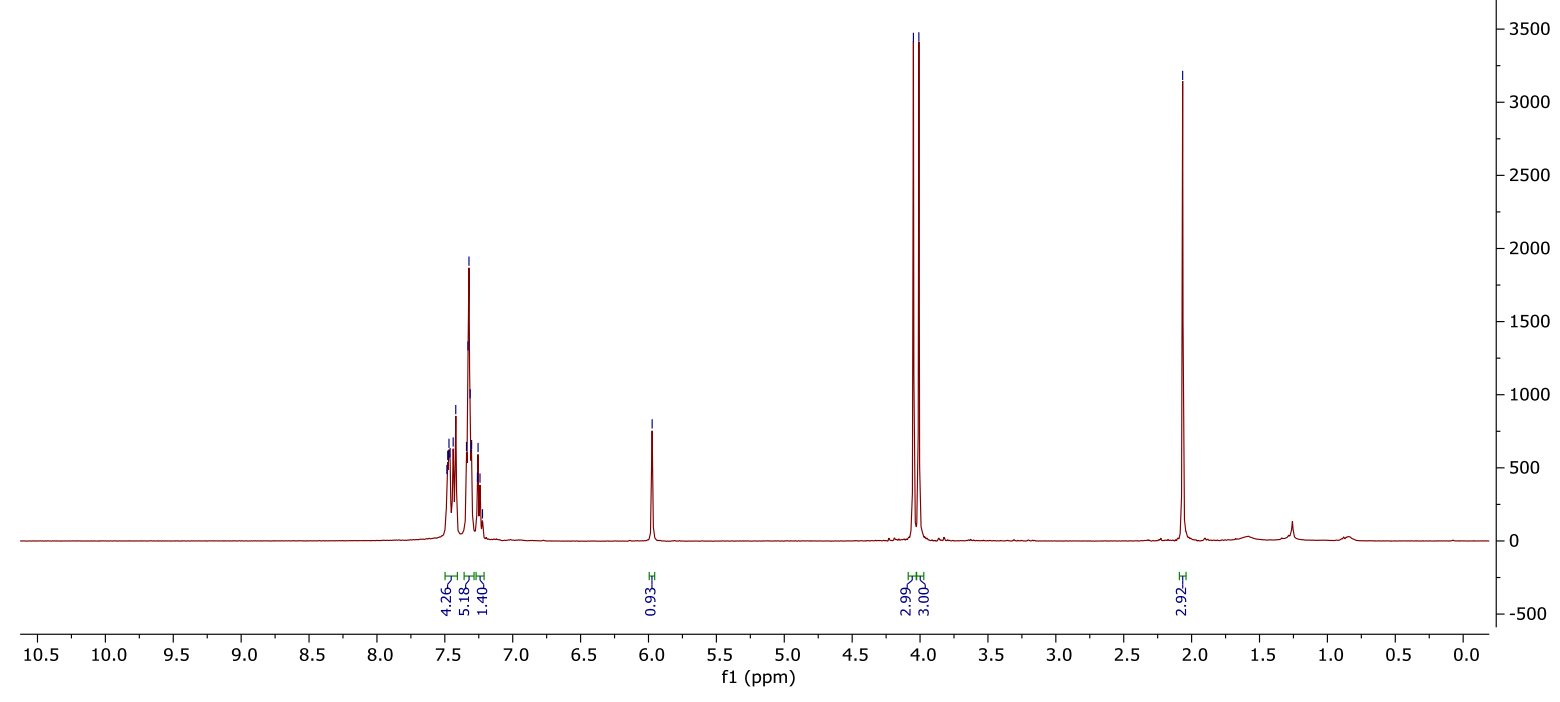




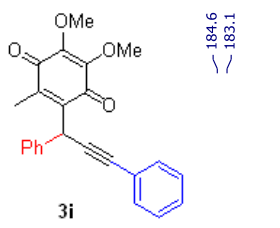

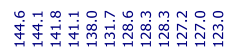

:

${ }^{13} \mathrm{C}\{\mathrm{H}\} \operatorname{MMR}\left(100 \mathrm{MHz}, \mathrm{CD} \mathrm{Cl}_{3}\right)$

$\stackrel{m}{0}$

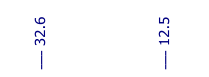

$5^{1900}$ $-1800$

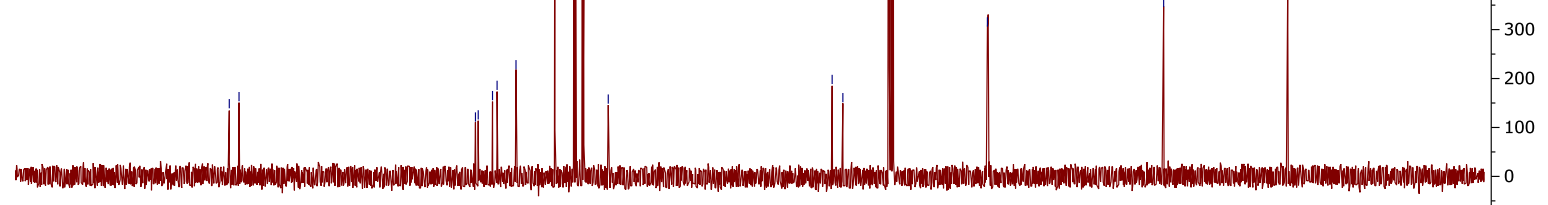

\section{(n)}
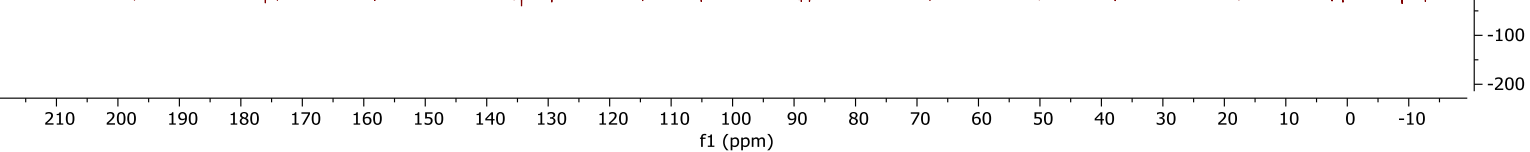
$-200$

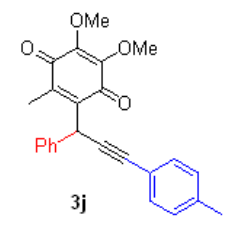

${ }^{1} \mathrm{H} \mathrm{NMR}\left(400 \mathrm{MHz}, \mathrm{CD} \mathrm{Cl}_{3}\right)$
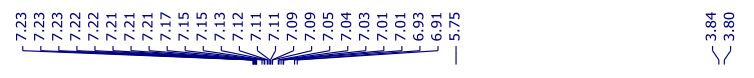

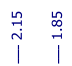
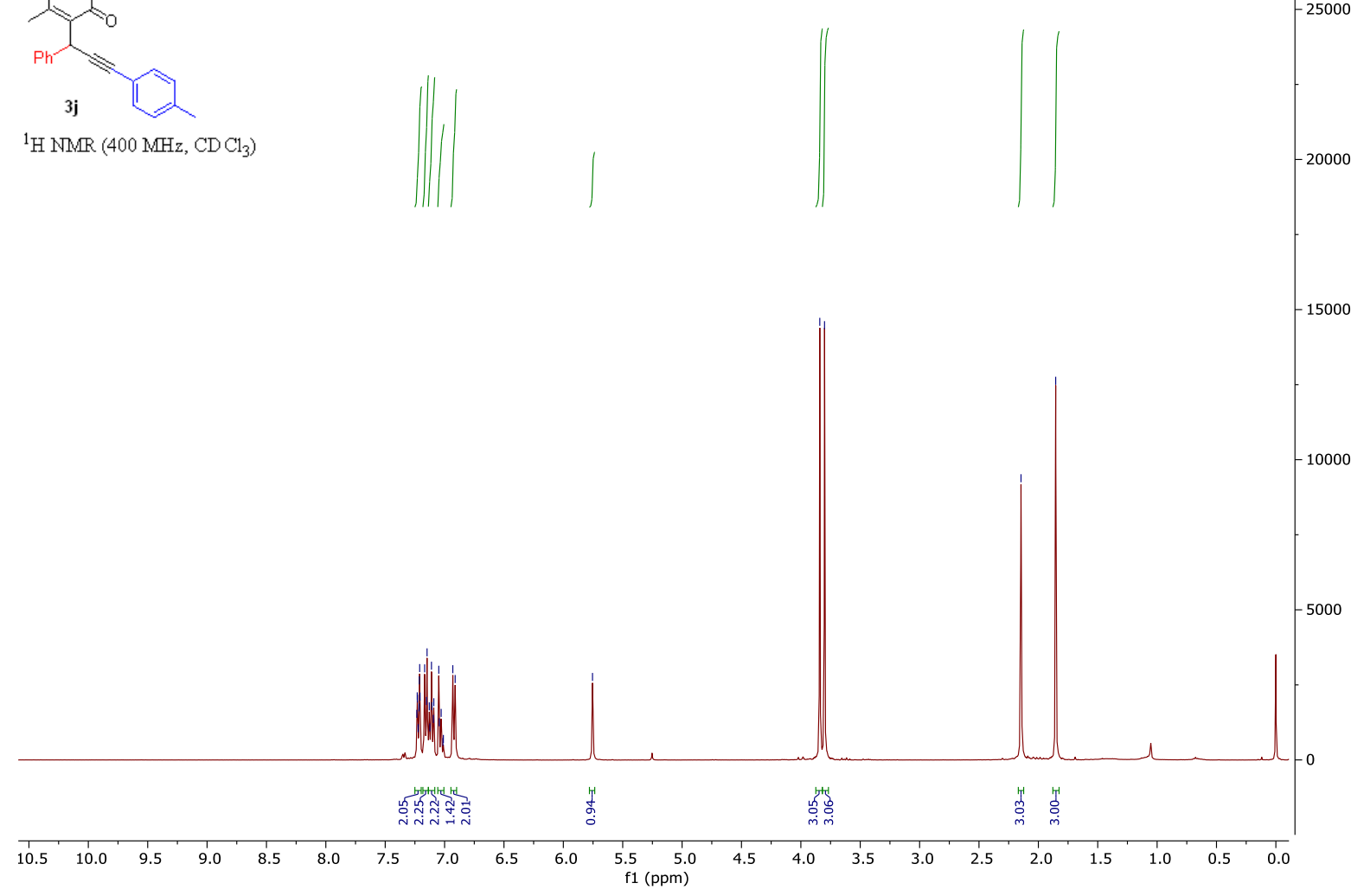

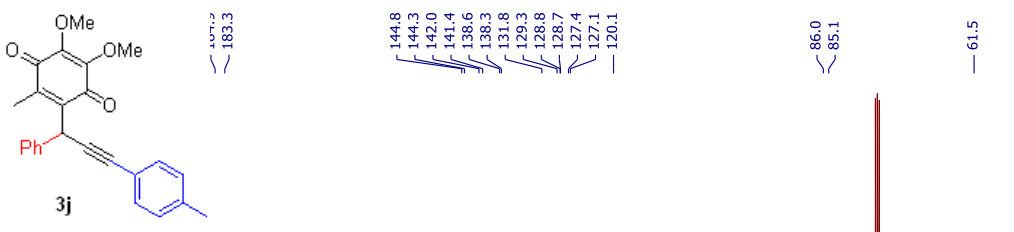

${ }^{13} \mathrm{C}\{\mathrm{H}\} \mathrm{MMR}\left(100 \mathrm{MHz}, \mathrm{CD} \mathrm{Cl}_{3}\right)$
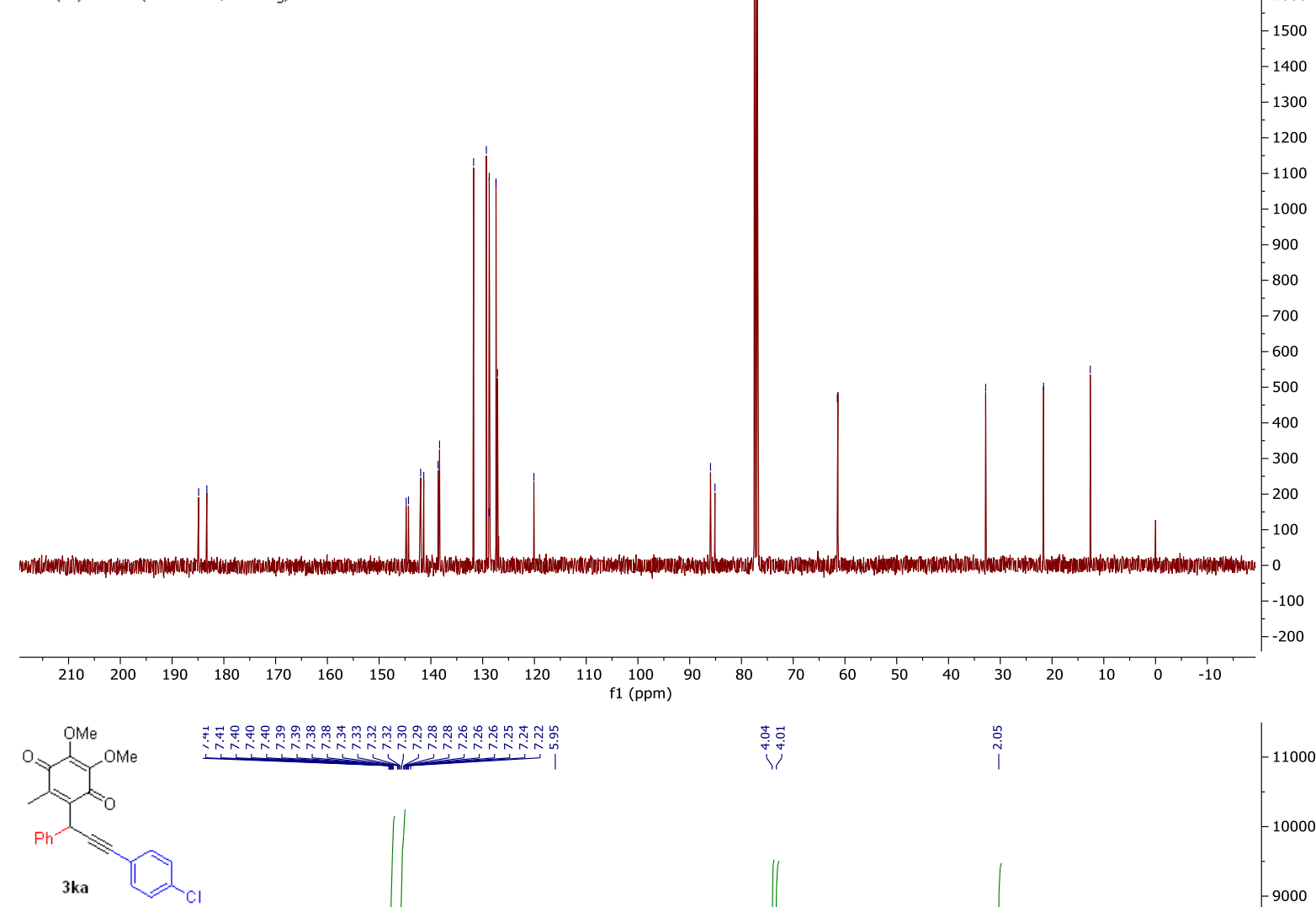

${ }^{1} \mathrm{H} \mathrm{NMR}\left(400 \mathrm{MHz}, \mathrm{CD} \mathrm{Cl}_{3}\right.$ )

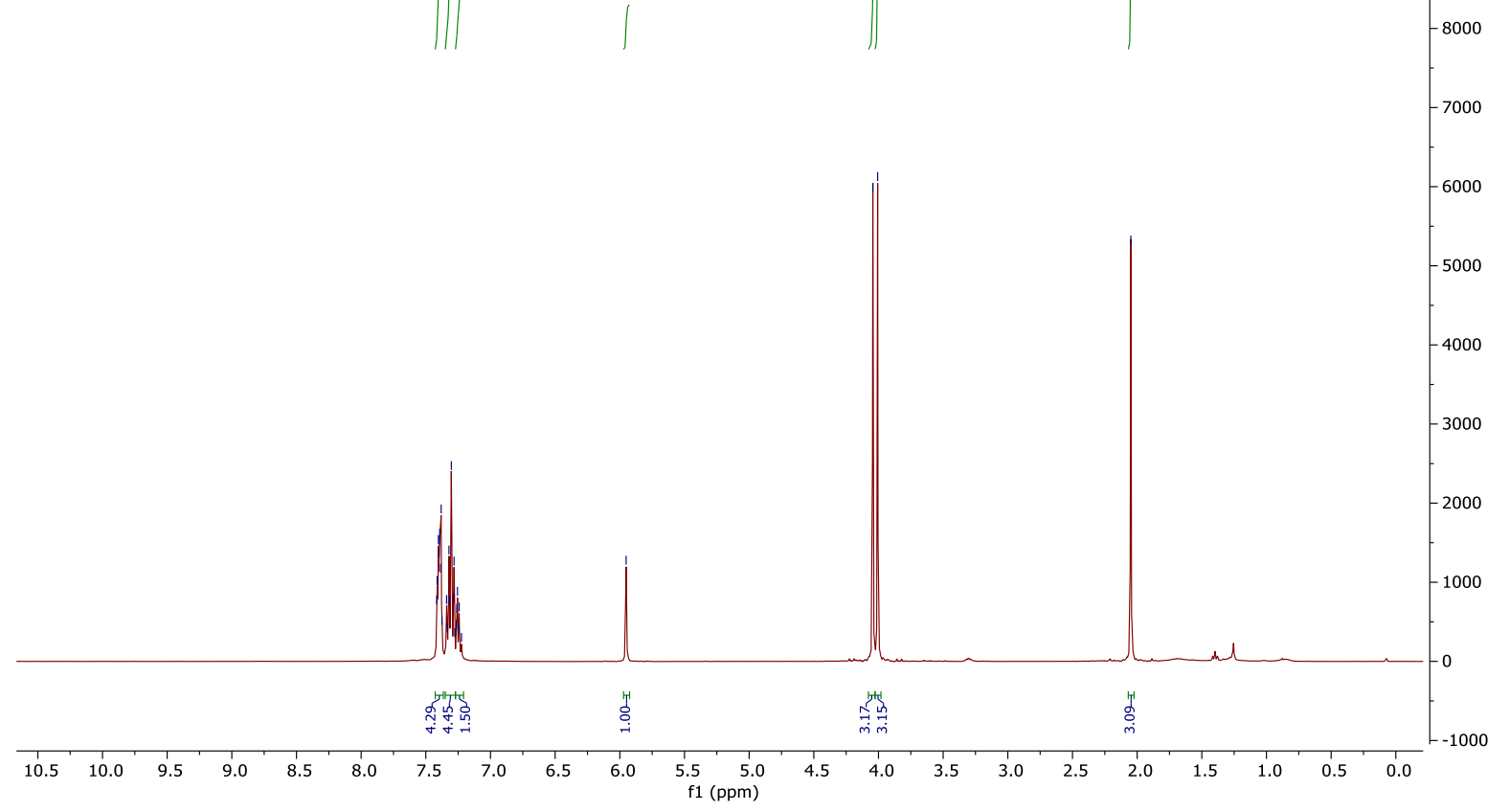




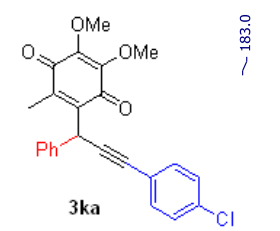

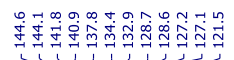

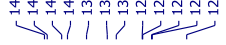

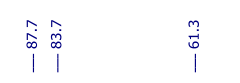

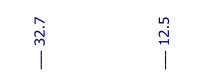

$-2100$

${ }^{13} \mathrm{C}\{\mathrm{H}\} \mathrm{NMR}\left(100 \mathrm{MHz}, \mathrm{CD} \mathrm{Cl}_{3}\right)$
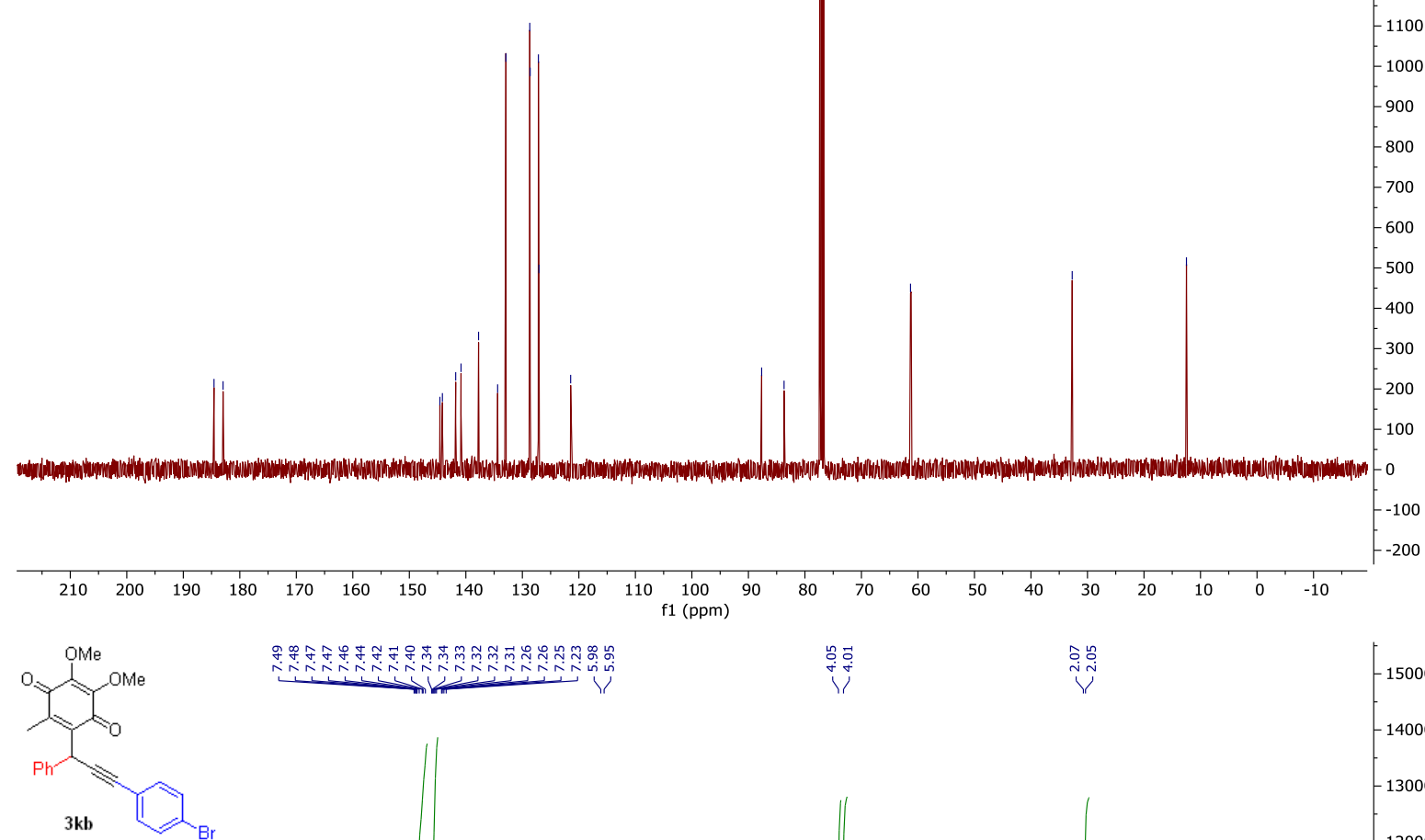

${ }^{1} \mathrm{H} \mathrm{NMR}\left(400 \mathrm{MHz}, \mathrm{CD} \mathrm{Cl}_{3}\right)$

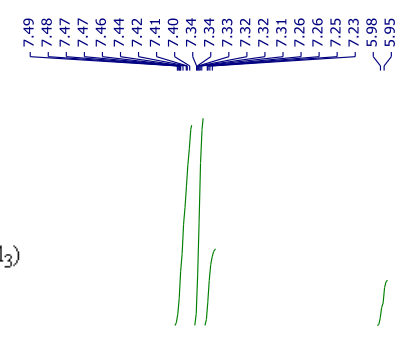

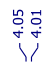

ํํํำ

15000 14000

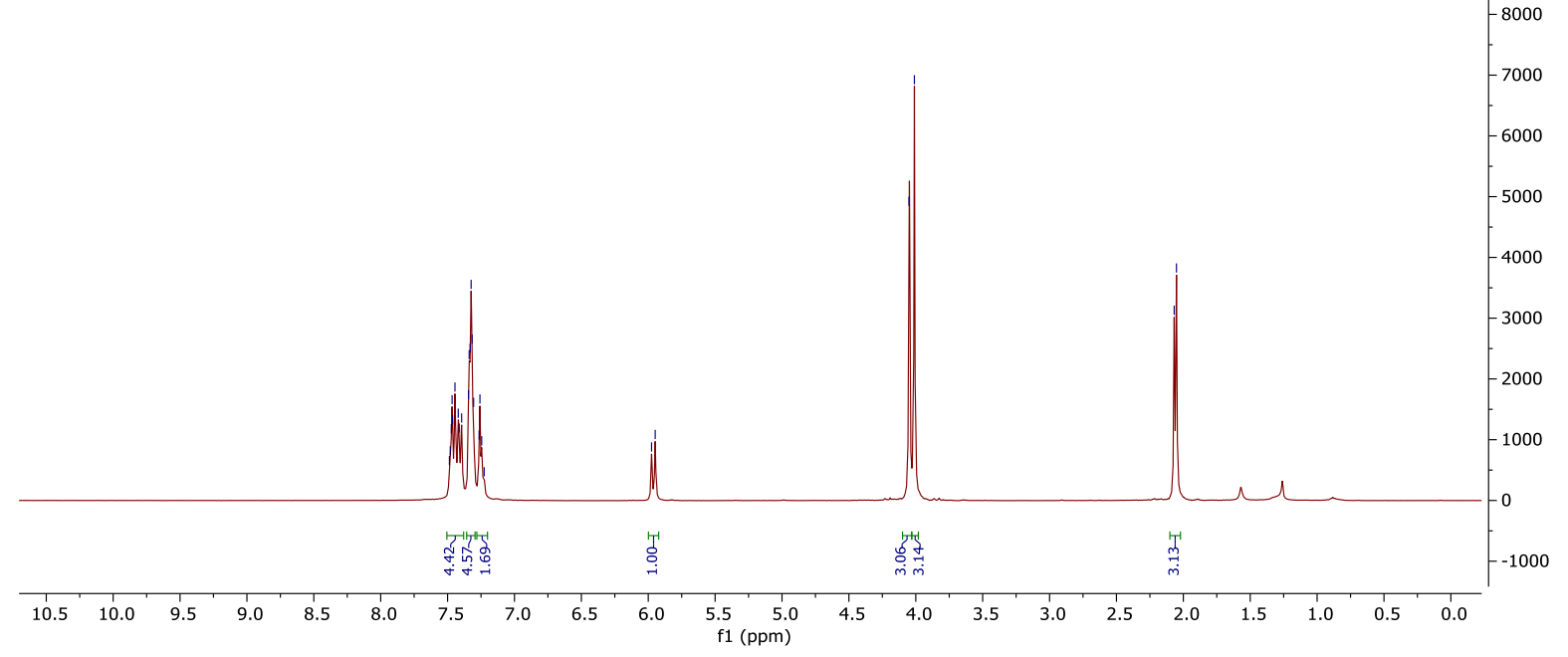




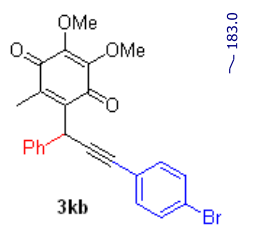

$\stackrel{m}{i}$

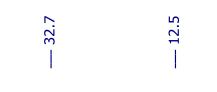

$-1600$

${ }^{3} \mathrm{C}\{\mathrm{H}\} \mathrm{NMR}\left(100 \mathrm{MHz}, \mathrm{CD} \mathrm{Cl}{ }_{3}\right)$
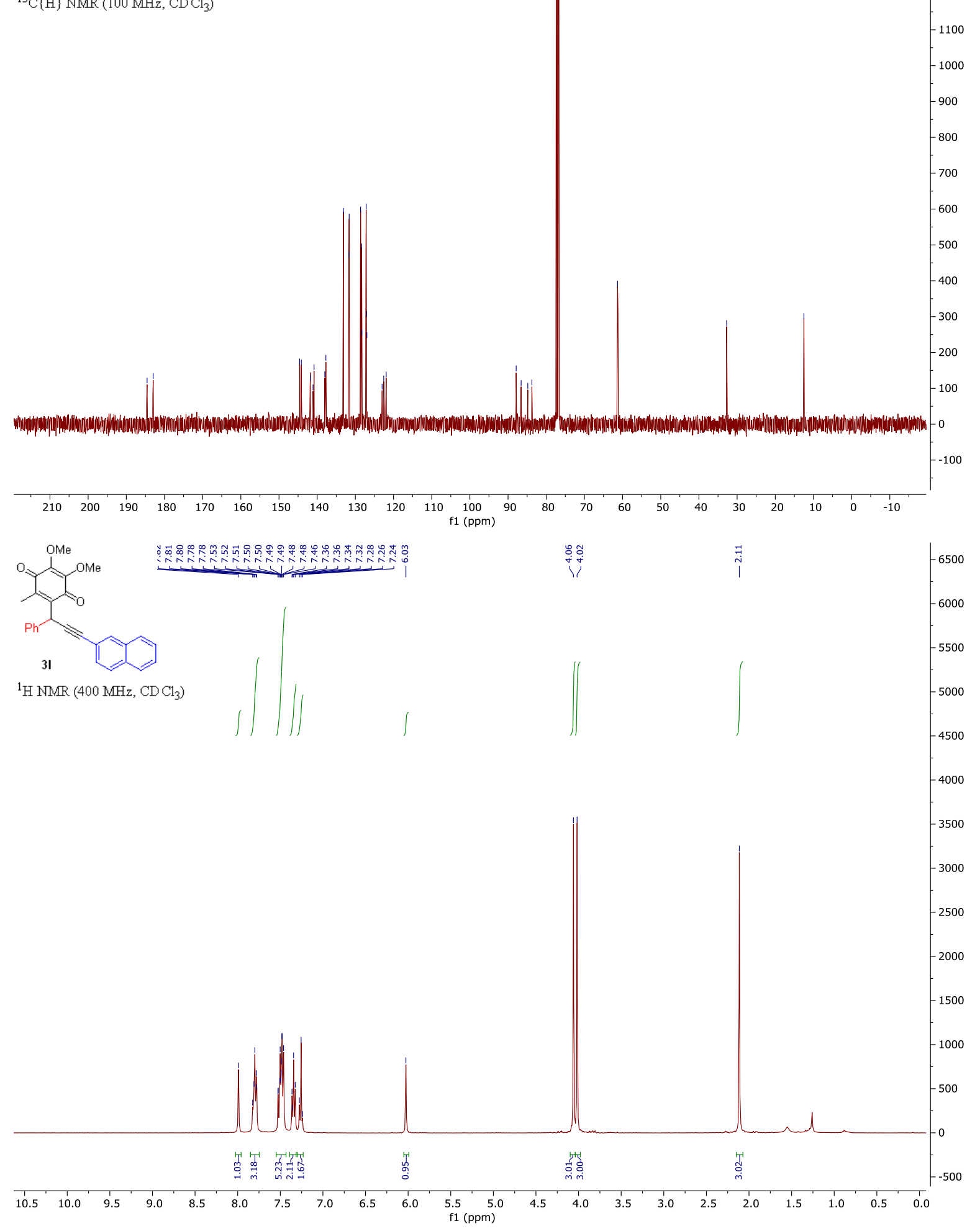


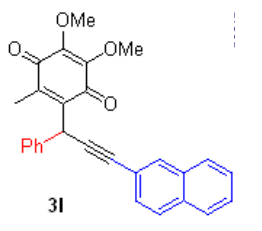

${ }^{13} \mathrm{C}\{\mathrm{H}\} \mathrm{MMR}\left(100 \mathrm{MHz}, \mathrm{CD} \mathrm{Cl}_{3}\right)$
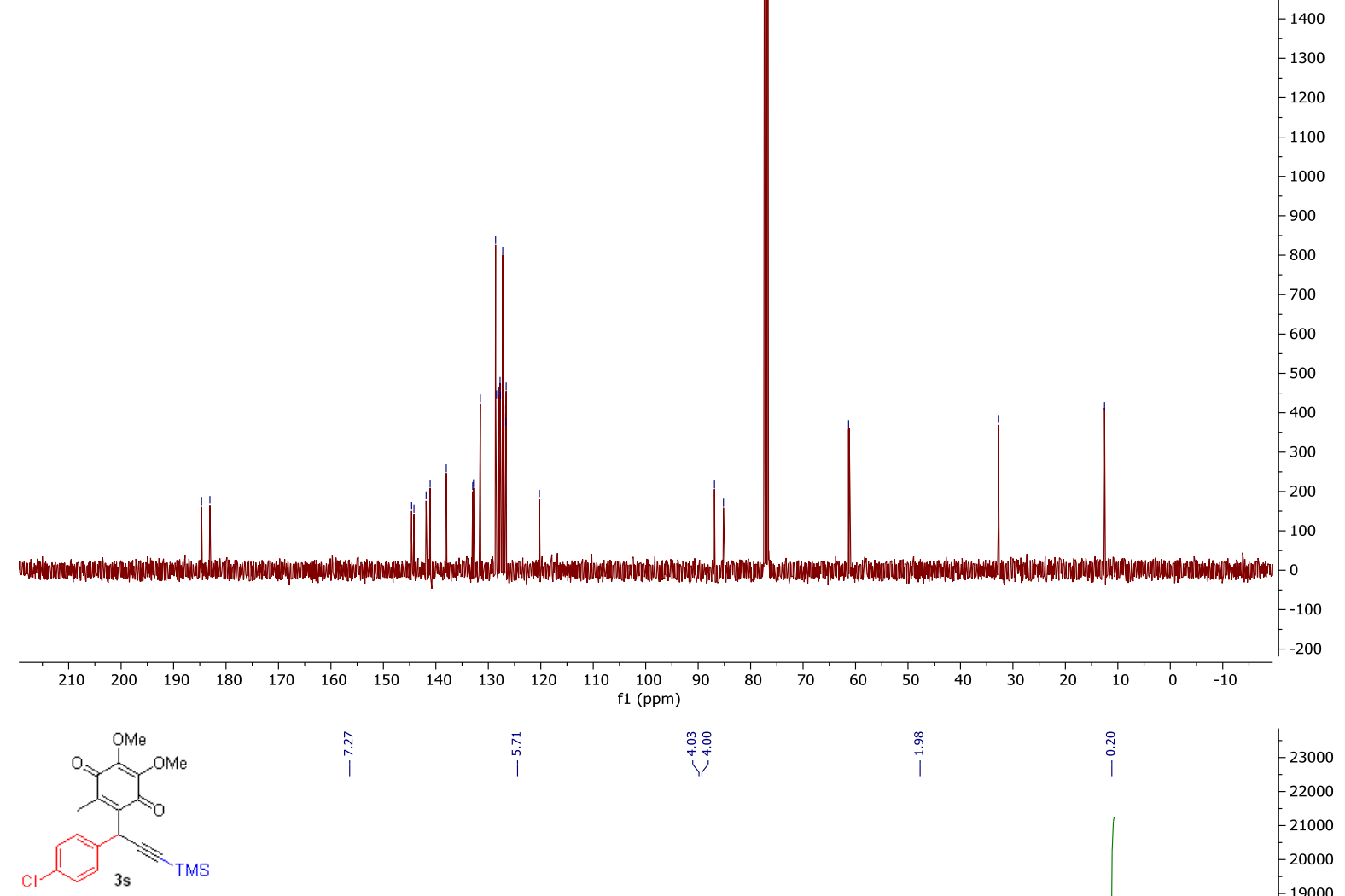

$\left.{ }^{1} \mathrm{H} \mathrm{NMR} \mathrm{(400} \mathrm{MHz,} \mathrm{CD} \mathrm{Cl}_{3}\right)$
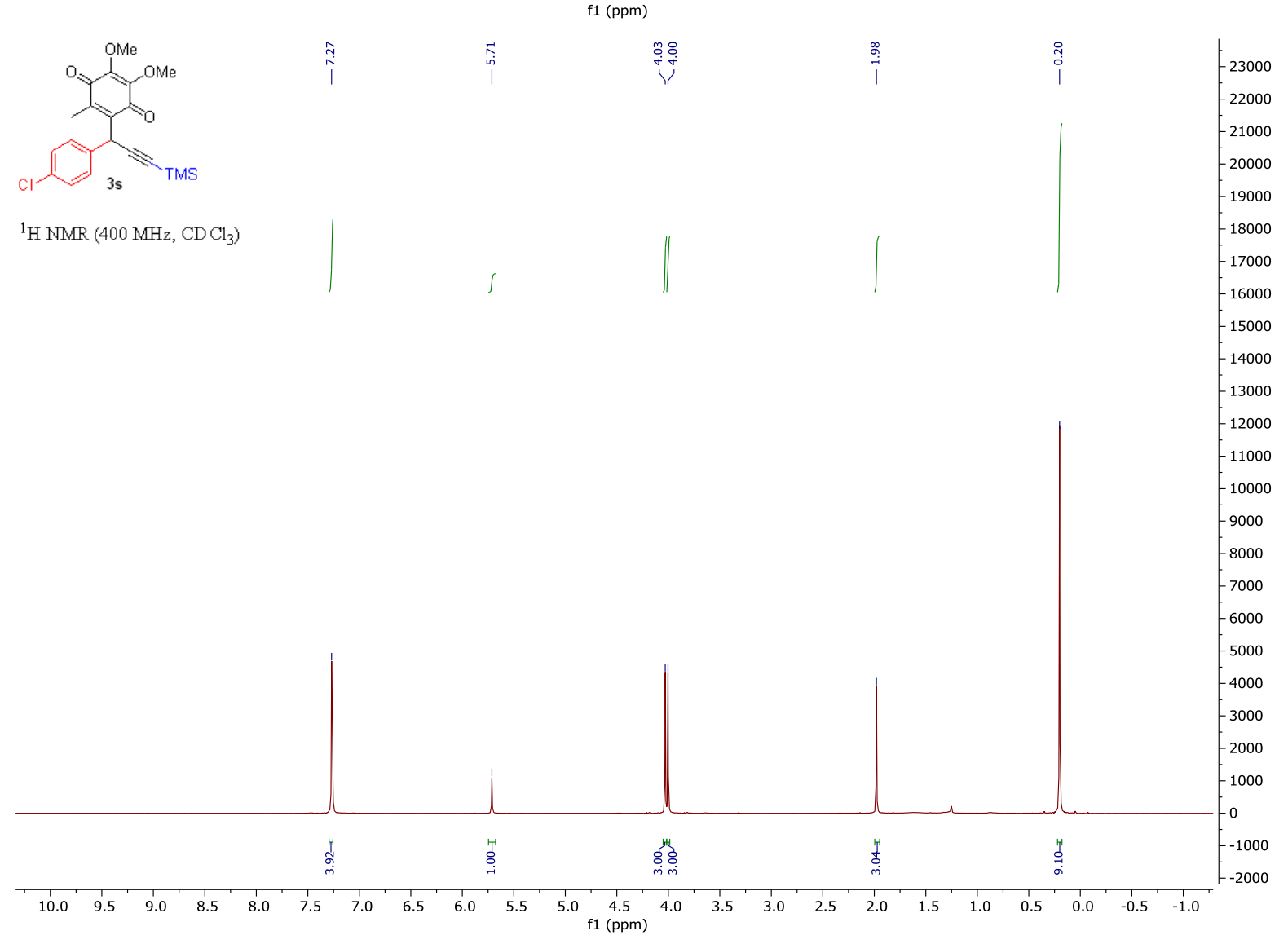


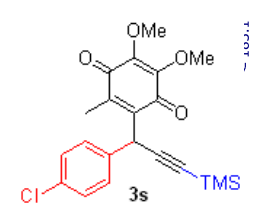

${ }^{13} \mathrm{C}\langle\mathrm{H}\} \mathrm{MMR}\left(100 \mathrm{MHz}, \mathrm{CD} \mathrm{Cl}_{3}\right)$
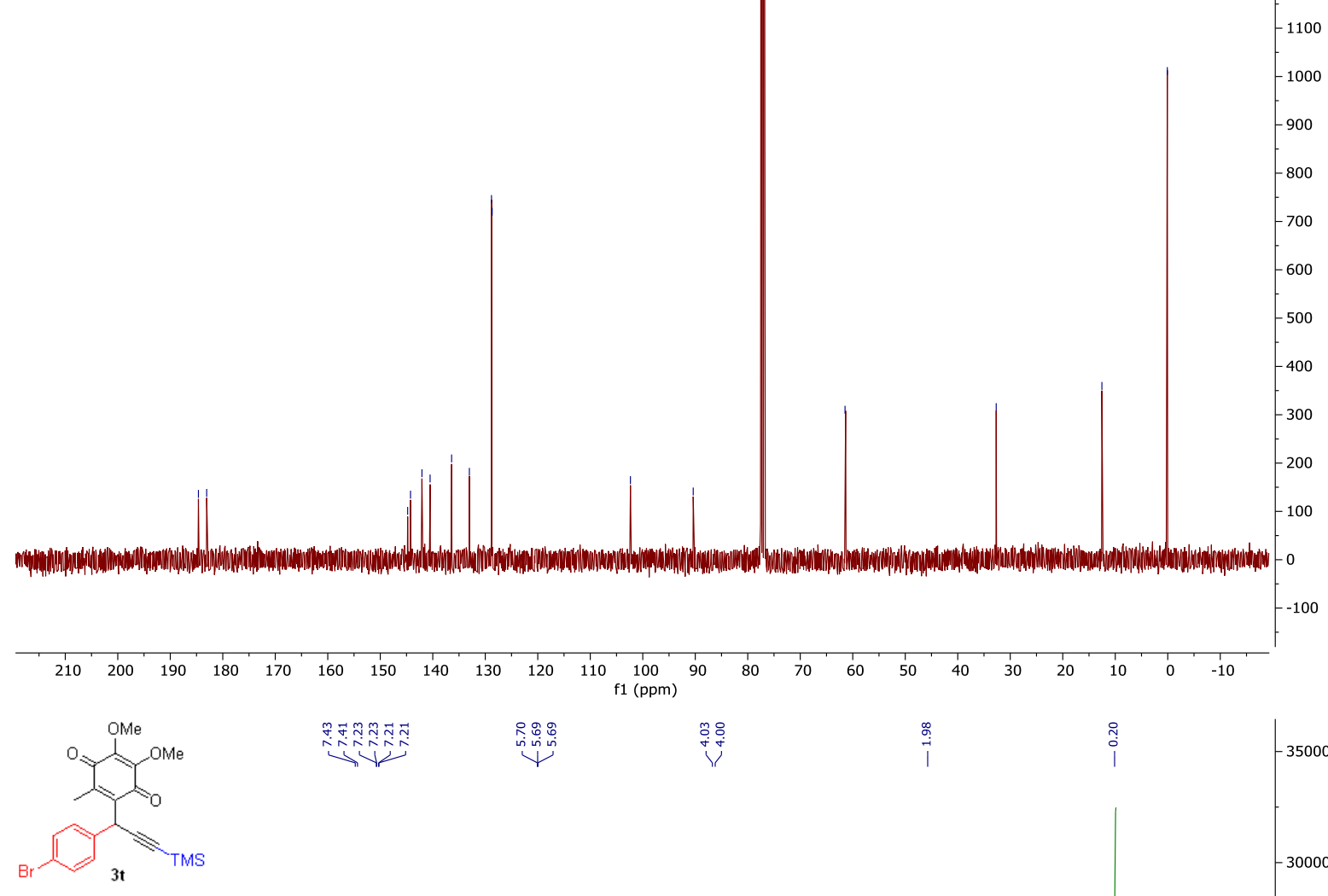

${ }^{1} \mathrm{H} \mathrm{NMR}\left(400 \mathrm{MHz}, \mathrm{CD} \mathrm{Cl}_{3}\right)$

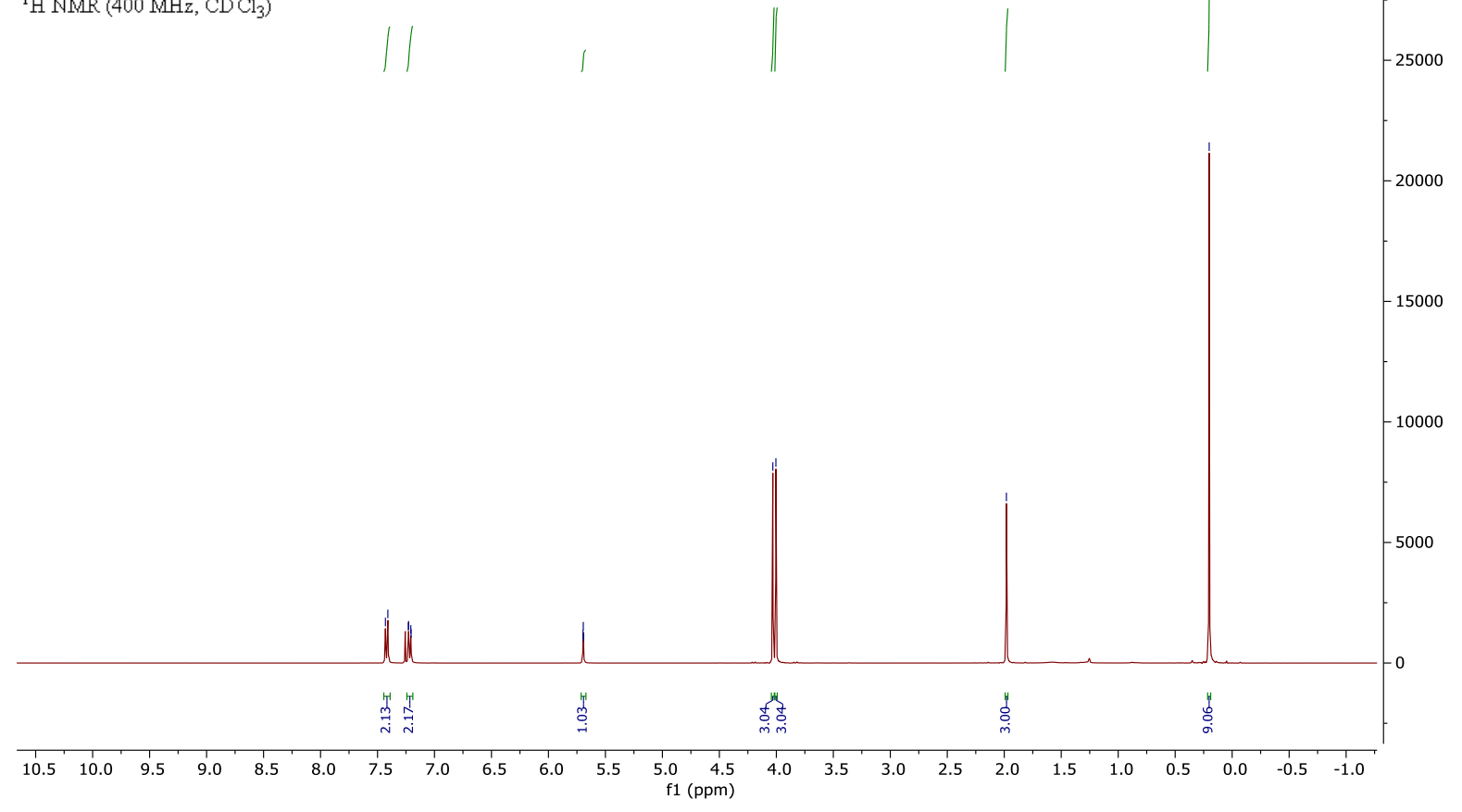




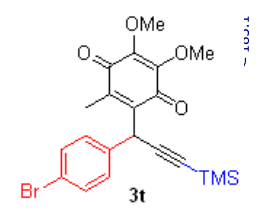

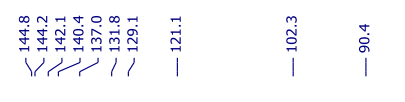

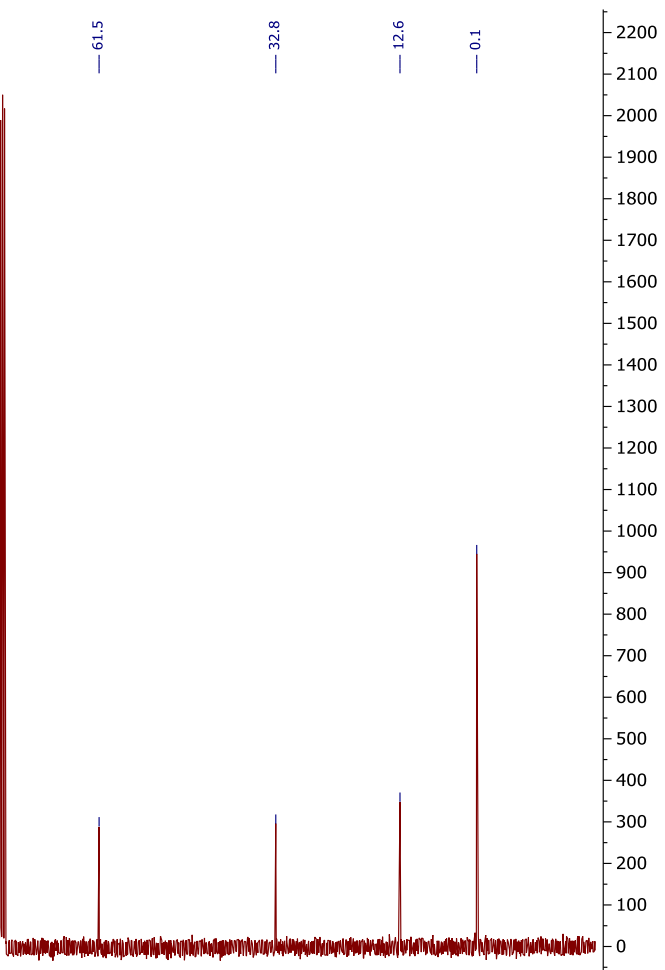

${ }^{13} \mathrm{C}(\mathrm{H}\} \mathrm{NMR}\left(100 \mathrm{MHz}, \mathrm{CD} \mathrm{Cl}_{3}\right)$

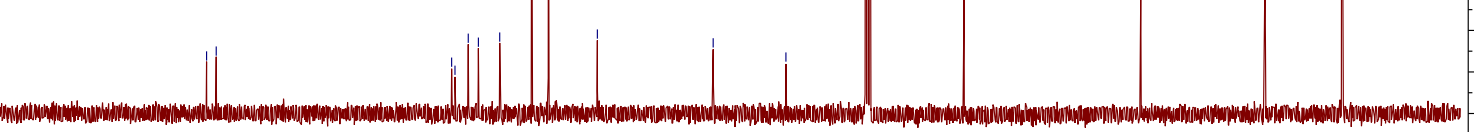
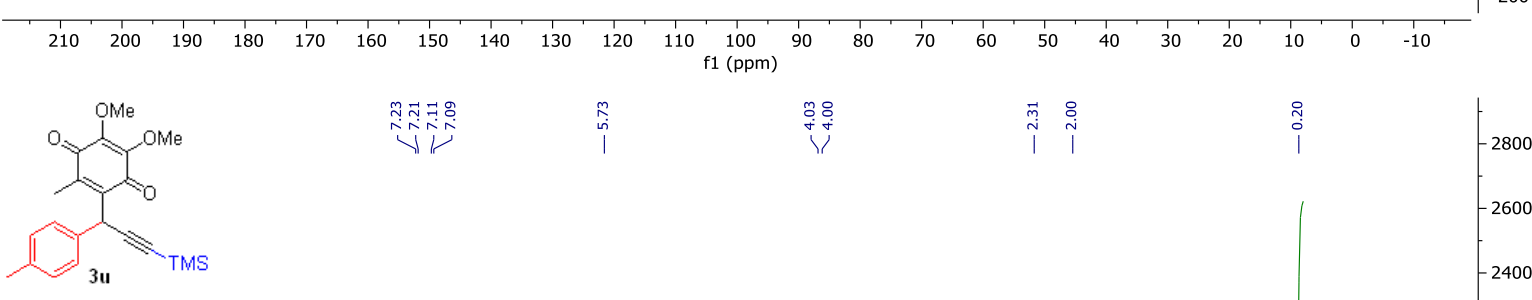

${ }^{1} \mathrm{H} \mathrm{NMR}\left(400 \mathrm{MHz}, \mathrm{CD} \mathrm{Cl}_{3}\right)$

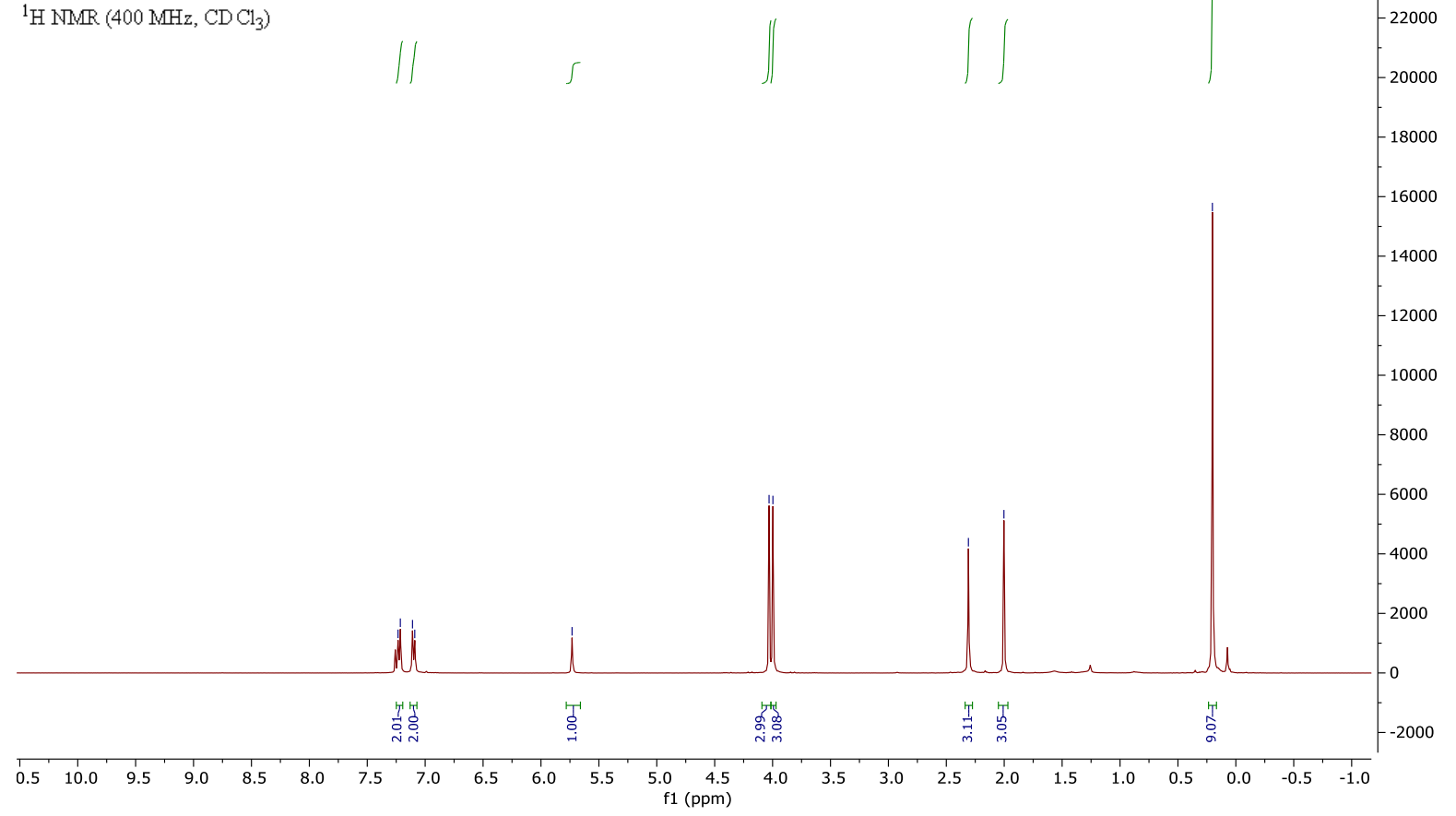




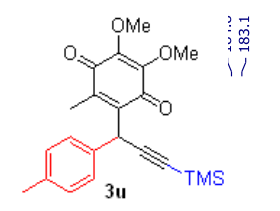

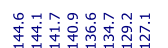

$\stackrel{n}{0}$

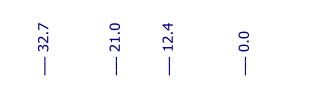

$-2100$

$-2000$

$-1900$

${ }^{13} \mathrm{C}(\mathrm{H}\} \mathrm{MMR}(100 \mathrm{MHz}, \mathrm{CD} \mathrm{Cl})$
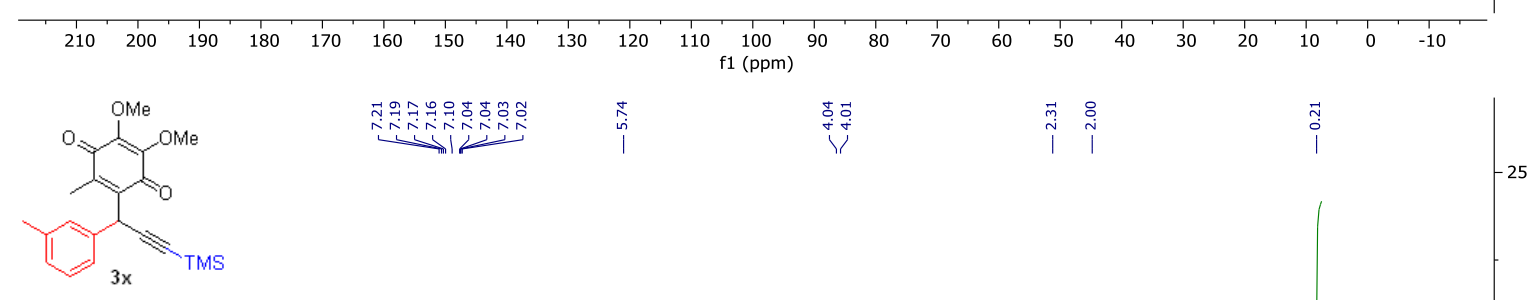

${ }^{1} \mathrm{H} \mathrm{NMR}\left(400 \mathrm{MHz}, \mathrm{CD} \mathrm{Cl}_{3}\right)$

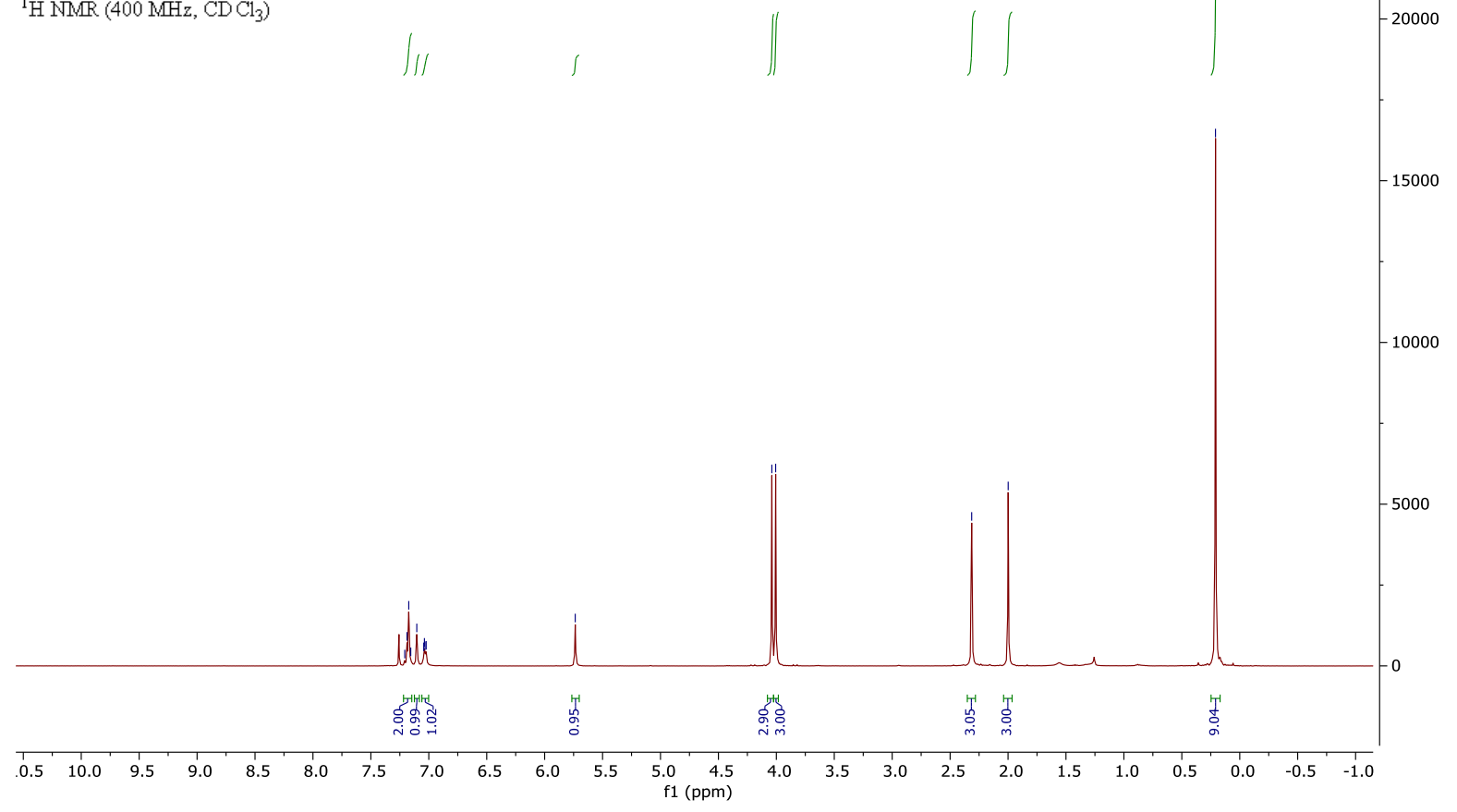




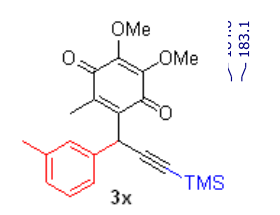

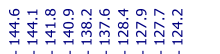

${ }^{13} \mathrm{C}(\mathrm{H}\} \mathrm{NMR}\left(100 \mathrm{MHz}, \mathrm{CDCl}_{3}\right)$

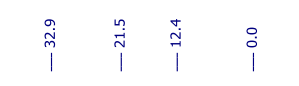

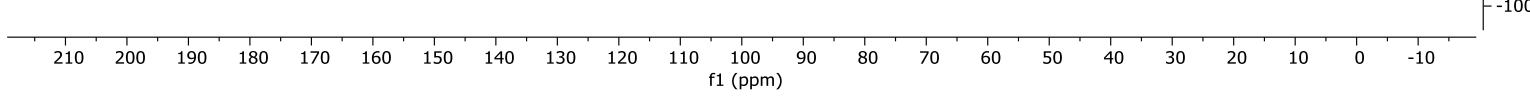

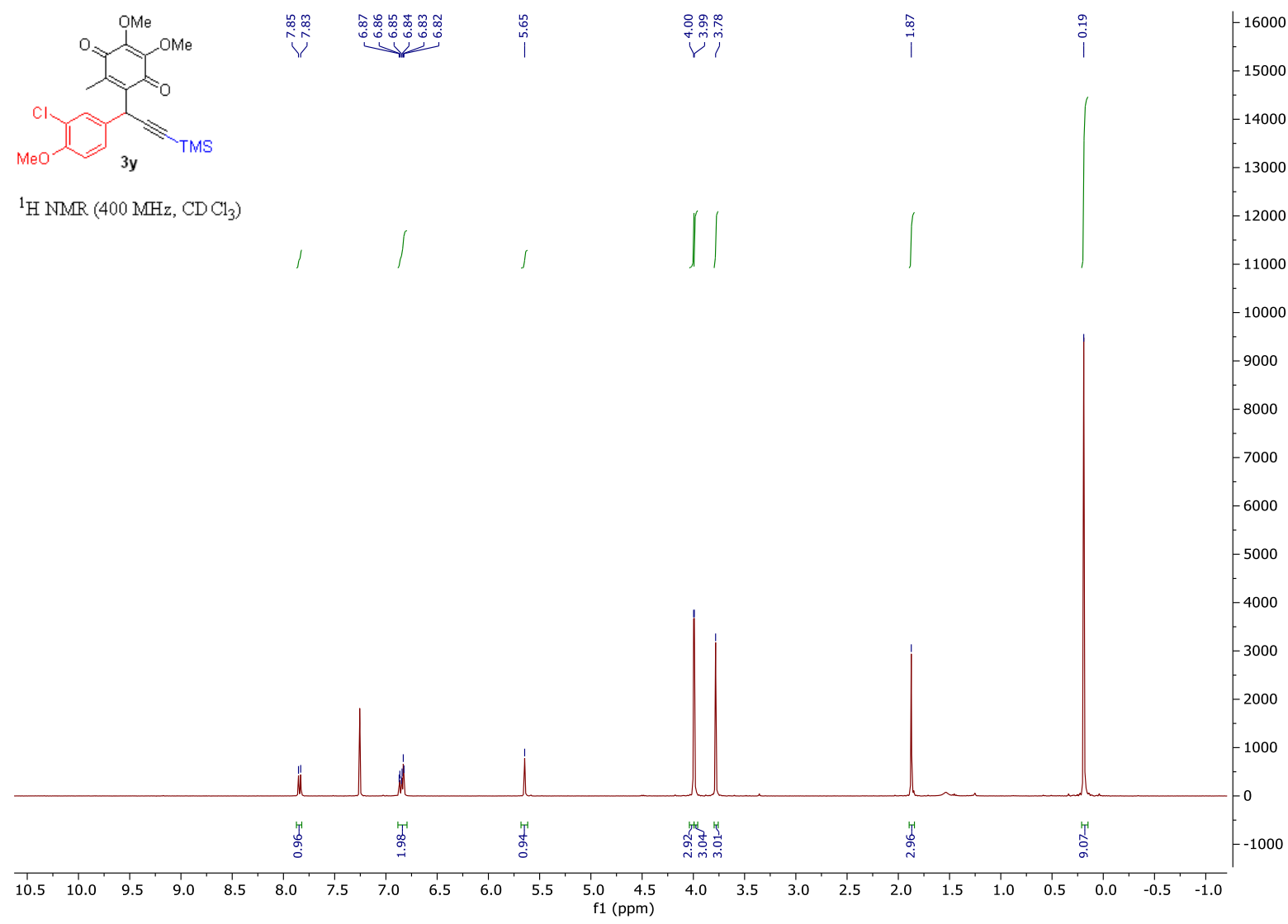




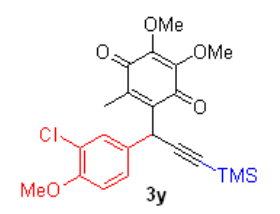

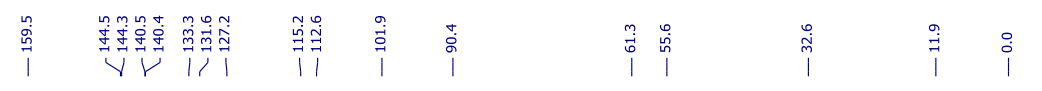

${ }^{13} \mathrm{C}\{\mathrm{H}\} \operatorname{NMR}\left(100 \mathrm{MHz}, \mathrm{CD} \mathrm{Cl}_{3}\right)$

(a)

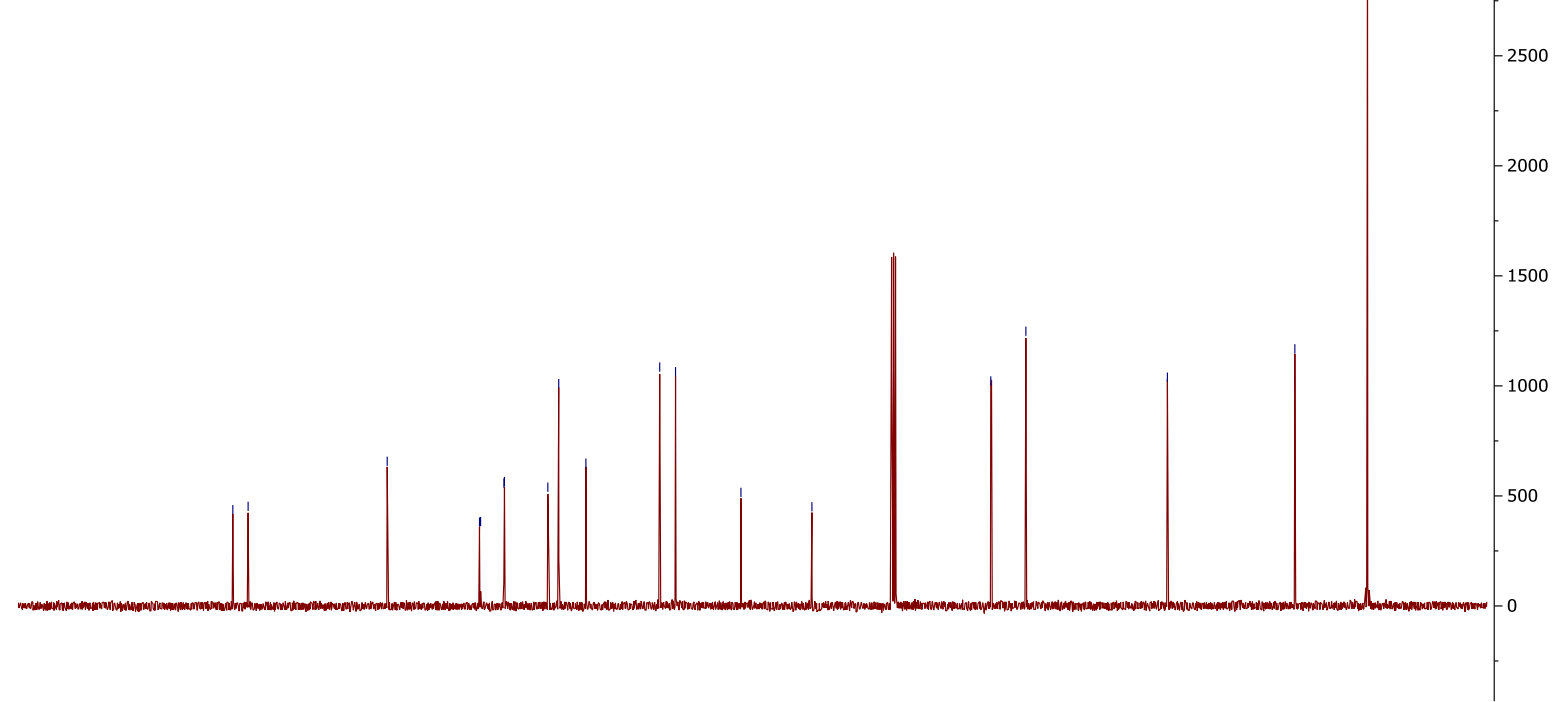

\begin{tabular}{rlllllllllllllllllllllll}
\hline 210 & 200 & 190 & 180 & 170 & 160 & 150 & 140 & 130 & 120 & 110 & 100 & 90 & 80 & 70 & 60 & 50 & 40 & 30 & 20 & 10 & 0 & -10
\end{tabular}

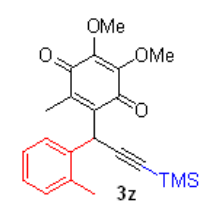

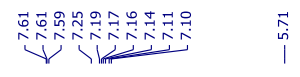

$\stackrel{\substack{c \\ \dot{+}}}{\dot{+}}$

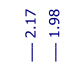

${ }^{1} \mathrm{H} \mathrm{NMR}\left(400 \mathrm{MHz}, \mathrm{CDCl}_{3}\right)$

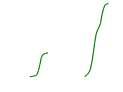

S

lik

॥

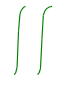

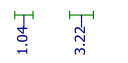

午

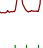

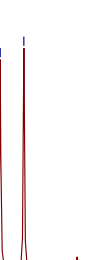

$-3500$

3000

2500

2000

1500

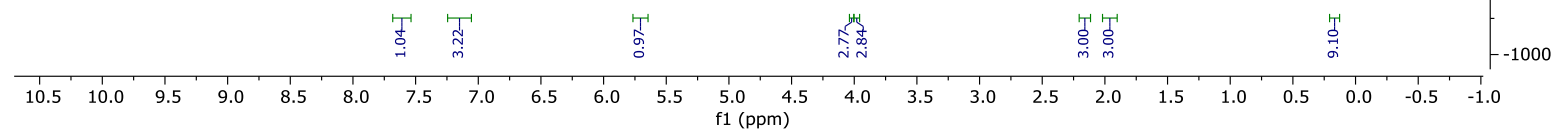




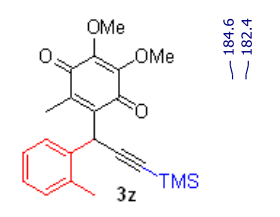

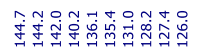

${ }^{13} \mathrm{C}\langle\mathrm{H}\} \mathrm{NMR}\left(100 \mathrm{MHz}, \mathrm{CDCl} \mathrm{C}_{3}\right)$
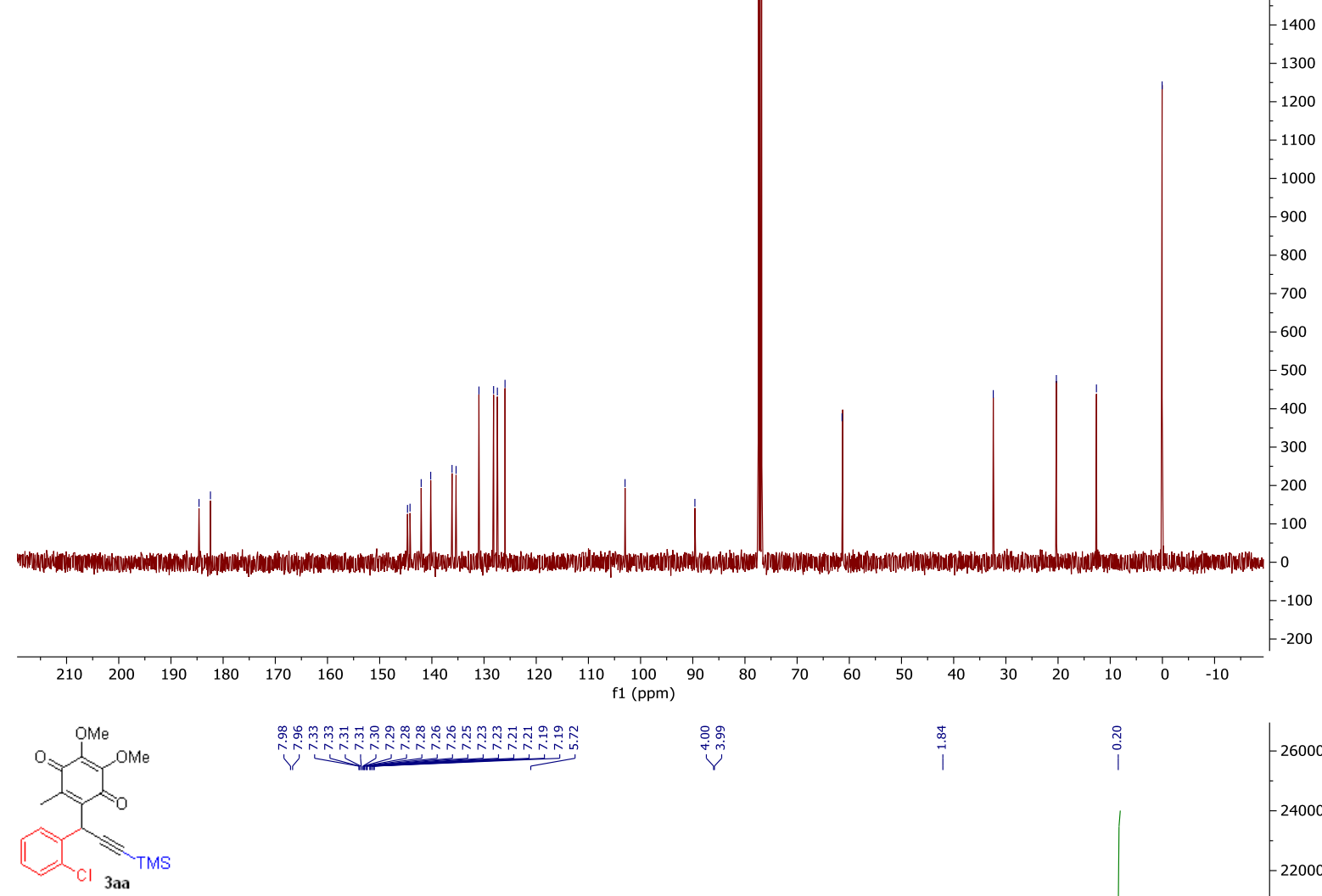

$\left.{ }^{1} \mathrm{H} \mathrm{NMR}(400 \mathrm{MHz}, \mathrm{CD} \mathrm{Cl})_{3}\right)$

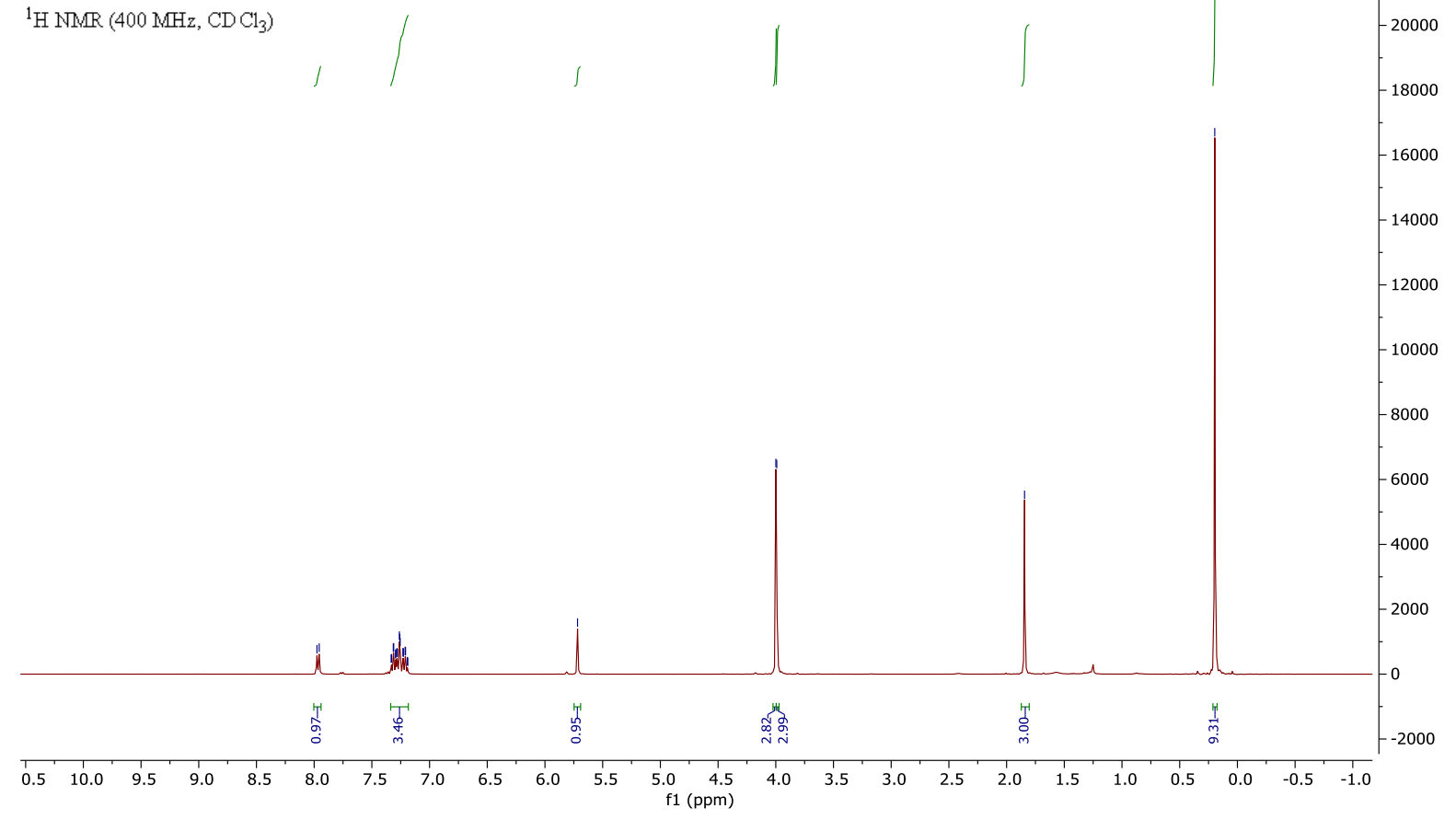




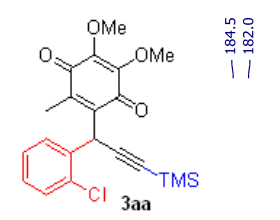

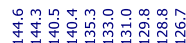

चर긱

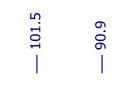

ì

$\stackrel{m}{\stackrel{m}{i}} \stackrel{0}{\vec{i}} \quad \vec{i}$

$-2400$

${ }^{13} \mathrm{C}\langle\mathrm{H}\} \mathrm{NMR}\left(100 \mathrm{MHz}, \mathrm{CDCl}_{3}\right)$

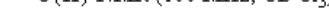

(1)
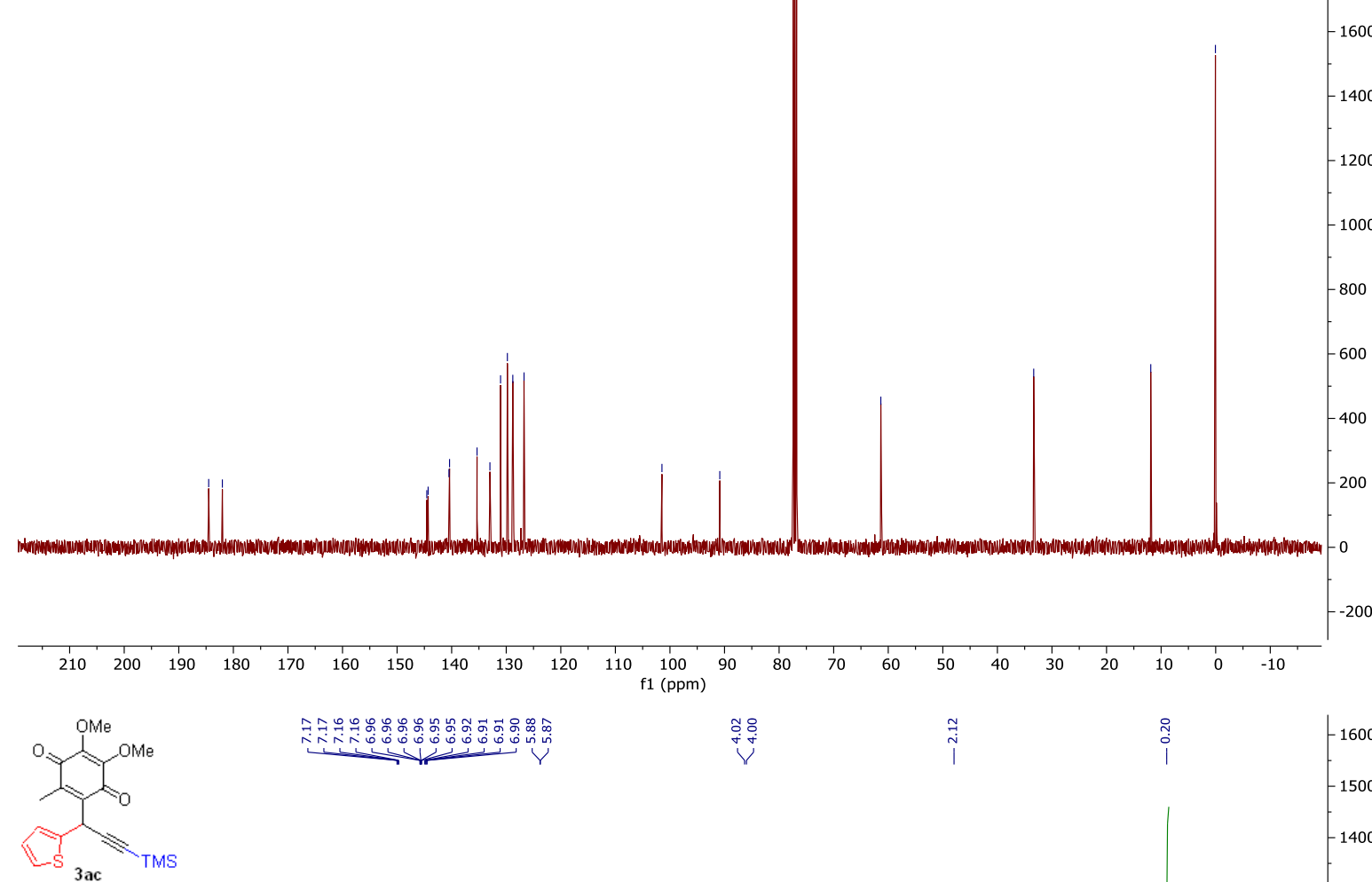

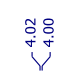

$\stackrel{7}{i}$

${ }^{1} \mathrm{H} \mathrm{NMR}\left(400 \mathrm{MHz}, \mathrm{CD} \mathrm{Cl}_{3}\right)$

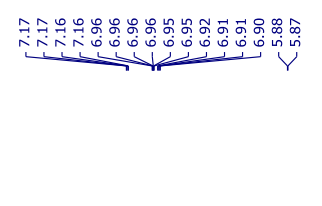

(
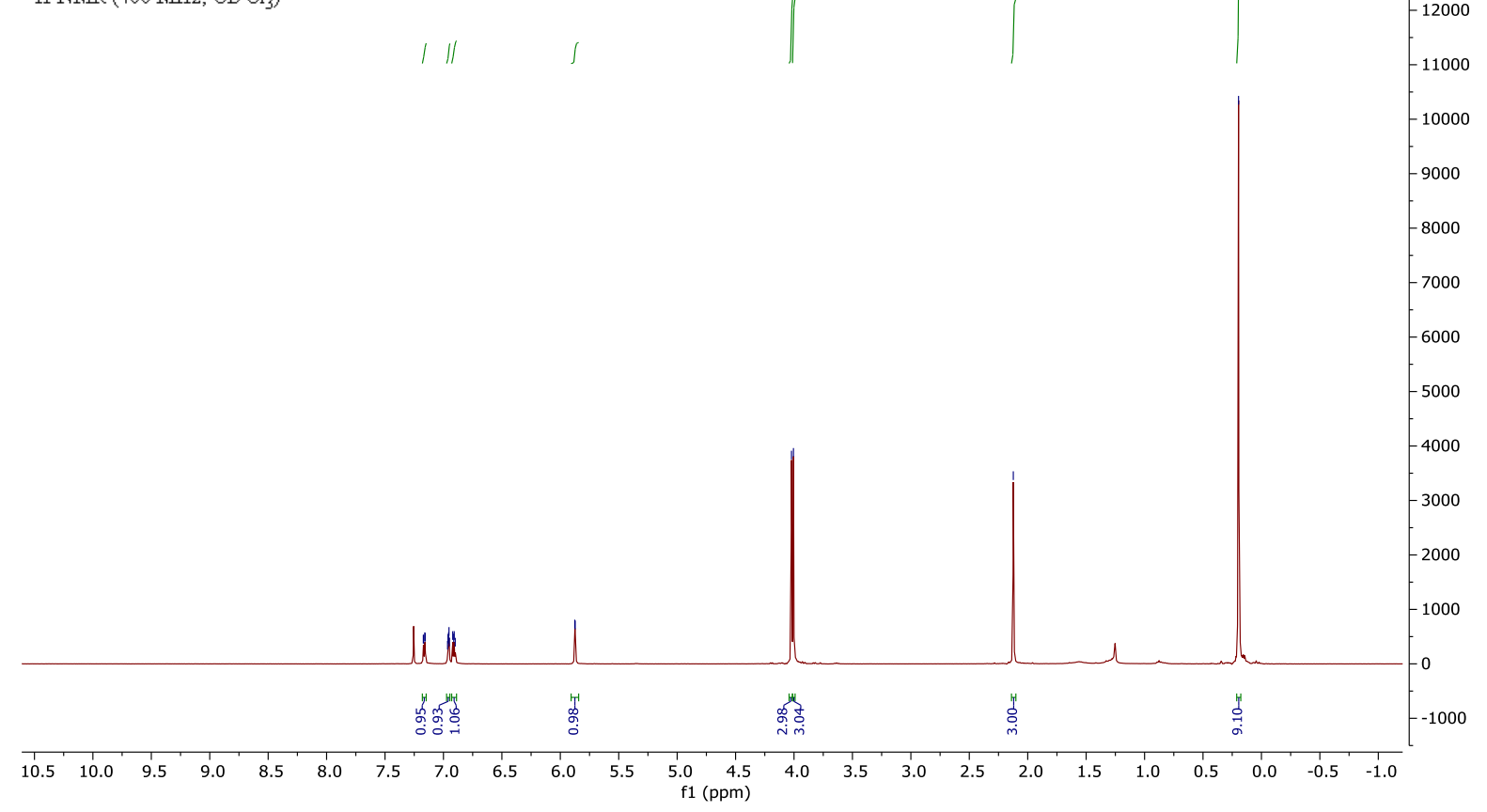

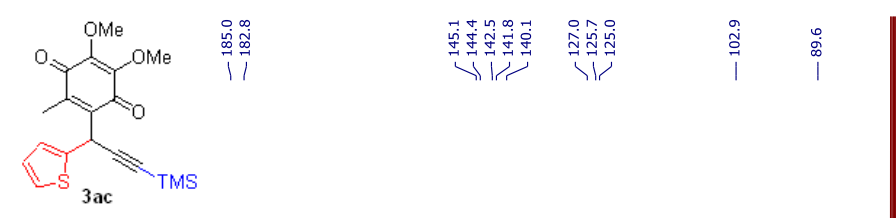

${ }^{13} \mathrm{C}(\mathrm{H}\} \mathrm{NMR}\left(100 \mathrm{MHz}, \mathrm{CD} \mathrm{Cl}_{3}\right)$
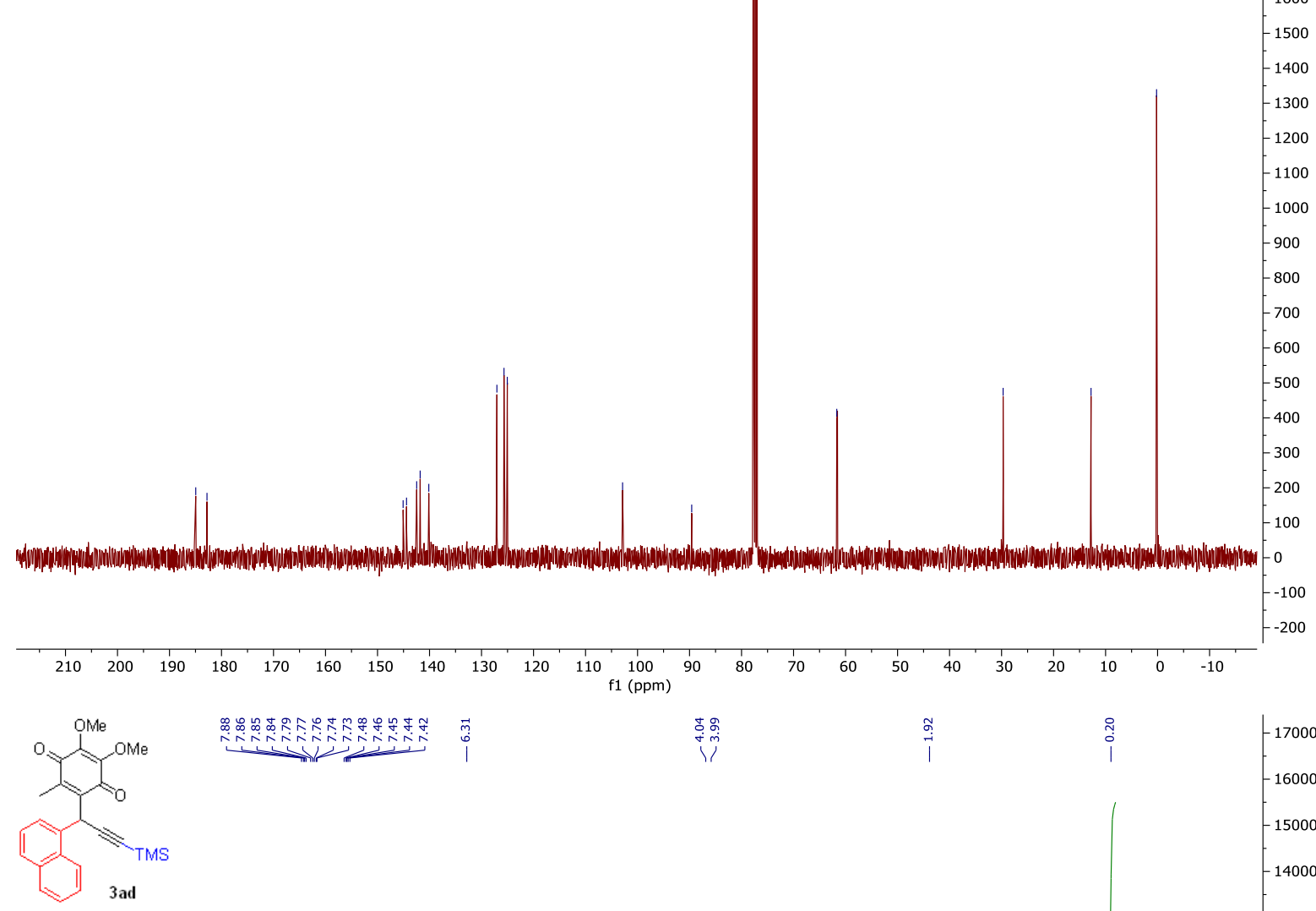

${ }^{1} \mathrm{H} \mathrm{NMR}\left(400 \mathrm{MHz}, \mathrm{CD} \mathrm{Cl}_{3}\right)$

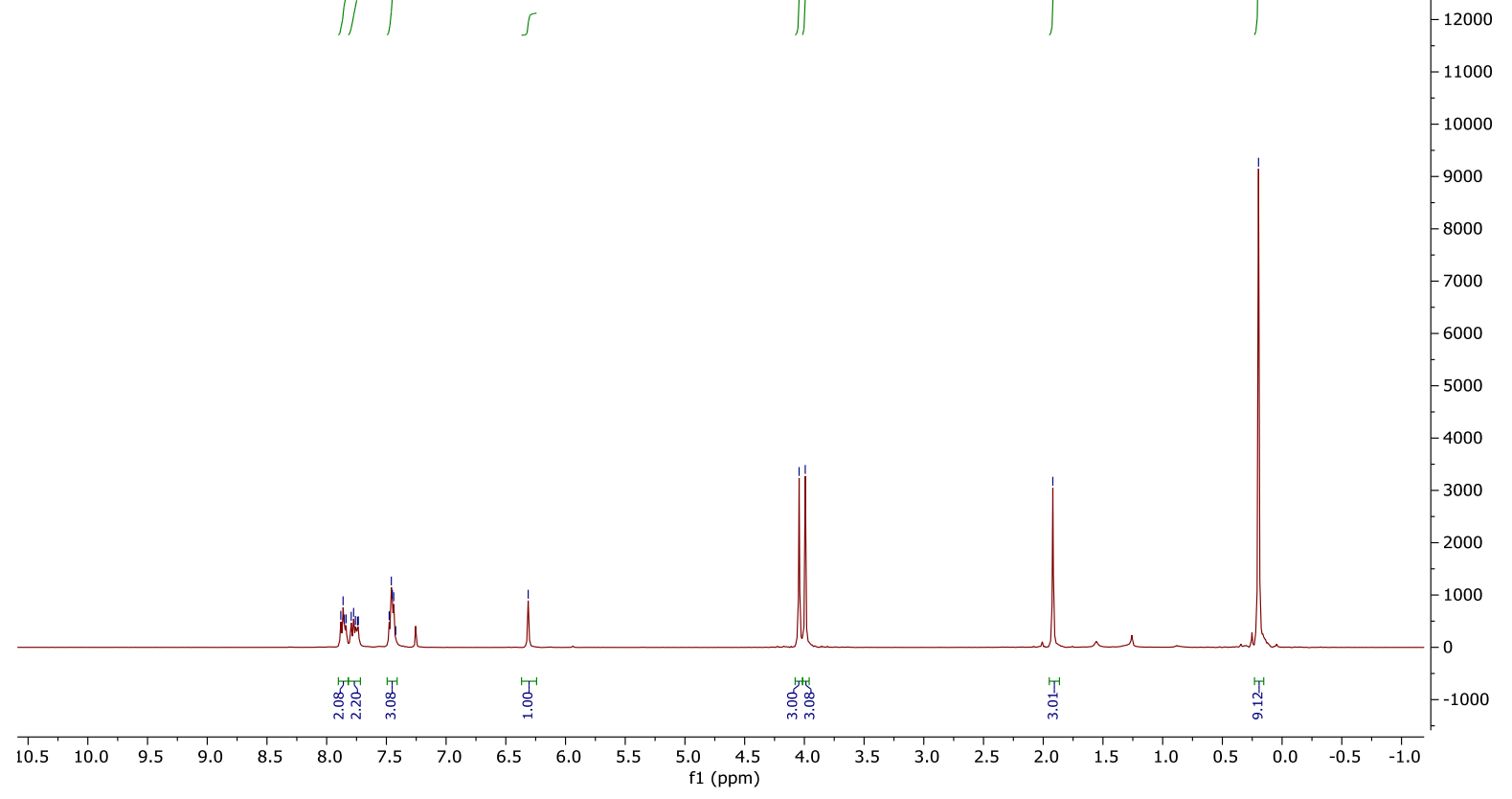




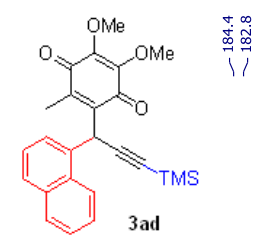

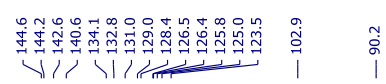

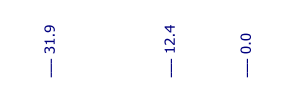

$-3400$

${ }^{13} \mathrm{C}\{\mathrm{H}\} \mathrm{NMR}\left(100 \mathrm{MHz}, \mathrm{CD} \mathrm{Cl}_{3}\right)$
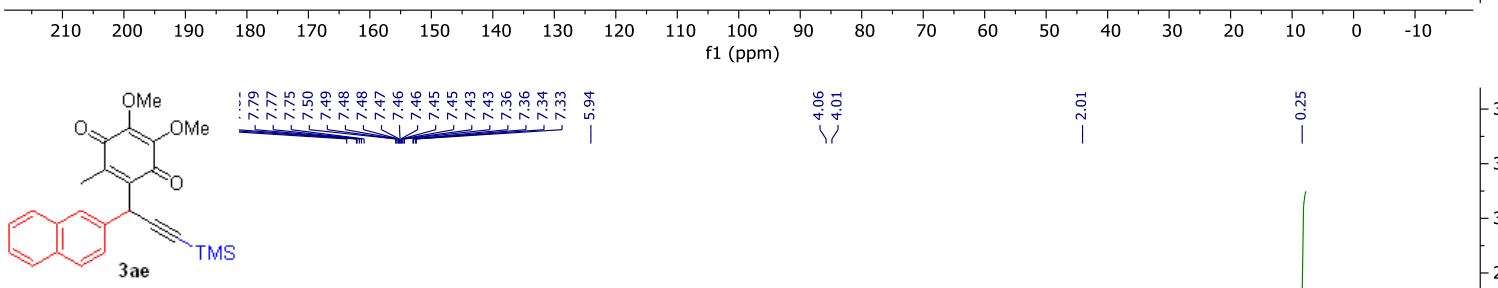

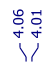

$\stackrel{\vec{i}}{i}$

34000

32000

$\left.{ }^{1} \mathrm{H} \mathrm{NMR} \mathrm{(400} \mathrm{MHz,} \mathrm{CD} \mathrm{Cl}_{3}\right)$<smiles>C1=CCCC=C1</smiles>

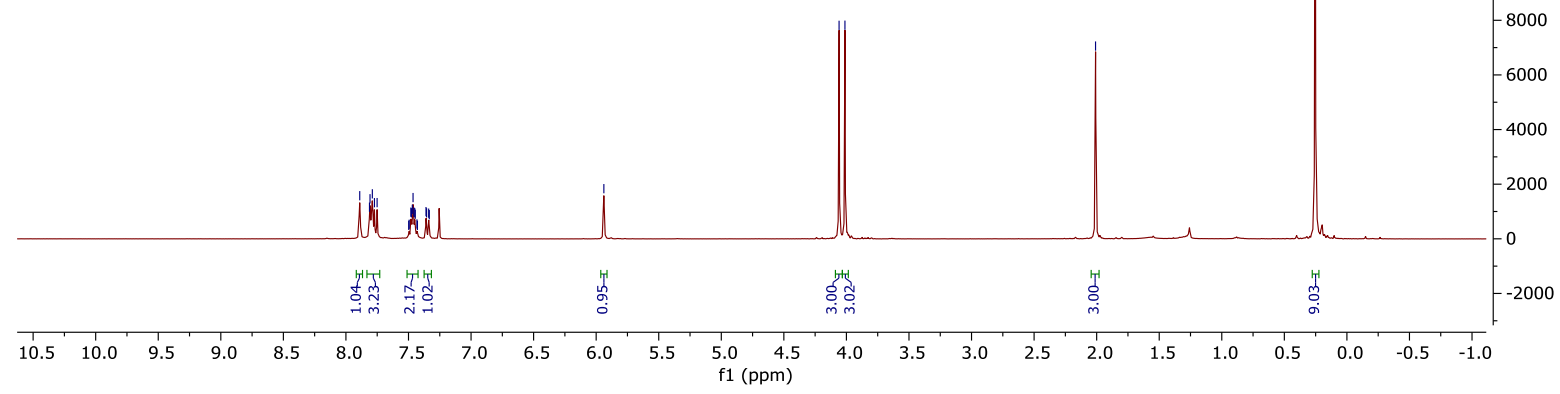




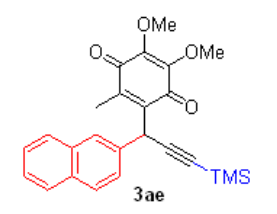

${ }^{13} \mathrm{C}\{\mathrm{H}\} \operatorname{NMR}\left(100 \mathrm{MHz}, \mathrm{CD} \mathrm{Cl}_{3}\right)$

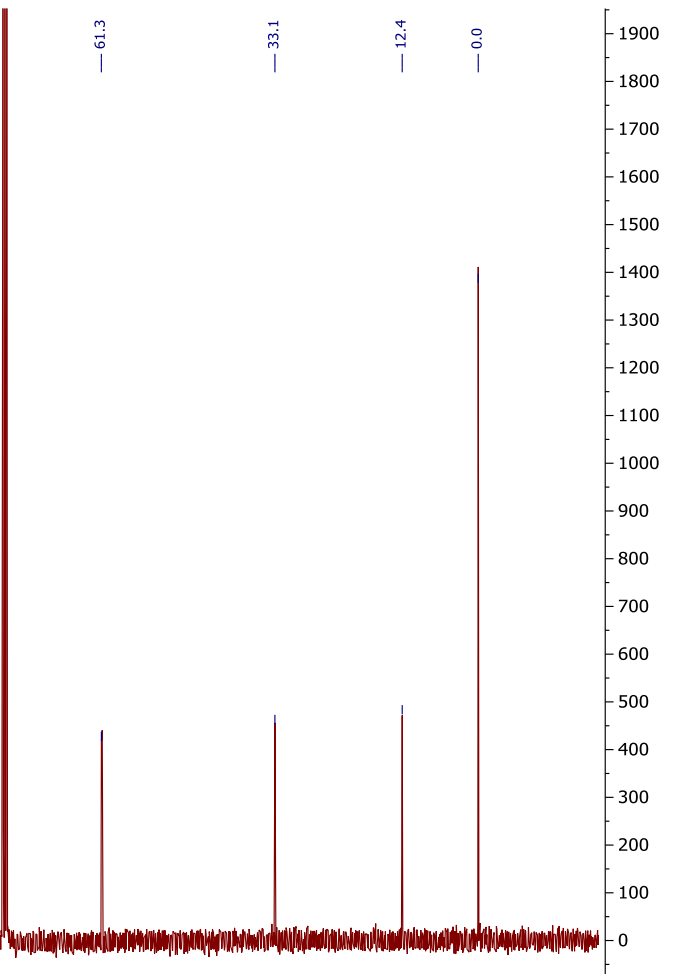

\section{(1)}
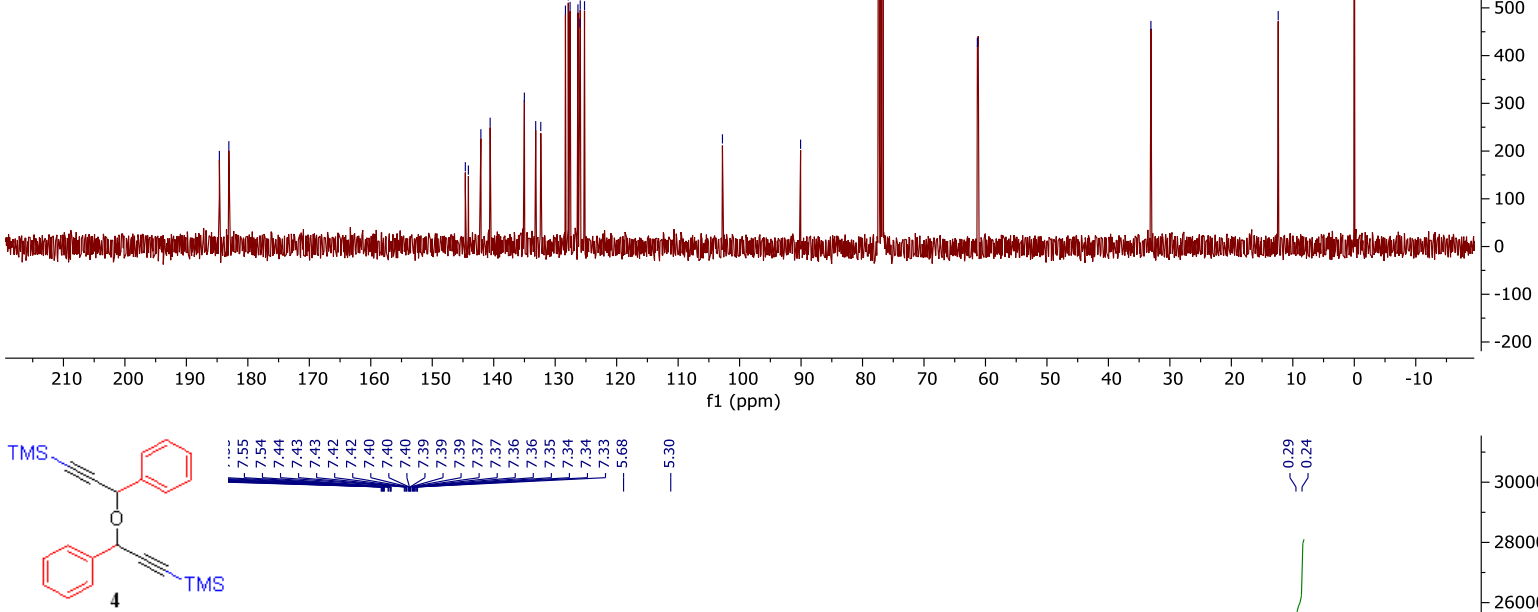

$\left.{ }^{1} \mathrm{H} \mathrm{MMR}(400 \mathrm{MHz}, \mathrm{CD} \mathrm{Cl})_{3}\right)$

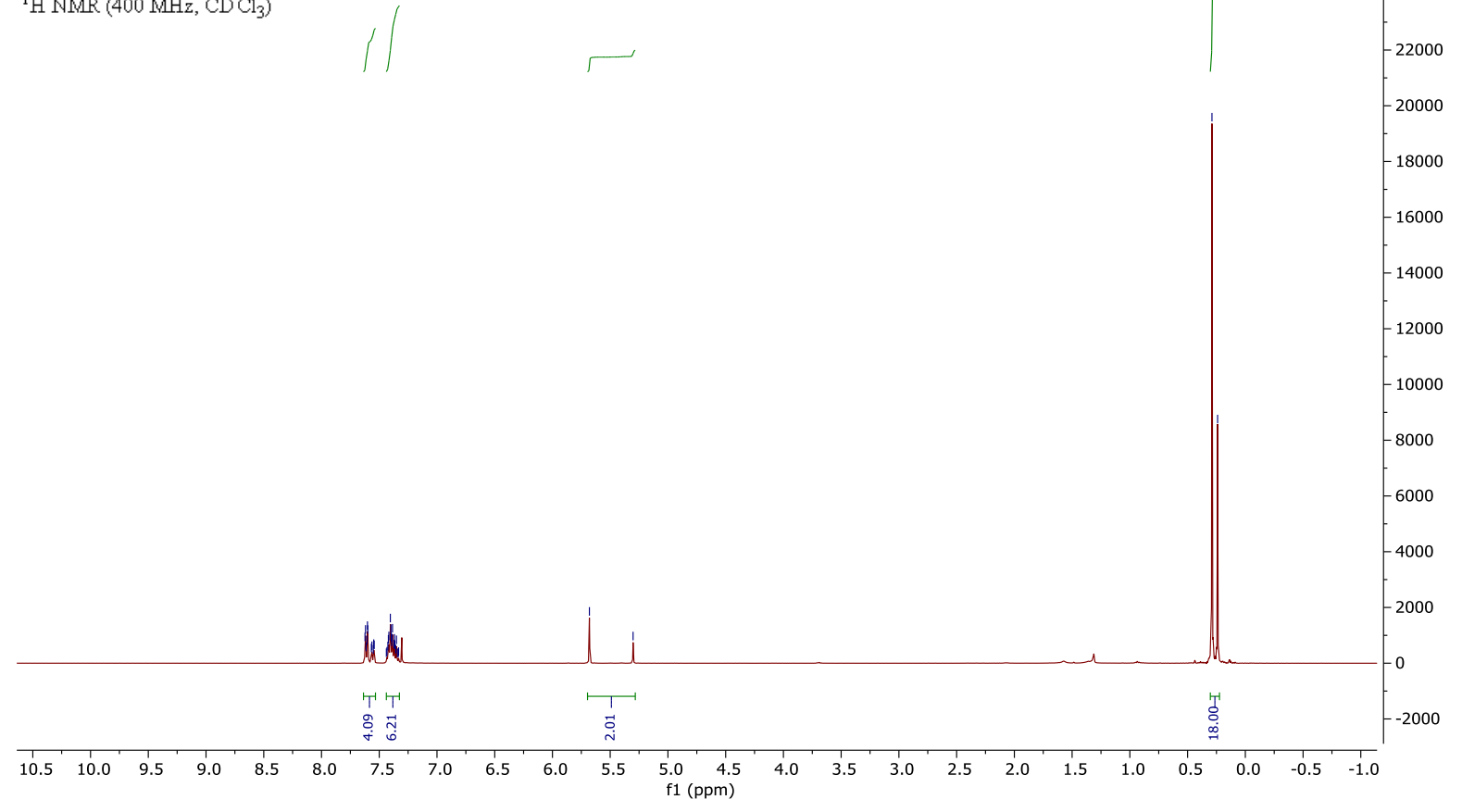


2. Mechanistic studies - LCMS analysis of raw reaction mixture
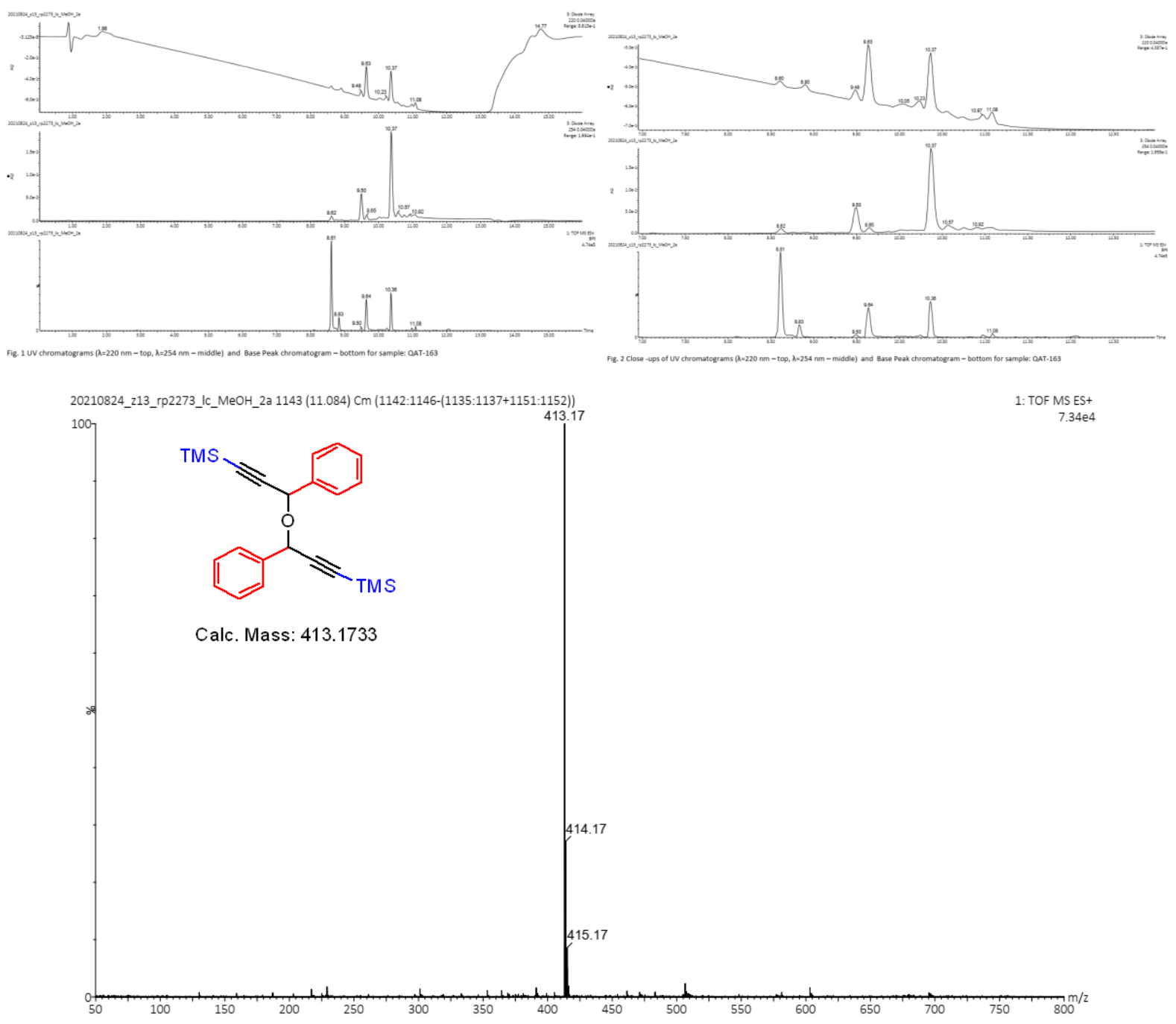

Fig.11 MS spectrum of the rt=11.08 peak

\begin{tabular}{|l|c|}
\hline $\begin{array}{c}\text { Experimental } \\
\text { Instrument Parameters } \\
- \text { MS }\end{array}$ & QAT-163 \\
\hline Polarity & ESI + \\
\hline Capillary Voltage (kV) & 3.00 \\
\hline Source temp. [C] & 120.0 \\
\hline Sampling Cone & 60.0 \\
\hline Source Offset & 50.0 \\
\hline $\begin{array}{l}\text { Source Gas Flow } \\
\text { (mL/min) }\end{array}$ & 0.00 \\
\hline Desolvation temp. [C] & 250.0 \\
\hline Cone Gas [L/h] & 100.0 \\
\hline $\begin{array}{l}\text { Desolvation Gas Flow } \\
{[\mathrm{L} / \mathrm{h}]}\end{array}$ & 700.0 \\
\hline Nebuliser Gas Flow[bar] & 4.5 \\
\hline
\end{tabular}

\begin{tabular}{|c|c|c|c|c|}
\hline $\begin{array}{c}\text { Experimental } \\
\text { Instrument Parameters }\end{array}$ & \multicolumn{4}{|c|}{ QAT-163 } \\
\hline Solvent A & \multicolumn{4}{|c|}{$0.1 \%$ formic acid in water } \\
\hline Solvent B & \multicolumn{4}{|c|}{ Methanol } \\
\hline Run time & \multicolumn{4}{|c|}{$16.00 \mathrm{~min}$} \\
\hline Flow rate & \multicolumn{4}{|c|}{$0.30 \mathrm{ml} / \mathrm{min}$} \\
\hline \multirow[t]{7}{*}{ Gradient table } & $\begin{array}{l}\text { time } \\
\text { [min] }\end{array}$ & \%A & $\% \mathrm{~B}$ & Curve \\
\hline & 0.00 & 95 & 5 & - \\
\hline & 0.50 & 95 & 5 & 6 \\
\hline & 10.00 & 0 & 100 & 6 \\
\hline & 12.00 & 0 & 100 & 6 \\
\hline & 13.00 & 95 & 5 & 6 \\
\hline & 16.00 & 95 & 5 & 6 \\
\hline
\end{tabular}


QAT-134

z13_rp2209 7 (0.245) Cm (7:9)

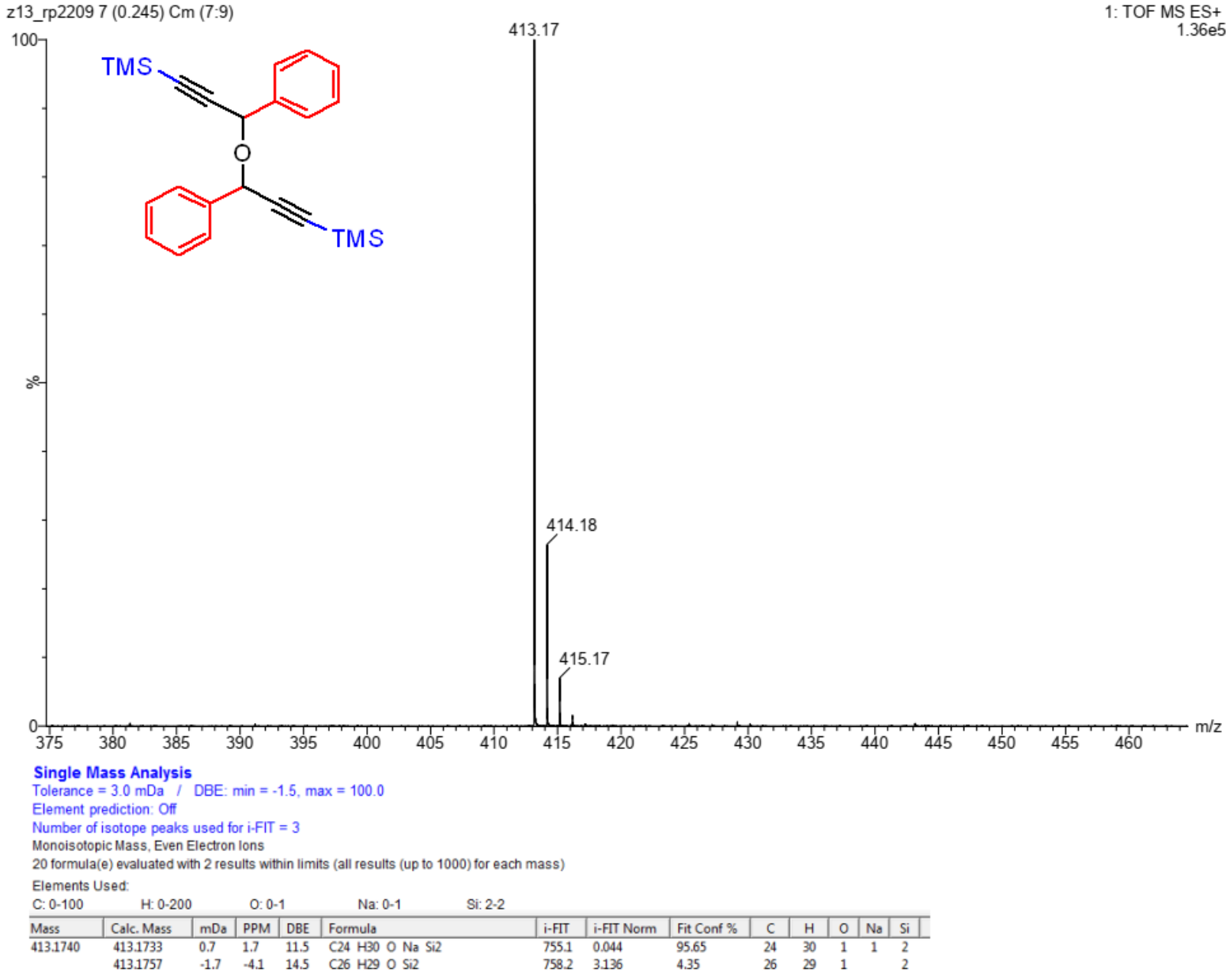

